$32 / 75-95$ gs 2

4 Energy Technology Division

Energy Technology Division

ANL-95/6

Energy Technology Division

Encrgy Technology Division

Energy Techmology Division

Energy Technology Division

Encrgy Technology Division

Energy Technology Division

Energy Technology Division Energy Technology Division Energy Technology Division Energy Technology Division Energy Technology Division Energy Technology Division

Energy Technology Duision Energy Technology Division

Energy Technology Division

Energy Technology Division

Energy Technology Duision

Energy Toshology Dishion

Energy Technology Division

by M. Bottoni, F. C. Chang, and J. Ding

Evergy Tochnology Division

Fnergy Technology Division

Energy Technology Drvision

Energy Technology Divion

Energy Tachmology Division

Energy Techmology Divislon

Energy Technology Division

Energy Tachnology Division

Energy Technology Division

Energy Technology Duision

Energy Technology Division

Energy Technology Division

Energy Technology Division

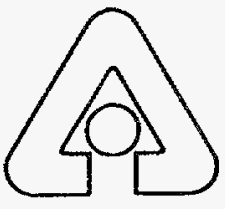

Argonne National Laboratory, Argonne, Illinois 60439

operated by The University of Chicago

for the United States Department of Energy under Contract W-31-109-Eng-38

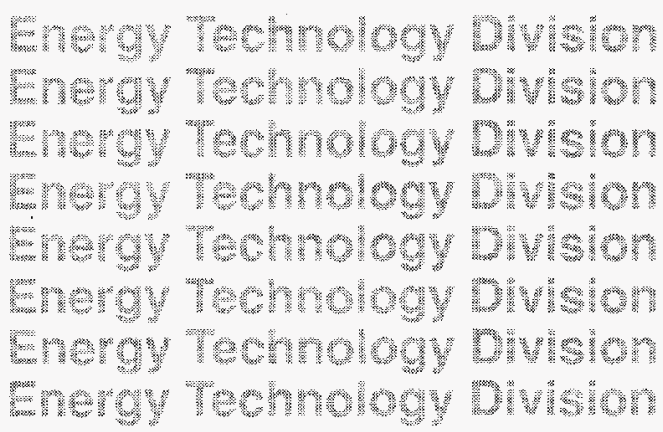

First Assessment of Computations of Turbulent Bubbly Flow and Particulate Flow with the COMMIX-M Program 
Argonne National Laboratory, with facilities in the states of Illinois and Idaho, is owned by the United States government, and operated by The University of Chicago under the provisions of a contract with the Department of Energy.

\section{DISCLAIMER}

This report was prepared as an account of work sponsored by an agency of the United States Government. Neither the United States Government nor any agency thereof, nor any of their employees, makes any warranty, express or implied, or assumes any legal liability or responsibility for the accuracy, completeness, or usefulness of any information, apparatus, product, or process disclosed, or represents that its use would not infringe privately owned rights. Reference herein to any specific commercial product, process, or service by trade name, trademark, manufacturer, or otherwise, does not necessarily constitute or imply its endorsement, recommendation, or favoring by the United States Government or any agency thereof. The views and opinions of authors expressed herein do not necessarily state or reflect those of the United States Government or any agency thereof.

Reproduced from the best available copy.

Available to DOE and DOE contractors from the

Office of Scientific and Technical Information

P.O. Box 62

Oak Ridge, TN 37831

Prices available from (615) 576-8401

Available to the public from the National Technical Information Service

U.S. Department of Commerce

5285 Port Royal Road

Springfield, VA 22161 


\section{DISCLAIMER}

Portions of this document may be illegible in electronic image products. Images are produced from the best available original document. 
Distribution

Category:

Advanced Coal Research

UC-113

ARGONNE NATIONAL LABORATORY

9700 South Cass Avenue, Argonne, Illinois 60439

ANL-95/6

\title{
FIRST ASSESSMENT OF COMPUTATIONS OF TURBULENT BUBBLY FLOW AND PARTICULATE FLOW WITH THE COMMIX-M PROGRAM
}

\author{
by \\ M. Bottoni, F. C. Chang, and J. Ding \\ Energy Technology Division
}

May 1994

Work sponsored by

U.S. Department of Energy

Pittsburgh Energy Technology Center

Advanced Power Generation Fundamental Research Division 


\section{Contents}

Nomenclature

Abstract

1 Introduction.

2 Synopsis of COMMIX-M Code

3 Fundamental Equations

3.1 Conservation Equations for Mass, Momentum, and Enthalpy.................................. 3

3.1.1 Mass Conservation Equations.............................................................................. 3

3.1.2 Momentum Equations .................................................................................................... 3

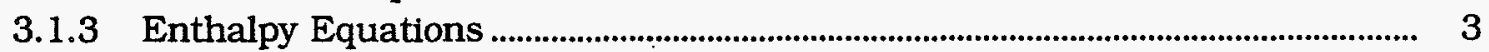

3.2 Governing Equations for Turbulence Models ............................................................................ 4

3.2.1 Single-Phase Flow ........................................................................................................... 4

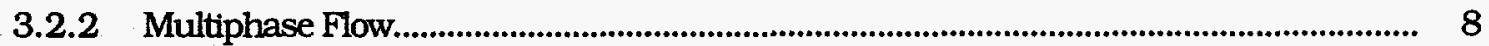

3.2.3 Attenuation of Turbulent Kinetic Energy Due to Small Particles ................... 9

4 Computation of Lift, Drag, and Virtual Mass Forces......................................................... 14

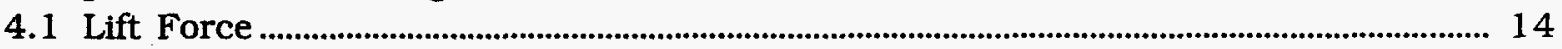

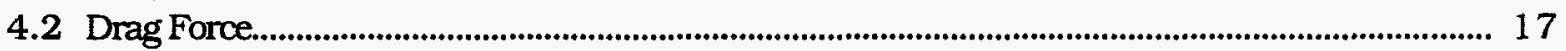

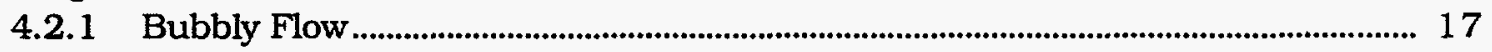

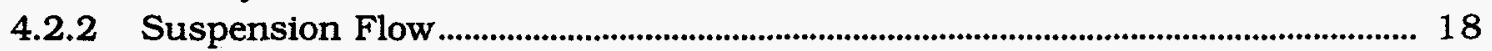

4.3 Virtual Mass Force ............................................................................................................ 19

5 First Assessment of Computations for Turbulent Bubbly Flow ............................................. 20

5.1 Comparison of COMMIX-M-Calculated Results with Experimental

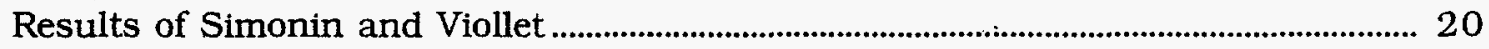

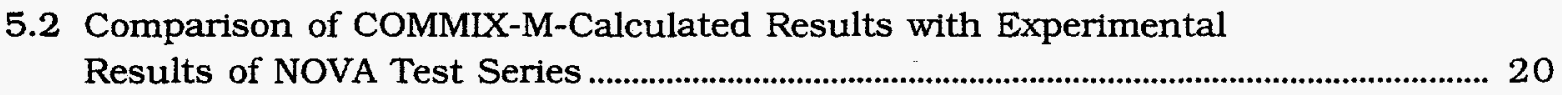

6 First Assessment of Computations of Turbulent Particulate Flow ......................................... 22

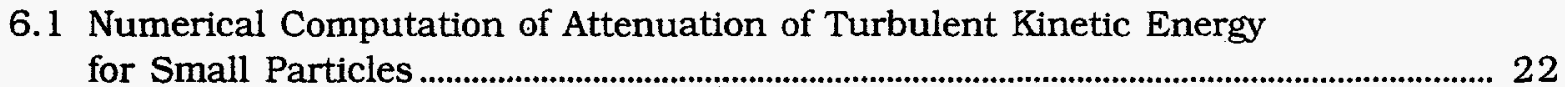

6.2 Comparison of COMMIX-M-Calculated Results with Experimental Results of Tsuji, Morikawa, and Shiomi........................................................................ 22

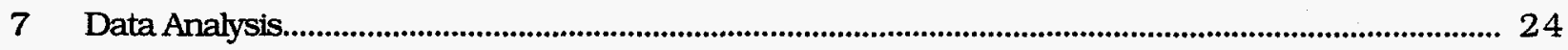

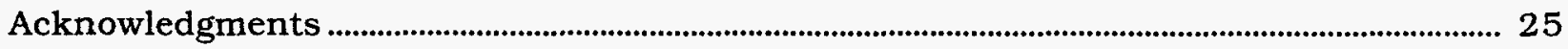

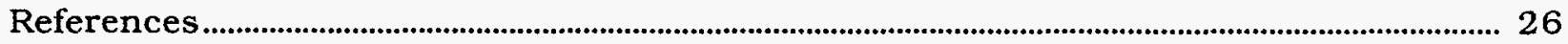

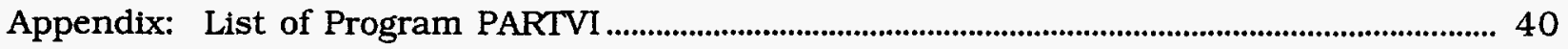




\section{Figures}

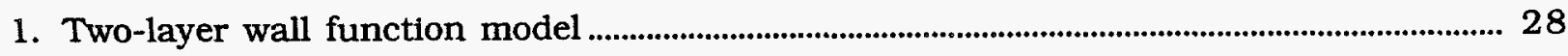

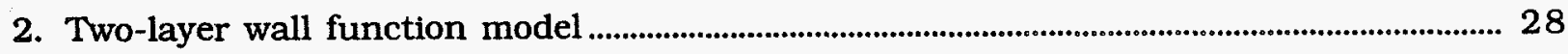

3. Run No. 1: radial distribution of air volume fraction at inlet, and comparison of

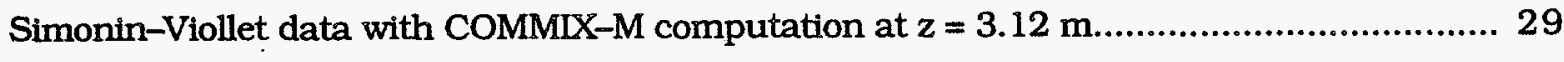

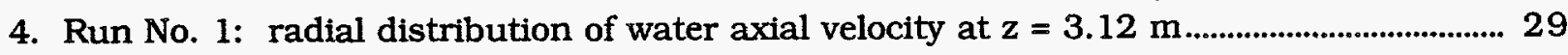

5. Run No. 1: radial distribution of air axial velocity at $z=3.12 \mathrm{~m}$........................................ 30

6. Run No. 1: radial distribution of turbulence kinetic energy of water phase at $z=3.12 \mathrm{~m}$

7. Run No. 2: radial distribution of void fraction at inlet, and comparison of Simonin-Viollet data with COMMIX-M computation at $z=3.12 \mathrm{~m}$.

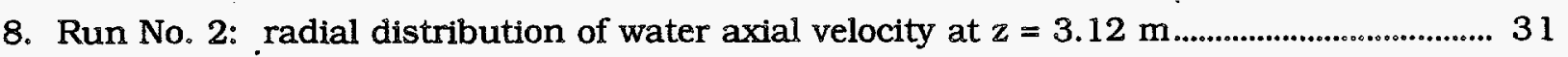

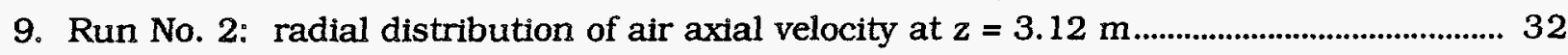

10. Run No. 2: radial distribution of turbulence kinetic energy of water phase at $z=3.12 \mathrm{~m}$

11. NOVA test series, Run No. 1: radial distribution of void fraction at inlet, and comparison of experimental data from the NOVA test series with COMMIX-M computation

12. NOVA test series, Run No. 1: computed radial distributions of air and water axial velocities

13. NOVA test series, Run No. 3: radial distribution of void fraction at outlet, and comparison of experimental data from NOVA test series with COMMLX-M computation

14. NOVA test series, Run No. 3: computed radial distributions of air and water axial velocities

15. Attenuation of turbulence intensity due to particles vs. particle diameter

16. Radial distribution of turbulence intensity for test case 1 of Tsuji-

Morikawa-Shiomi experiments.

17. Radial distribution of turbulence intensity for test case 2 of TsujiMorikawa-Shiomi experiments. 
18. Radial distribution of turbulence intensity for test case 3 of TsujiMorikawa-Shiomi experiments

19. Radial distribution of normalized axial velocity for test case 3 of Tsuji-Morikawa-Shiomi experiments

20. Radial distribution of turbulence intensity for test case 4 of TsujiMorikawa-Shiomi experiments

21. Radial distribution of normalized axial velocity for test case 4 of TsujiMorikawa-Shiomi experiments

22. Simplified flow chart of PROCESS program, used for data analysis

\section{Tables}

1. Characteristics at inlet for computed turbulent bubbly flow experiments reported by Simonin and Viollet

2. Characteristics at inlet of two simulated test runs of NOVA series

3. Characteristics of computed experiments from Tsuji, Morikawa, and Shiomi series 


\section{Nomenclature}

Ac Acceleration modulus, defined by Eq. 4.3.6

$A_{i}$ Interfacial area per unit volume $\left(\mathrm{m}^{2} / \mathrm{m}^{3}\right)$

A Cross flow area $\left(\mathrm{m}^{2}\right)$

An Amplitude in velocity spectrum of fluid (m)

$a_{n}$ Amplitude in velocity spectrum of particles (m)

$c_{1}$ Constant $(=2.8)$, used in Eq. 3.2.1.13

c2 Constant ( $=0.47)$, used in Eq. 3.2.1.13

c3 Constant $(=0.47)$, used in Eq. 3.2.1.13

$c_{1 \varepsilon}$ Constant $(=1.44)$, used in Eq. 3.2.1.2

$c_{2 \varepsilon}$ Constant $(=1.92)$, used in Eq. 3.2.1.2

$c_{3 \varepsilon}$ Constant $(=0.8)$, used in Eq. 3.2.1.2

$c_{1 \phi}$ Constant $(=3.1)$, used in Eq. 3.2.1.11

$c_{1 \phi}^{\prime} \quad$ Constant $(=0.5)$, used in Eq. 3.2.1.11

$c_{2 \phi}$ Constant $(=0.5)$, used in Eq. 3.2.1.11

$c_{3 \phi}$ Constant $(=0.5)$, used in Eq. 3.2.1.11

$\mathrm{C}_{\mathrm{D}} \quad$ Friction coefficient

$c_{k}$ Constant $(=0.09)$, used in Eq. 3.2.1.13

$\mathrm{c}_{\mathrm{p}} \quad$ Specific heat $(\mathrm{J} / \mathrm{kg}-\mathrm{K})$

$c_{S \phi} \quad$ Constant $(=0.07)$, used in Eq. 3.2.1.8

$\mathrm{C}_{\mathrm{v}_{\mathrm{m}}}$ Virtual mass coefficient

$c_{\mu} \quad$ Constant $(=0.09)$, used in Eq. 3.2.1.14

$\mathrm{c}_{\pi \mathrm{k}}$ Constant $(=0.02)$, used in Eq. 3.2.2.4

$\mathrm{c}_{\pi \varepsilon}$ Constant $(=1.2)$, used in Eq. 3.2.2.6

$\mathrm{c}_{\phi}^{\prime} \quad$ Constant $(=0.13)$, used in Eq. 3.2.1.12 
D.(v) Dissipation spectrum of turbulent kinetic energy $\left(\mathrm{m}^{3} / \mathrm{s}^{3}\right)$

$\mathrm{d}_{\mathrm{b}} \quad$ Particle diameter $(\mathrm{m})$

E Constant $(=9.0)$, used in Eq. 3.2.1.16

$F_{L} \quad$ Lift force per unit volume $\left(\mathrm{N} / \mathrm{m}^{3}\right)$

$\vec{F}_{\mathrm{vm}}$ Virtual mass force per unit volume $\left(\mathrm{N} / \mathrm{m}^{3}\right)$

$\overrightarrow{\mathrm{f}}_{\mathrm{vm}}$ Virtual mass force acting on one particle $(\mathrm{N})$

G Production or suppression of turbulence kinetic energy due to buoyancy $\left(\mathrm{J} / \mathrm{s}-\mathrm{m}^{3}\right) /$ mass flow $(\mathrm{kg} / \mathrm{s})$

$\mathrm{G}_{\mathbf{i} \phi}$ Buoyancy production in scalar flux equations $\left(\mathrm{m}-\mathrm{K} / \mathrm{s}^{2}\right)$

g $\left(=\frac{1}{2} \overline{\phi^{2}}\right)$, one-half of the variance of temperature fluctuations $\left(\mathrm{K}^{2}\right)$

$\overrightarrow{\mathrm{g}} \quad$ Gravity acceleration $\left(\mathrm{m} / \mathrm{s}^{2}\right)$

$g_{i}$ Components of gravitational acceleration $(i=1,2$, and 3$)\left(\mathrm{m} / \mathrm{s}^{2}\right)$

$\mathrm{H} \quad$ Attenuation of turbulent kinetic energy due to particles

h Specific enthalpy $(\mathrm{J} / \mathrm{kg})$

K Turbulence kinetic energy $(\mathrm{J} / \mathrm{kg})$

$\mathrm{K}_{\mathrm{ij}}^{\mathrm{M}} \quad$ Drag force between components $\mathrm{i}$ and $\mathrm{j}\left(\mathrm{kg} / \mathrm{m}^{3} \mathrm{~s}\right)$

Ku. Kurtosis

L Length scale (m)

L Force (N)

$\mathrm{m}_{\mathrm{b}} \quad$ Mass of a particle $(\mathrm{kg})$

$\mathrm{n} \quad\left(=\mathrm{N} / \mathrm{V}_{\mathrm{f}}\right)$ Number density of particles in a computational cell $\left(\mathrm{m}^{-3}\right) /$ frequency $\left(\mathrm{s}^{-1}\right)$

$\mathrm{N} \quad$ Number of particles in a cell of volume $V_{f}$

$P \quad$ Mean shear production in $\mathrm{k}$ and $\varepsilon$ equations $\left(\mathrm{J} / \mathrm{s}-\mathrm{m}^{3}\right)$

$\mathrm{P}_{\mathrm{i} \phi} \quad$ Mean field production in scalar flux equations $(i=1,2$, and 3$)\left(\mathrm{m}-\mathrm{K} / \mathrm{s}^{2}\right)$

p Pressure $\left(\mathrm{N} / \mathrm{m}^{2}\right)$ 
Q Specific power generation $\left(\mathrm{W} / \mathrm{m}^{3}\right) /$ volumetric flow $\left(\mathrm{m}^{3} / \mathrm{h}\right)$

q Heat flux $\left(\mathrm{W} / \mathrm{m}^{2}\right)$

r Particle or bubble radius (m)

r Coordinate direction (m)

R Constant (= 0.5), used in Eq. 3.2.1.12

Re Reynolds number

Rf (= - G/P), flux Richardson number

$R_{m} \quad$ Normalized root mean squared relative velocity between the phases

S Skewness

$\overline{\bar{S}} \quad$ Strain rate term, defined by Eq. 4.1 .4

T . Temperature (K)

$\mathrm{T}^{*} \quad$ Temperature, defined by Eq. 3.2.1.23 (K)

$T(v)$ Energy flux $\left(\mathrm{m}^{2} / \mathrm{s}^{3}\right)$

t Time (s)

$U_{i}$ Components of mean velocity $(i=1,2$, and 3$)(m / s)$

$u_{i} \quad$ Fluctuation of velocity component $(i=1,2$, and 3$)(\mathrm{m} / \mathrm{s})$

un Fluctuation of velocity component normal to the wall $(\mathrm{m} / \mathrm{s})$

$\mathrm{u}^{*} \quad$ Friction velocity $(\mathrm{m} / \mathrm{s})$

$\overrightarrow{\mathrm{U}} \quad$ Mean flow velocity $(\mathrm{m} / \mathrm{s})$

u Fluctuation of velocity $(\mathrm{m} / \mathrm{s})$

$\mathrm{u}^{+} \quad$ Dimensionless velocity defined by Eq. 3.2.1.16

$\overline{\mathrm{u} \phi} \quad(=\Phi)$ scalar heat flux in the $\mathrm{x}_{1}$ coordinate direction $(\mathrm{m}-\mathrm{K} / \mathrm{s})$

$\overline{u_{i} u_{j}}$ Reynolds stress $\left(m^{2} / s^{2}\right)$

$\vec{V} \quad$ Momentum density source arising from viscous dissipation $\left(\mathrm{Kg} / \mathrm{m}^{2} \mathrm{~s}^{2}\right)$

$\mathrm{V}_{\mathrm{b}} \quad$ Particle volume $\left(\mathrm{m}^{3}\right)$ 
$V_{g}\left(=N V_{b}\right)$ Volume of particles in a computational cell $\left(\mathrm{m}^{3}\right)$

$V_{f} \quad$ Fluid volume in a control cell $\left(\mathrm{m}^{3}\right)$

v Velocity component $(\mathrm{m} / \mathrm{s})$

$\overline{v \phi}$ Scalar heat flux in the $x_{2}$ coordinate direction $(m-k / s)$

W Mass concentration of particles

$\mathrm{W}_{\mathrm{e}} \quad$ Weber number

w Velocity component $(\mathrm{m} / \mathrm{s})$

$\overline{w \phi}$ Scalar flux in the $x_{3}$ coordinate direction $(m-k / s)$

$\mathrm{x} \quad$ Flowing quality

$x_{i} \quad$ Coordinate $(i=1,2$, and 3$)(m)$

$\mathrm{x}_{\mathrm{n}}$ Distance from the wall $(\mathrm{m})$

y Coordinate direction $(\mathrm{m})$

$y_{1} \quad$ Thickness of laminar sublayer (m)

$\mathrm{y}_{\ell}^{+} \quad$ Dimensionless thickness of laminar sublayer

yp Distance of node $\mathrm{p}$ from the wall (m)

z Coordinate direction (m)

\section{Greek}

$\alpha \quad$ Volume fraction

$\bar{\alpha} \quad$ Constant defined by Eq. 3.2.3.3

$\alpha_{n} \quad$ Constant defined by Eq. 3.2.3.10

$\beta \quad\left[=\frac{1}{\rho}\left(\frac{\partial \rho}{\partial T}\right)_{p}\right]$, volume expansion coefficient at constant pressure $\left(\mathrm{K}^{-1}\right)$

$\Gamma \quad$ Mass transfer rate between phases $\left(\mathrm{kg} / \mathrm{m}^{3} \mathrm{~s}\right)$

$\Gamma_{\mathrm{g}}$ Total (laminar plus turbulent) diffusivity in temperature fluctuation equation $\left(\mathrm{m}^{2} / \mathrm{s}\right)$

$\Gamma_{\mathrm{gl}}\left(=\frac{\lambda}{\rho c_{p}}\right)$, laminar diffusivity $\left(\mathrm{m}^{2} / \mathrm{s}\right)$ 
$\Gamma \mathrm{gt} \quad\left(=c_{\phi} \frac{\mathrm{k}^{2}}{\varepsilon}\right)$, turbulent diffusivity $\left(\mathrm{m}^{2} / \mathrm{s}\right)$

$\Gamma_{\phi} \quad\left(=\rho \Gamma_{\phi}^{\nu}=\mu_{\ell}+\rho c_{s \phi} \frac{\mathrm{K}^{2}}{\varepsilon}\right)$, total (laminar plus turbulent) dynamic diffusivity in scalar heat flux equations $\left(\mathrm{m}^{2} / \mathrm{s}\right)$

$\Gamma_{\phi}^{\nu} \quad\left(=v_{\ell}+c_{s \phi} \frac{\mathrm{K}^{2}}{\varepsilon}\right)$, total (laminar plus turbulent) kinematic diffusivity in scalar heat flux equations $(\mathrm{kg} / \mathrm{m}-\mathrm{s})$

$\gamma \quad$ Constant defined by Eq. 3.2.3.4

$\delta \quad$ Constant defined by Eq. 3.2.3.5

$\delta_{\mathrm{n}} \quad$ Constant defined by Eq. 3.2.3.11

$\delta_{\text {ij }} \quad$ Kronecker delta

$\Delta \quad$ Divergence of fluid velocity $\left(s^{-1}\right)$

$\varepsilon \quad$ Dissipation of turbulence kinetic energy $(\mathrm{W} / \mathrm{kg})$

$\eta \quad$ Reduced viscosity, defined by Eq. 4.2.2.4/Kolmogorov microscale of length (m)

$\theta \quad$ Azimuthal coordinate

$\theta_{\mathrm{n}} \quad$ Phase lag

$\lambda \quad$ Thermal conductivity $(\mathrm{W} / \mathrm{m}-\mathrm{K})$

$\lambda_{\mathrm{n}} \quad$ Phase angle in velocity spectrum

$\mu_{1} \quad$ Laminar dynamic viscosity $(\mathrm{kg} / \mathrm{m}-\mathrm{s})$

$\mu_{\mathrm{t}} \quad$ Turbulent dynamic viscosity $(\mathrm{kg} / \mathrm{m}-\mathrm{s})$

$v \quad$ Wave number $\left(\mathrm{m}^{-4}\right)$

v1 Laminar kinematic viscosity $\left(\mathrm{m}^{2} / \mathrm{s}\right)$

$v_{\mathrm{t}} \quad$ Turbulent kinematic viscosity $\left(\mathrm{m}^{2} / \mathrm{s}\right)$

$\xi \quad$ Constant $(=1.5)$ introduced in Eq. 3.2.3.18

$\Pi \quad$ Production of turbulent kinetic energy due to particles $\left(\mathrm{W} / \mathrm{m}^{3}\right)$ 
$\pi_{i \phi}$ Pressure-scalar gradient correlation in scalar heat flux equations (m-K/s )

$\rho \quad$ Density $\left(\mathrm{kg} / \mathrm{m}^{3}\right)$

$\sigma \quad$ Surface tension $\left(\mathrm{N} / \mathrm{m}^{2}\right) /$ standard deviation

$\sigma^{2} \quad$ Variance

$\sigma_{\mathbf{k}} \quad(=1.0)$, turbulence Prandtl number

$\sigma \mathrm{t} \quad(=0.9)$, turbulence Prandtl number for heat transport

$\sigma_{\varepsilon} \quad(=1.3)$, turbulence Prandtl number for $\varepsilon$

$\tau \quad$ Shear stress $\left(\mathrm{N} / \mathrm{m}^{2}\right)$

$\phi \quad$ Temperature fluctuation (K)

$\bar{\phi}^{2} \quad$ Variance of temperature fluctuations $\left(K^{2}\right)$

$\chi \quad(=0.41)$ von Karman constant

$\omega_{\mathrm{n}} \quad$ Angular velocity in velocity spectrum $\left(\mathrm{s}^{-1}\right)$

\section{Indices}

b Bubble or particle

i Free or dummy index

j Free or dummy index

k Phase or component

g Gas/air

1 Laminar/fluid

L Lift

n Normal to the wall

p Particle

P. First computational node close to the wall

$\mathrm{S}_{1} \quad$ Slip

TP Two-phase 
t Turbulence

T Transpose

vm Virtual mass

w Wall 


\title{
First Assessment of Computations of Turbulent Bubbly Flow and Particulate Flow with the COMMIX-M Program
}

\author{
by
}

M. Bottoni, F. C. Chang, and J. Ding

\begin{abstract}
The COMMIX-M computer code, which describes steady-state and transient singleand multicomponent flows in engineering systems, has been implemented to simulate suspension flows in laminar regimes and turbulent and bubbly particulate flows. This report presents a synopsis of the present code's capabilities, with particular emphasis on the recent development of turbulence models, and explains in detail the modifications necessary to simulate particulate flows and bubbly flows. First results of computations of turbulent bubbly and particulate flows are then given and compared with results of computations reported in the literature and with preliminary experimental results obtained at the Kernforschungszentrum Karlsruhe (Germany).
\end{abstract}

\section{Introduction}

The COMMIX-M computer code describes steady-state and transient single- and multicomponent flows in complex engineering systems. Recently, the code has been developed to simulate suspension flows in a laminar regime and turbulent bubbly and particulate flows. A two-phase turbulence model has been modified to be applicable to the latter simulations.

The goal of this report is to make a first assessment of the capability of the code to simulate turbulent bubbly and particulate flows.

In Sec. 2 of the report, we present a synopsis of the main code characteristics. The fundamental equations solved, including those for the turbulence models, are presented in Sec. 3. The most important code developments, which have enabled the simulation of suspension and bubbly flows with respect to the computation of lift forces, drag forces, and virtual mass forces, are explained in Sec. 4. Preliminary computation results are presented in Sec. 5 for bubbly flow and in Sec. 6 for particulate flow. These results enable us to identify the deficiencies of the current models, and therefore, provide a hint of how the program must be improved. Processing of output data for computing energy spectral distributions of velocity fluctuations is explained in Sec. 7 .

\section{Synopsis of COMMIX-M Code}

The COMMIX-M code was developed in 1987-1988 by H. M. Domanus, T. H. Chien, and R. C. Schmitt of the Analytical Thermal Hydraulics Section of the Materials and Components Technology (MCT) Division, now reorganized as the Energy Technology (ET) Division of Argonne National Laboratory. Code development resumed in 1990 and is currently carried on by all staff members of the above-mentioned section. 
The code describes steady-state and transient thermal and fluid-dynamic problems in multiphase or multicomponent flows in general two- or three-dimensional geometric configurations. The fluid-dynamic problems can be coupled to thermal problems in inner or outer structures.

The program is structured to handle up to 10 different fields (phases or components) even though it has been checked and validated only on the subcase of a limited number of fields, as explained below.

The basic equations for the conservation of mass, momentum, and enthalpy of the components (or phases) are given in Sec. 3. Single-phase flow turbulence can be described on the basis of a $\mathrm{K}-\varepsilon$ model or of a Reynolds stress model (RSM). This later model is based on six transport equations for the components of the Reynolds stress tensor, on three equations for the transport of turbulent thermal fluxes, and on one equation for the variance of temperature fluctuations. Thus, including the equation for the dissipation of turbulent kinetic energy, 11 equations are used. However, the RSM is still being checked and verified. Simulated two-phase flow turbulence is based on a modified $K-\varepsilon$ model, which takes into account the additional production of turbulent kinetic energy due to bubbles. This model is now undergoing verification.

With respect to treatment of the momentum equation, the code consists of two main branches:

1. Only one momentum equation for the mixture is solved; continuity equations are solved for every component separately in terms of mass fractions. In this branch, an enthalpy equation for the mixture can be solved, if required.

2. Separate momentum equations are solved for every component; continuity equations are also solved for every component in terms of volume fractions. No energy equation is used in this branch.

Mass exchange between the phases can be simulated in both branches, but the code does not provide for a boiling model.

Discretization of convective terms in the transport equations is based on first-order upwind discretization or on skew upwinding. 1 The latter scheme is used only for the energy equation. All transport equations are transformed into an algebraic equation that is formally similar to the equation that would be obtained by discretizing a Poisson equation and is simply referred to as a Poisson (-like) equation. The Poisson equation is solved for pressure, enthalpy, and, if required, for turbulent quantities, by using either a direct solver, the Yale Sparse Matrix Package (YSMP) ${ }^{2}$ or an iterative method of conjugate gradients. ${ }^{3}$ The YSMP technique is applicable to both symmetric and nonsymmetric matrices, whereas the conjugate gradient method assumes that the matrices of coefficients are symmetric and positive definite.

The COMMIX-M code consists of $\approx 300$ subroutines, written in FORTRAN, and $\approx 50,000$ statements. Plotting facilities are available for temperature and velocity distributions, obtained from a restart file. Computer-aided preparation of input data is being linked to the code. 
Thus far, the program has been verified in the following cases:

- Laminar flow of immiscible fluids, with different densities and viscosities, between parallel plates. In this case, an analytical solution for the velocity distribution is known. Results of numerical computation agree with analytical results within $1 \% .4$

- Analysis of liquid/solid suspensions for which experimental data are available. Results of these simulations have been published. 5

A single-phase flow version of COMMIX-M is referred to as COMMLX-1C and has been documented in Ref. 6.

\section{Fundamental Equations}

\subsection{Conservation Equations for Mass, Momentum, and Enthalpy}

\subsubsection{Mass Conservation Equations}

The mass conservation equation for every component $K$ is

$$
\frac{\partial}{\partial t}\left(\rho_{k} \alpha_{k}\right)+\nabla \cdot\left(\rho_{k} \alpha_{k} \vec{U}_{k}\right)=\Gamma_{k}
$$

where $\Gamma_{\mathbf{k}}\left(\mathrm{kg} / \mathrm{m}^{3} \mathrm{~s}\right)$ is the mass source.

\subsubsection{Momentum Equations}

The momentum equation for every component $\mathrm{K}$ is

$$
\begin{aligned}
\frac{\partial}{\partial \mathrm{t}}\left(\alpha_{\mathrm{k}} \rho_{\mathrm{k}} \overrightarrow{\mathrm{U}}_{\mathrm{k}}\right)+\nabla \cdot\left(\alpha_{\mathrm{k}} \rho_{\mathrm{k}} \overrightarrow{\mathrm{U}}_{\mathrm{k}} \overrightarrow{\mathrm{U}}_{\mathrm{k}}\right)= & -\alpha_{\mathrm{k}} \nabla_{\mathrm{p}}+\overrightarrow{\mathrm{V}}_{\mathrm{k}}+\alpha_{\mathrm{k}} \rho_{\mathrm{k}} \overrightarrow{\mathrm{g}}+\mathrm{K}_{\mathrm{kj}}^{\mathrm{M}}\left(\overrightarrow{\mathrm{U}}_{\mathrm{k}}-\overrightarrow{\mathrm{U}}_{\mathrm{j}}\right) \\
& +\overrightarrow{\mathrm{F}}_{\mathrm{Lk}}+\overrightarrow{\mathrm{F}}_{\mathrm{vm}, \mathrm{k}},
\end{aligned}
$$

where $\vec{V}_{k}$ is the momentum density source arising from viscous dissipation, $K_{k j}^{M}$ is the drag force at the interface between components $k$ and $j, \vec{F}_{L}$ is the lift force, and $\vec{F}_{v m}$ is the virtual mass force. The analytical expressions of the latter two forces are given below in apposite sections.

\subsubsection{Enthalpy Equations}

The enthalpy equation for every component $\mathrm{K}$ is

$$
\frac{\partial}{\partial t}\left(\rho_{k} h_{k}\right)+\nabla \cdot\left(\rho_{k} h_{k} \vec{U}_{k}\right)=-\nabla \cdot \vec{q}_{k}+\frac{d p}{d t}+Q_{k}+\Gamma_{k} h_{k},
$$

where $Q_{\mathrm{k}}$ is the specific power generation. In Eqs. 3.1.2 and 3.1.3, it is assumed that all components have the same pressure. 


\subsection{Governing Equations for Turbulence Models}

\subsubsection{Single-Phase Flow}

The transport equations for turbulent kinetic energy $K$ and its dissipation $\varepsilon$ are

$$
\rho \frac{\partial \mathrm{K}}{\partial \mathrm{t}}+\rho U_{j} \frac{\partial \mathrm{K}}{\partial \mathrm{x}_{\mathrm{j}}}=\mathrm{P}+\mathrm{G}-\rho \varepsilon+\frac{\partial}{\partial \mathrm{x}_{\mathrm{j}}}\left[\left(\mu_{\ell}+\frac{\mu_{\mathrm{t}}}{\sigma_{\mathrm{k}}}\right) \frac{\partial \mathrm{K}}{\partial \mathrm{x}_{\mathrm{j}}}\right]
$$

and

$$
\rho \frac{\partial \varepsilon}{\partial t}+\rho U_{j} \frac{\partial \varepsilon}{\partial x_{j}}=c_{1 \varepsilon} \frac{\varepsilon}{k}(P+G)\left(1+c_{3 \varepsilon} R_{f}\right)-c_{2 \varepsilon} \frac{\varepsilon^{2}}{k}+\frac{\partial}{\partial x_{j}}\left[\left(\frac{\mu_{t}}{\sigma_{\varepsilon}}+\mu_{\ell}\right) \frac{\partial \varepsilon}{\partial x_{j}}\right],
$$

or

$$
\rho \frac{\partial \varepsilon}{\partial t}+\rho U_{j} \frac{\partial \varepsilon}{\partial x_{j}}=c_{1 \varepsilon} \frac{\varepsilon}{K}(P+G)\left(1+c_{3 \varepsilon} R_{f}\right)-c_{2 \varepsilon} \frac{\varepsilon^{2}}{K}+\frac{\partial}{\partial x_{j}}\left(\mu \ell \frac{\partial \varepsilon}{\partial x_{j}}+c_{\varepsilon} \frac{\rho K}{\varepsilon} \overline{u_{j} u_{k}} \frac{\partial \varepsilon}{\partial x_{k}}\right)
$$

with

$$
\begin{aligned}
& P=\mu_{t}\left[\frac{\partial U_{i}}{\partial x_{j}}\left(\frac{\partial U_{i}}{\partial x_{j}}+\frac{\partial U_{j}}{\partial x_{i}}\right)\right], \\
& G=-\rho \beta g_{i} \overline{u_{i} \phi} \\
& R_{f}=-\frac{G}{P} \\
& \beta=-\frac{1}{\rho}\left(\frac{\partial \rho}{\partial T}\right)_{p} .
\end{aligned}
$$

Equation 3.2.1.2b, with $c_{\varepsilon}=0.15$, is used in combination with Eq. 3.2.1.13 for the Reynolds stress model.

We refer the reader to the Nomenclature list for the definition of the symbols. In the $\mathrm{K}-\varepsilon$ model, Eq. 3.2.1.4 is approximated by

$$
G=-\frac{\mu_{t}}{\rho \sigma_{t}}\left(\frac{\partial \rho}{\partial T}\right)_{p}\left(\frac{\partial T}{\partial x_{j}} g_{j}\right)
$$

The transport equations for scalar heat fluxes $\left(\overline{u_{i} \phi}: \overline{u \phi}, \overline{v \phi}\right.$, and $\left.\overline{w \phi}\right)$ are 


$$
\frac{\partial}{\partial t}\left(\overline{u_{i} \phi}\right)+U_{j} \frac{\partial}{\partial x_{j}}\left(\overline{u_{i} \phi}\right)=\frac{\partial}{\partial x_{j}}\left[\left(v_{\ell}+c_{s \phi} \frac{K^{2}}{\varepsilon}\right) \frac{\partial\left(\overline{u_{i} \phi}\right)}{\partial x_{j}}\right]+P_{i \phi}+G_{i \phi}+\pi_{i \phi},
$$

with

$$
\begin{aligned}
P_{i \phi} & =-\left(\overline{u_{i} u_{j}} \frac{\partial T}{\partial x_{j}}+\overline{u_{j} \phi} \frac{\partial U_{i}}{\partial x_{j}}\right) \\
G_{i \phi} & =-\beta g_{1} \phi^{2}
\end{aligned}
$$

and

$$
\pi_{i \phi}=-c_{1 \phi} \frac{\varepsilon}{K} \overline{u_{i} \phi}+c_{2 \phi} \overline{u_{j} \phi} \frac{\partial U_{i}}{\partial x_{j}}+c_{3 \phi} \beta g_{i} \overline{\phi^{2}}-c_{1 \phi} \frac{\varepsilon}{K} \overline{u_{n} \phi} \delta_{i n} f\left(\frac{L}{x_{n}}\right)
$$

The transport equation for variance of temperature fluctuations $\left(g=\frac{1}{2} \overline{\phi^{2}}\right)$ is

$$
\frac{\partial g}{\partial t}+\frac{\partial\left(U_{j} g\right)}{\partial x_{j}}=\frac{\partial}{\partial x_{j}}\left[\left(c_{\phi}^{\prime} \frac{K^{2}}{\varepsilon}+\frac{\lambda}{\rho c_{p}}\right) \frac{\partial g}{\partial x_{j}}\right]-\overline{u_{j} \phi} \frac{\partial T}{\partial x_{j}}-\frac{\varepsilon}{K} \frac{g}{R} .
$$

The transport equations for Reynolds stresses $\left(\overline{u_{i} u_{j}}\right)$ are

$$
\begin{aligned}
& \frac{\partial\left(\overline{u_{1} u_{j}}\right)}{\partial t}+U_{\ell} \frac{\partial\left(\overline{u_{1} u_{j}}\right)}{\partial x_{\ell}}=\frac{\partial}{\partial x_{\ell}}\left[c_{k} \frac{K^{2}}{\varepsilon} \frac{\partial\left(\overline{u_{1} u_{j}}\right)}{\partial x_{\ell}}+v_{\ell} \frac{\partial\left(\overline{u_{1} u_{j}}\right)}{\partial x_{\ell}}\right]-\left(1-c_{2}\right)\left(\overline{u_{i} u_{\ell}} \frac{\partial U_{j}}{\partial x_{\ell}}+\overline{u_{j} u_{\ell}} \frac{\partial U_{i}}{\partial x_{\ell}}\right) \\
& \quad-\left[\frac{2}{3} \varepsilon \delta_{i j}+c_{1} \frac{\varepsilon}{K}\left(\overline{u_{1} u_{j}}-\frac{2 K \delta_{j k}}{3}\right)-\frac{2}{3} c_{2} \overline{u_{n} u_{m}} \frac{\partial u_{n}}{\partial x_{m}} \delta_{i j}-\left(1-c_{3}\right) \beta\left(g_{i} \overline{u_{j} \phi}+g_{j} \overline{u_{i} \phi}\right)\right] \\
& +\frac{2}{3} c_{3} \beta g_{\ell} \overline{u_{\ell} \phi} \delta_{i j}-c_{1} \frac{\varepsilon}{K}\left(\overline{u_{i} u_{j}}\right)-\left(1-c_{3}\right) \beta\left(g_{i} \overline{u_{j} \phi}+g_{j} \overline{u_{i} \phi}\right) .
\end{aligned}
$$

The numerical values of the coefficients used in the above equations are as follows:

$$
\begin{array}{llrl}
c_{1 \varepsilon}=1.44, & c_{2 \varepsilon}=1.92, & c_{3 \varepsilon}=0.8, & \sigma_{k}=1.0, \\
c_{1 \phi}=3.1, & c_{2 \phi}=0.4, & c_{3 \phi}=0.5, & \sigma_{t}=0.9, \\
c_{1 \phi}^{\prime}=0.5, & c_{\phi}^{\prime}=0.13, & R=0.5, & \sigma_{\varepsilon}=1.3, \\
c_{1}=2.8, & c_{2}=0.47, & c_{3}=0.47, & c_{s \phi}=0.07, \\
c_{k}=0.09 . & &
\end{array}
$$


The boundary conditions used for the above equation are illustrated in Figs. 1 and 2, which show the two-layer wall function model used in COMMIX-M, where $P$ is the node adjacent to the wall, $y_{p}$ is the distance from $P$ to the wall, and $y_{1}$ is the thickness of the viscous sublayer. The distance $y_{p}$ is fixed, for a given mesh system. The thickness of the viscous sublayer, $\mathrm{y}_{1}$, however, is not a constant.

When $y_{p}>y_{1}$, the first node is in a fully turbulent zone and it holds, for the turbulent kinetic energy and its dissipation,

$$
\mathrm{K}_{\mathrm{p}}=\mathrm{u}^{* 2} / \sqrt{\mathrm{c}_{\mu}},
$$

and

$$
\varepsilon_{\mathrm{p}}=\mathrm{u}^{*} /\left(\chi \mathrm{y}_{\mathrm{p}}\right)
$$

where

$$
u^{*}=\frac{u_{p}}{u^{+}}=\frac{\chi u_{p}}{\ln (y+E)}
$$

Equation 3.2.1.16 gives the "universal law of the wall" in terms of friction velocity $u^{*}$, defined by

$$
\mathbf{u}^{*}=\sqrt{\frac{\tau_{\mathrm{w}}}{\rho}} .
$$

$\chi(=0.42)$ is the von Karman constant, and $E(=9.0)$ is a constant that is dependent on the roughness of the wall.

When $y_{p}<y_{1}$, the node $P$ is in the laminar sublayer, and one has

$$
\mathrm{K}_{\mathrm{p}}=\mathrm{u}^{* 2}\left(\mathrm{y}_{\mathrm{p}} / \mathrm{y}_{\ell}\right) / \sqrt{\mathrm{c}_{\mu}} \text {, }
$$

and

$$
\varepsilon_{\mathrm{p}}=\mathrm{u}^{*} /\left(\chi \mathrm{y}_{\ell}\right)
$$

The thickness of the laminar sublayer $y_{1}$ is evaluated by matching the velocity at the edge of the viscous sublayer $\left(y=y_{1}\right)$ to that obtained from the law of the wall. Thus, one has

$$
\mathrm{u}^{+}=\mathrm{y}_{\ell}^{+}=\frac{1}{\chi} \ln \left(\mathrm{Ey}_{\ell}^{+}\right)
$$


with

$y_{\ell}=v_{\ell} y_{\ell}^{+} / u^{*}$

For the scalar fluxes, the boundary conditions are

$$
-\left(\overline{u_{i} \phi}\right)_{p}= \begin{cases}T^{*} u^{*} & \text { if } y_{p} \geq y_{\ell} \\ -c_{\mu} \frac{k^{2}}{\varepsilon} \frac{\partial T}{\partial x_{i}} & \text { if } y_{p}<y_{\ell}\end{cases}
$$

with

$$
\mathrm{T}^{*}=\frac{\mathrm{q}_{\mathrm{w}}}{\rho \mathrm{c}_{\mathrm{p}} \mathrm{u}^{*}}
$$

The boundary conditions for the variance of the temperature fluctuations are as follows:

$$
\begin{aligned}
& \text { If } \mathrm{y}_{\mathrm{p}} \geq \mathrm{y}_{1}, \\
& \mathrm{~g}_{\mathrm{p}}=\frac{\mathrm{T}^{* 2} \mathrm{R} \sigma_{\mathrm{t}}}{\sqrt{\mathrm{c}_{\mu}}},
\end{aligned}
$$

where $\sigma_{\mathrm{t}}(=0.9)$ is the turbulence Prandtl number for heat transport.

$$
\begin{aligned}
& \text { If } \mathrm{y}_{\mathrm{p}}<\mathrm{y}_{1} \\
& \mathrm{~g}_{\mathrm{p}}=\frac{1}{\mathrm{~A}}\left[\Gamma_{\mathrm{g} \ell} \frac{\mathrm{g}_{\ell}}{\mathrm{y}_{\ell}-\mathrm{y}_{\mathrm{p}}}+\Gamma_{\mathrm{gp}} \frac{\mathrm{g}_{\mathrm{w}}}{\mathrm{y}_{\mathrm{p}}}+\frac{\left(\mathrm{u}^{*} \mathrm{~T}^{*}\right)^{2} \sigma_{\mathrm{t}}}{2 v_{\mathrm{t}}} \mathrm{y}_{\ell}-\frac{\mathrm{y}_{\ell}}{\mathrm{R} v_{\ell}}\left(\mathrm{u} * \mathrm{~T}^{*}\right)^{2}\right]
\end{aligned}
$$

with

$$
A=v_{p} \frac{y_{\ell}}{y_{p}}+\frac{\Gamma_{g \ell}}{y_{\ell}-y_{p}}+\frac{\Gamma_{g p}}{y_{p}}
$$

and

$$
\Gamma_{g}=\dot{c_{\phi}} \frac{\mathrm{K}^{2}}{\varepsilon}+\frac{\lambda}{\rho c_{p}}
$$

The boundary conditions for Reynolds stresses are

$$
\begin{array}{ll}
\left(-\overline{u_{i} u_{j}}\right)_{p}=u^{* 2} & i \neq j \\
\left(\overline{u_{i} u_{j}}\right)_{p}=u^{* 2} / \sqrt{c_{\mu}} & i=j .
\end{array}
$$


The above equations, with the relative boundary conditions, can be used in the frame of three different turbulence models at increasing levels of sophistication:

- In the frame of the $\mathrm{K}-\varepsilon$ model, Eqs. 3.2.1.1 - 3.2.1.7 are used.

- In the frame of a so-called anisotropic turbulence model, Eqs. 3.2.1.1 3.2.1.12 are used. Further details about this model are given in Ref. 7 .

- In the frame of the Reynolds stress model, Eqs. 3.2.1.2 - 3.2.1.13 are used.

In this case, the turbulence kinetic energy is computed as $\mathrm{K}=\overline{\mathrm{u}_{\mathrm{i}} \mathrm{u}_{\mathrm{i}}} / 2$.

\subsubsection{Multiphase Flow}

The $\mathrm{K}-\varepsilon$ model has been extended to the case of multiphase or multicomponent flows. So far, however, it has been tested and applied only for the case of a two-component flow in which a carrying fluid transports particles.

The transport equation for the turbulence kinetic energy becomes, for every component $\mathrm{k}$ :

$$
\begin{aligned}
\alpha_{k} \rho_{k} \frac{\partial K_{k}}{\partial t}+\alpha_{k} \rho_{k} U_{k j} \frac{\partial K_{k}}{\partial x_{j}}= & P_{k}+G_{k}+\Pi_{k}-\alpha_{k} \rho_{k} \varepsilon_{k} \\
& +\frac{\partial}{\partial x_{j}}\left[\left(\mu_{\ell k}+\frac{\mu_{t k}}{\sigma_{t}}\right) \frac{\partial K_{k}}{\partial x_{j}}\right]
\end{aligned}
$$

with

$$
\begin{aligned}
& P_{k}=\alpha_{k} \mu_{t k} \frac{\partial U_{k i}}{\partial x_{j}}\left(\frac{\partial U_{k i}}{\partial x_{j}}+\frac{\partial U_{k j}}{\partial x_{i}}\right) \\
& G_{k}=\frac{\mu_{t k}}{\rho_{k} \sigma_{t}} \frac{\partial\left(\alpha_{k} \rho_{k}\right)}{\partial T_{k}} \frac{\partial T_{k}}{\partial x_{j}} g_{j},
\end{aligned}
$$

and

$$
\Pi_{k}=c_{\pi k} \rho_{k}\left(1-\alpha_{k}\right) \frac{\left|\vec{V}_{S \ell}\right|^{3}}{r_{b}} .
$$

The additional term $\Pi_{k}$, which does not appear in Eq. 3.2.1.1 for single-phase flow, represents the production of turbulent kinetic energy due to particles of radius $r_{b}$. $V_{S l}$ is the slip velocity between carrying fluid and carried particles. We used $c_{\pi k}=0.02$ in the applications, but the numerical value of this constant is not yet validated. 
The transport equation for the dissipation of turbulent kinetic energy becomes

$$
\begin{aligned}
\alpha_{k} \rho_{k} \frac{\partial \varepsilon_{k}}{\partial t}+\alpha_{k} \rho_{k} U_{k j} \frac{\partial \varepsilon_{k}}{\partial x_{j}}= & {\left[c_{1 \varepsilon} \frac{\varepsilon_{k}}{K_{k}}\left(P_{k}+G_{k}\right)+\Pi_{\varepsilon k}\right]\left(1+c_{3 \varepsilon} R_{f k}\right) } \\
& -c_{2 \varepsilon} \alpha_{k} \rho_{k} \frac{\varepsilon_{k}^{2}}{K_{k}}+\frac{\partial}{\partial x_{j}}\left[\left(\mu_{\ell k}+\frac{\mu_{t k}}{\sigma_{\varepsilon}}\right) \frac{\partial \varepsilon_{k}}{\partial x_{j}}\right],
\end{aligned}
$$

where the additional term $\Pi_{\varepsilon \mathbf{k}}$, representing the dissipation of turbulent kinetic energy produced by the particles, is given by

$$
\Pi_{\varepsilon k}=c_{\pi \varepsilon} \frac{\varepsilon_{k}}{K_{k}} \Pi_{k}
$$

with $\mathrm{c}_{\pi \varepsilon}=1.2$.

\subsubsection{Attenuation of Turbulent Kinetic Energy Due to Small Particles}

The additional production of turbulent kinetic energy, modeled by term $\Pi_{k}$ in Eq. 3.2.2.1, is due essentially to the formation of a wake beyond the particles and to vortex shedding. The mechanism of vortex shedding is strong at high particle Reynolds numbers,

$$
\operatorname{Re}_{\mathrm{b}}=\frac{\mathrm{d}_{\mathrm{b}} \rho_{\ell}\left|\overrightarrow{\mathrm{V}}_{\mathrm{s} \ell}\right|}{\mu_{\ell}}
$$

but becomes negligible below $\mathrm{Re}_{\mathrm{b}} \approx 400$. At even lower particle Reynolds numbers, for $\mathrm{Re}_{\mathrm{b}}<110$, the turbulent kinetic energy of the carrying fuid is damped because the particles are entrained in the oscillating motion of the fluid turbulent fluctuations and dissipate energy due to shearing. Therefore, when small particles are entrained by a fluid in turbulent motion, the turbulent kinetic energy of the fluid becomes lower than in singlephase flow at the same Reynolds number.

The physical modeling of the attenuation of turbulent kinetic energy due to small particles is summarized in this section, following the treatment of Ref. 8 . The implementation of this modeling in the COMMIX-M code is explained at the end of this section.

Let us assume that the particles transported by a fluid are spherical, of uniform size, and have Reynolds number $\mathrm{Re}_{\mathrm{b}}<110$. We further assume that the particle phase is dilute, so that interactions between the particles are negligible. The equation describing the motion of one particle in a turbulent flow is (see, for instance Ref. 9)

$$
V_{b} \rho_{b} \frac{d u_{b}(t)}{d t}=6 \pi \mu_{\ell t} r_{b}\left[u_{\ell}(t)-u_{b}(t)\right]+V_{b} \rho_{\ell} \frac{d u_{\ell}(t)}{d t}
$$

Term (I) 


$$
+C_{v m} V_{b} \rho_{\ell}\left[\frac{d u_{\ell}(t)}{d t}-\frac{d u_{b}(t)}{d t}\right]+6 \pi_{b}^{2} \sqrt{\pi \rho_{\ell} \mu_{\ell t}} \int_{0}^{t} \frac{\frac{d u_{\ell}\left(t^{\prime}\right)}{d t^{\prime}}-\frac{d u_{b}\left(t^{\prime}\right)}{d t^{\prime}}}{\sqrt{t-t^{\prime}}}
$$

(IV)

(V)

Eq. 3.2.3.2, originally devised for slow motion of a particle in a stationary fluid, can be applied to turbulent flow by replacing the molecular dynamic viscosity of the fluid $\mu_{\ell}$, with the turbulent viscosity, $\mu_{\ell}$. Terms at the right-hand side of Eq. 3.2.3.2 represent: (II) the viscous force (Stoke's drag force); (III) the force arising from the pressure gradient around the particle, due to fluid acceleration; (IV) the virtual mass force; (V) the transient viscous force or Basset force. Eq. 3.2.3.2 can be rearranged as

$$
\frac{d u_{b}(t)}{d t}=\bar{\alpha}\left[u_{b}(t)-u_{\ell}(t)\right]+\gamma \frac{d u_{\ell}(t)}{d t}+\delta \int_{0}^{t} \frac{\frac{d u_{\ell}\left(t^{\prime}\right)}{d t^{\prime}}-\frac{d u_{b}\left(t^{\prime}\right)}{d t^{\prime}}}{\sqrt{t-t^{\prime}}},
$$

with the definition of the coefficients

$$
\begin{aligned}
& \bar{\alpha}=\frac{18 \mu_{\ell \mathrm{t}}}{\mathrm{d}_{\mathrm{b}}^{2}\left(\rho_{\mathrm{b}}+\mathrm{C}_{\mathrm{vm}} \rho_{\ell}\right)}, \\
& \gamma=\frac{1+\mathrm{C}_{\mathrm{vm}}}{\frac{\rho_{\mathrm{b}}}{\rho_{\ell}}+\mathrm{C}_{\mathrm{vm}}}, \\
& \delta=\frac{g \sqrt{v_{\ell \mathrm{t}}}}{\sqrt{\pi} \mathrm{d}_{\mathrm{b}}\left(\frac{\rho_{\mathrm{b}}}{\rho_{\ell}}+\mathrm{C}_{\mathrm{vm}}\right)} .
\end{aligned}
$$

In Ref. 8, the fluid and particle velocities are decomposed in mean values and turbulent fluctuations, and are represented by their velocity spectra as

$$
\begin{aligned}
& \mathrm{u}_{\ell}(\mathrm{t})=\mathrm{U}_{\ell}+\mathrm{u}_{\ell}=\mathrm{U}_{\ell}+\sum_{1}^{N} \mathrm{u}_{\ell \mathrm{n}}=\mathrm{U}_{\ell}+\sum_{1}^{N} \mathrm{n} A_{\mathrm{n}} \omega_{\mathrm{n}} \sin \left(2 \pi \mathrm{nt}+\lambda_{\mathrm{n}}\right), \\
& \mathrm{u}_{\mathrm{b}}(\mathrm{t})=\mathrm{U}_{\mathrm{b}}+\mathrm{u}_{\mathrm{b}}=\mathrm{U}_{\mathrm{b}}+\sum_{1}^{N} \mathrm{u}_{\mathrm{bn}}=\mathrm{U}_{\mathrm{b}}+\sum_{1}^{N} a_{\mathrm{n}} \omega_{\mathrm{n}} \sin \left(2 \pi n \mathrm{n}+\lambda_{\mathrm{n}}-\mathrm{g}_{\mathrm{n}}\right),
\end{aligned}
$$

where $\omega_{n}=2 \pi n$ and $g_{n}$ is the lag in the phase angle between the fluid and particle fluctuations. Introducing Eqs. 3.2.3.7 and 3.2.3.8 into 3.2.3.3 and imposing the condition that for every frequency $n$, the coefficients multiplying the functions $\sin \left(\omega_{n} t+\lambda_{n}\right)$ and $\cos \left(\omega_{n} t+\lambda_{n}\right)$ are equal, one derives an analytical expression for the amplitude ratio, $a_{n} / A_{n}$, and for the phase lag $\theta_{n}$, as

$$
\frac{a_{m}}{A_{m}}=\frac{\left(\alpha_{n}+\delta_{n}\right)^{2}+\left(1+\delta_{n}\right)\left(\gamma+\delta_{n}\right)}{\left[\left(1+\delta_{n}\right)^{2}\left(\gamma+\delta_{n}\right)^{2}\right] \cos \theta_{n}}
$$




$$
\operatorname{tg} \theta_{n}=\frac{\left(\alpha_{n}+\delta_{n}\right)(1-\gamma)}{\left(1+\delta_{n}\right)\left(\gamma+\delta_{n}\right)+\left(\alpha_{n}+\delta_{n}\right)^{2}}
$$

where

$$
\begin{aligned}
& \alpha_{\mathrm{n}}=\bar{\alpha} / \omega_{\mathrm{n}}, \\
& \delta_{\mathrm{n}}=\delta / \sqrt{\pi / 2 \omega_{\mathrm{n}}} .
\end{aligned}
$$

The normalized root-mean-squared (RMS) relative velocity between fluid and particles is obtained as

$$
R_{n}=\frac{\left(u_{\ell n}-u_{b n}\right)_{R M S}}{\left(u_{\ell n}\right)_{R M S}}=\left[1+\left(\frac{a_{n}}{A_{n}}\right)^{2}-\frac{2 a_{n}}{A_{n}} \cos \theta_{n}\right]^{1 / 2} .
$$

In the subcase in which only viscous forces are important $(\gamma=\delta=0)$, one obtains

$$
\begin{aligned}
& \frac{a_{n}}{A_{n}}=\frac{\bar{\alpha}^{2}}{\left(\omega_{n}^{2}+\bar{\alpha}^{2}\right) \cos \theta_{n}}, \\
& \operatorname{tg} \theta_{n}=\omega_{n} / \bar{\alpha}
\end{aligned}
$$

while Eq. 3.2.3.13 still holds. This simplifying assumption is used in the numerical application explained in the next section.

Let us define $\mathrm{K}(\mathrm{v})$ and $\mathrm{D}(\mathrm{v})$ as the turbulent kinetic energy and its dissipation per unit wave number $v$ and

$$
\mathrm{W}=\frac{\alpha_{\mathrm{bPb}}}{\alpha_{\mathrm{bPb}}+\alpha_{\ell \rho \ell}}
$$

the mean concentration of the particles. The dissipation spectrum of the fluid-particles two-phase (TP) flow is then given by

$$
\mathrm{D}(\mathrm{r})_{\mathrm{TP}}=2 v_{\ell v} 2 \mathrm{~K}(\mathrm{v})_{\mathrm{TP}}+\frac{36 \mathrm{~W} v_{\ell \rho \ell} R_{\mathrm{v}}^{2}}{\mathrm{~d}_{\mathrm{b}}^{2} \rho_{\mathrm{b}}} \mathrm{K}(\mathrm{v})_{\mathrm{TP}}
$$

The first term at the right-hand side of Eq. 3.2.3.17 is the energy dissipation of the continuous phase, assumed to be formally identical to the dissipation spectrum, $D(v)=$ $2 v_{\ell} v^{2} \mathrm{~K}(\mathrm{v})$, of a single phase flow. ${ }^{10}$ The second term is proved in Ref. 8 to represent the energy dissipation arising from the shearing action of the oscillatory motion of the particles entrained by the turbulent oscillations of the fluid. The energy flow through the energy cascade which leads to viscous dissipation of the turbulent kinetic energy in the equilibrium range is given by

$$
\frac{\mathrm{dT}(v)_{\mathrm{TP}}}{\mathrm{d} v}=-\mathrm{D}(\mathrm{v})_{\mathrm{TP}}
$$


The relationship between the energy flux, $T(v)$, and the turbulent kinetic energy, $K(v)$, which has been proven for single-phase flow in the equilibrium range, is assumed to hold also in the two-phase flow case, namely

$$
\mathrm{T}(v)_{\mathrm{TP}}=\frac{1}{\xi} \varepsilon_{\mathrm{TP}}^{1 / 3} v^{5 / 3} \mathrm{~K}(v)_{\mathrm{TP}}
$$

where $\xi \approx 1.5$ and

$$
\begin{aligned}
& \varepsilon_{\mathrm{TP}}=\int_{0}^{\infty} \mathrm{D}(v)_{\mathrm{TP}} \mathrm{dv} . \\
& =\int_{0}^{\infty}\left(2 v_{\ell} v^{2}+\frac{36 \mathrm{~W}_{\ell} \rho_{\ell} \mathrm{R}_{\mathrm{v}}^{2}}{\mathrm{~d}_{\mathrm{b}}^{2} \rho_{\mathrm{b}}}\right) \mathrm{K}(v)_{\mathrm{TP}} \mathrm{d} v .
\end{aligned}
$$

(We note that formula 29 of Ref. 8 seems to be wrong. The constant 15 in the first term of the integral should be replaced by 2. )

Combining Eqs. 3.2.3.18 and 3.2.3.19. and integrating, one obtains

$$
\mathrm{K}(v)_{\mathrm{TP}}=c \xi v-5 / 3 \varepsilon_{\mathrm{TP}}^{-1 / 3} \exp \left\{-\frac{3}{2} \xi\left(\eta_{\mathrm{TP}} v\right)^{4 / 3}-\frac{36 \mathrm{~W} \rho_{\ell} \eta_{\mathrm{TP}}^{4 / 3} \xi}{\mathrm{d}_{\mathrm{b}}^{2} \rho_{\mathrm{b}}} \int_{0}^{v} v-5 / 3 \mathrm{R}_{\mathrm{v}}^{2} \mathrm{~d} v\right\}
$$

where, in analogy with the definition of Kolmogorov microscale of length in single-phase flow, we use

$$
\eta_{\mathrm{TP}}^{4 / 3}=\mathrm{v}_{\ell} \varepsilon_{\mathrm{TP}}^{-1 / 3}
$$

The integration constant $\mathrm{c}$ in Eq. 3.2.3.21 can be eliminated by imposing the condition that for $W=0$ (absence of particles), one obtains the same turbulence spectrum as for singlephase flow, namely 10

$$
K(v)=\xi \varepsilon^{2 / 3} v-5 / 3 \exp \left\{-\frac{3}{2} \xi(\eta v)^{4 / 3}\right\}
$$

Thus, one obtains

$$
c \varepsilon_{\mathrm{TP}}^{-1 / 3} \exp \left\{-\frac{3}{2} \xi\left(\eta_{\mathrm{TP}}\right)^{4 / 3}\right\}=\varepsilon^{2 / 3}\left\{\exp -\frac{3}{2} \xi(\eta v) 4 / 3\right\}
$$

and from Eq. 3.2.3.21

$$
\mathrm{K}(v)_{\mathrm{TP}}=\xi \varepsilon^{2 / 3} v^{-5 / 3} \exp \left\{-\frac{3}{2} \xi(\eta v)^{4 / 3} \cdot \frac{36 \mathrm{~W} \rho_{\ell} \xi \eta_{\mathrm{TP}}^{4 / 3}}{\mathrm{~d}_{\mathrm{b}}^{2} \rho_{\mathrm{b}}} \int_{0}^{v} v^{-5 / 3} \mathrm{R}_{\mathrm{v}}^{2} \mathrm{~d} v\right\}
$$




$$
\begin{aligned}
& =K(v) \exp \left\{-\frac{36 W \rho_{\ell} \xi \eta_{T P}^{4 / 3}}{d_{b}^{2} \rho_{b}} \int_{0}^{v} v-5 / 3 R_{v}^{2} d v\right\}, \\
& =K(v) H(v),
\end{aligned}
$$

where we defined the attenuation factor

$$
H(v)=\frac{K(v)_{T P}}{K(v)}=\exp \left\{-\frac{36 W_{\ell} \xi \eta_{T P}^{4 / 3}}{d_{b}^{2} \rho_{b}} \int_{0}^{v} v-5 / 3 R_{v}^{2} d v\right\}
$$

The main difficulty in applying this theoretical modeling in the COMMIX-M code is that the code computes integral values of the turbulent kinetic energy but not its spectral distribution. Thus, the attenuation factors, which depend on the wave number $v$, cannot be used directly. To cope with this difficulty, a spectral distribution must be assumed with the condition that its integration over the full spectrum yields the same turbulent kinetic energy as computed by the code.

Let

$$
\mathrm{K}_{0}=\int_{0}^{\infty} \mathrm{K}(v) \mathrm{d} v=\int_{0}^{v_{1}} \mathrm{~K}(v) \mathrm{d} v+\int_{v_{1}}^{\infty} \mathrm{K}(v) \mathrm{d} v
$$

be the value computed by the code, for a given computational cell, in a two-phase flow calculation but without accounting for the attenuation of turbulent kinetic energy due to particles. The wave number $v_{1}$ denotes the boundary between the large-scale range and the inertial subrange. In the inertial subrange and in the equilibrium range, the spectral distribution is given by

$$
K(v)=c_{0} v^{-5 / 3} \text {. }
$$

The proportionality constant $c_{0}$ must be determined by imposing the condition that the integrated value, according to Eq. 3.2.3.27, is equal to $\mathrm{K}_{0}$. We impose this condition assuming $v_{1} \approx 10^{-1}$ and neglecting the first integral at the right-hand side of Eq. 3.2.3.27. Thus, we obtain

$$
\mathrm{c}_{\mathrm{o}} \approx \frac{2}{3} \mathrm{~K}_{\mathrm{o}} \mathrm{v}_{1}^{2 / 3}
$$

and

$$
\mathrm{K}(v) \approx \frac{2}{3} \mathrm{~K}_{0} v_{1}^{2 / 3} v^{-5 / 3}
$$

Next, the attenuation factor is computed with Eq. 3.2.3.26 and $K(v)_{T P}=K(v) H(v)$ using Eq. 3.2.3.25. Finally, integration of $\mathrm{K}(\mathrm{v})_{\mathrm{TP}}$ yields the updated value 


$$
\mathrm{K}_{\mathrm{OTP}}=\int_{0}^{\infty} \mathrm{K}(v)_{\mathrm{TP}} \mathrm{d} v=\int_{v_{1}}^{\infty} \mathrm{K}(v) \mathrm{d} v \text {. }
$$

The ratio

$$
\mathrm{H}_{\mathrm{o}}=\frac{\mathrm{K}_{\mathrm{OTP}}}{\mathrm{K}_{\mathrm{O}}}
$$

is the integral attenuation of the turbulent kinetic energy due to the particles.

\section{Computation of Lift, Drag, and Virtual Mass Forces}

The modeling of lift forces is of paramount importance for computing the distribution of volume fractions of the components in suspension flows. Drag forces between the components are important for computing the relative velocities and pressure drops. The stability of the numerical calculations, especially at high Reynolds numbers, is enhanced by the modeling of virtual mass forces. Because these topics are very important for the simulation of suspension and bubbly flows, they are explained in detail in this section. The components of the velocity are not capitalized in this section because there is no ambiguity with turbulent fluctuations.

\subsection{Lift Force}

A sphere of radius $\mathrm{r}_{\mathrm{b}}$, moving through a viscous liquid with velocity $\mathrm{V}_{\mathrm{Sl}}$ relative to a uniform simple shear, experiences a lift force

$$
\mathrm{L}_{\mathrm{z}}=\mathrm{c} \rho_{\ell} \mathrm{V}_{\mathrm{S} \ell} \mathrm{r}_{\mathrm{b}}^{2}\left(\mathrm{v}_{\ell}\left|\frac{\partial \mathrm{u}_{\ell}}{\partial \mathrm{z}}\right|\right)^{1 / 2} \operatorname{sign}\left(\frac{\partial \mathrm{u}_{\ell}}{\partial \mathrm{z}}\right)(\mathrm{N}),
$$

where $v_{1}$ is the kinematic viscosity of the liquid and $\partial u_{1} / \partial z$ is the velocity gradient perpendicular to the direction of motion. The constant $\mathrm{c}$ has been evaluated numerically as $c=81.2 / 4 \pi \simeq 6.46 .11$ The force $L$ acts in the $z$ direction.

Equation 4.1.1 can be generalized to three coordinate directions with the identity

$$
\left|\frac{\partial u_{\ell}}{\partial z}\right|^{1 / 2} \operatorname{sign}\left(\frac{\partial u_{\ell}}{\partial z}\right)=\frac{\frac{\partial u_{\ell}}{\partial z}}{\left|\frac{\partial u_{\ell}}{\partial z}\right|^{1 / 2}}
$$

and replacing the velocity gradients with twice the components of the strain rate tensor, which are in Cartesian coordinates;

$$
2 S_{i j}=2\left[\frac{1}{2}\left(\frac{\partial u_{i}}{\partial x_{j}}+\frac{\partial u_{j}}{\partial x_{i}}\right)-\frac{\Delta}{3} \delta_{i j}\right] .
$$

In tensor notation, one has 


$$
2 \overline{\overline{\mathrm{S}}}=\nabla \overline{\mathbf{u}}_{\ell}+\left(\nabla \overrightarrow{\mathrm{u}}_{\ell}\right)^{\mathrm{T}}-\frac{2}{3} \Delta \overline{\overline{\mathrm{I}}}
$$

where

$$
\Delta=\nabla \cdot \overrightarrow{\mathrm{u}}_{\ell}
$$

and the superscript $T$ denotes transpose.

The generalization of Eq. 4.1 .2 becomes

$$
\frac{2 S_{i j}}{\left(2 S_{\ell m} S_{m \ell}\right)^{1 / 4}}=\frac{2 S_{i j}}{(2 \overline{\bar{S}}: \bar{s})^{1 / 4}},
$$

where $S_{1 m}$ is the norm of the matrix formed with the $S_{i j}$ values. Therefore, the generalization of Eq. 4.1.1 can be written

$$
\mathrm{L}_{\mathrm{i}}=6.46 \rho_{\ell} v_{\ell}^{1 / 2} \mathrm{r}_{\mathrm{b}}^{2} \mathrm{~V}_{\mathrm{S} \ell \mathrm{j}} \frac{2 \mathrm{~S}_{\mathrm{ij}}}{\left(2 \mathrm{~S}_{\ell \mathrm{m}} \mathrm{S}_{\mathrm{m} \ell}\right)^{1 / 4}}(\mathrm{~N}) \quad(\mathrm{i}=1,2,3 \equiv \mathrm{x}, \mathrm{y}, \mathrm{z})
$$

or

$$
\overrightarrow{\mathrm{L}}=6.46 \rho_{\ell} \mathrm{v}_{\ell}^{1 / 2} \mathrm{r}_{\mathrm{b}}^{2} \overrightarrow{\mathrm{V}}_{\mathrm{S} \ell} \cdot \frac{\left[\nabla \overrightarrow{\mathrm{u}}_{\ell}+\left(\nabla \overrightarrow{\mathrm{u}}_{\ell}\right)^{\mathrm{T}}-\frac{2 \Delta}{3} \overline{\mathrm{I}}\right]}{\left(2 \mathrm{~S}_{\ell \mathrm{m}} \mathrm{S}_{\mathrm{m} \ell}\right)^{1 / 4}}
$$

Letting $\overrightarrow{\mathrm{u}}=(\mathrm{u}, \mathrm{v}, \mathrm{w})$, the components of the dot product

$$
\begin{aligned}
\overrightarrow{\mathrm{A}} & =\overrightarrow{\mathrm{v}}_{\mathrm{S} \ell} \cdot\left[\nabla \overrightarrow{\mathrm{u}}_{\ell}+\left(\nabla \overrightarrow{\mathrm{u}}_{\ell}\right)^{\mathrm{T}}-\frac{2 \Delta}{3} \overline{\overline{\mathrm{I}}}\right]=\overrightarrow{\mathrm{V}}_{\mathrm{S} \ell} \cdot 2 \overline{\overline{\mathrm{S}}} \\
& =\Sigma_{\mathrm{i}}\left\{\Sigma_{\mathrm{j}}\left[\left(\mathrm{u}_{\mathrm{gi}}-\mathrm{u}_{\ell \mathrm{j}}\left(\frac{\partial \mathrm{u}_{\mathrm{i}}}{\partial \mathrm{x}_{\mathrm{j}}}+\frac{\partial \mathrm{u}_{\mathrm{j}}}{\partial \mathrm{x}_{\mathrm{i}}}\right)\right]-\left(\mathrm{u}_{\mathrm{gi}}-\mathrm{u}_{\ell \mathrm{i}}\right) \frac{2 \Delta}{3}\right\} \bar{\delta}_{\mathrm{i}},\right.
\end{aligned}
$$

(where $\bar{\delta}_{i}$ is the unit vector) are

$$
\begin{aligned}
& \mathrm{A}_{\mathrm{x}}=\left(\mathrm{u}_{\mathrm{g}}-\mathrm{u}_{\ell}\right)\left(2 \frac{\partial \mathrm{u}_{\ell}}{\partial \mathrm{x}}-\frac{2}{3} \Delta\right)+\left(\mathrm{v}_{\mathrm{g}}-\mathrm{v}_{\ell}\right)\left(\frac{\partial \mathrm{u}_{\ell}}{\partial \mathrm{y}}+\frac{\partial \mathrm{v}_{\ell}}{\partial \mathrm{x}}\right)+\left(\mathrm{w}_{\mathrm{g}}-\mathrm{w}_{\ell}\right)\left(\frac{\partial \mathrm{u}_{\ell}}{\partial \mathrm{z}}+\frac{\partial \mathrm{w}_{\ell}}{\partial \mathrm{x}}\right),(4.1 .10 \mathrm{a}) \\
& \mathrm{A}_{\mathrm{y}}=\left(\mathrm{u}_{\mathrm{g}}-\mathrm{u}_{\ell}\right)\left(\frac{\partial \mathrm{u}_{\ell}}{\partial \mathrm{y}}+\frac{\partial \mathrm{v}_{\ell}}{\partial \mathrm{x}}\right)+\left(\mathrm{v}_{\mathrm{g}}-\mathrm{v}_{\ell}\right)\left(\frac{2 \partial \mathrm{v}_{\ell}}{\partial \mathrm{y}}-\frac{2}{3} \Delta\right)+\left(\mathrm{w}_{\mathrm{g}}-\mathrm{w}_{\ell}\right)\left(\frac{\partial \mathrm{w}_{\ell}}{\partial \mathrm{y}}+\frac{\partial \mathrm{v}_{\ell}}{\partial \mathrm{z}}\right),(4.1 .10 \mathrm{~b})
\end{aligned}
$$

and 


$$
A_{z}=\left(u_{g}-u_{\ell}\right)\left(\frac{\partial u_{\ell}}{\partial z}+\frac{\partial w_{\ell}}{\partial x}\right)+\left(v_{g}-v_{\ell}\right)\left(\frac{\partial v_{\ell}}{\partial z}+\frac{\partial w_{\ell}}{\partial \mathrm{y}}\right)+\left(w_{g}-w_{\ell}\right)\left(2 \frac{\partial w_{\ell}}{\partial z}-\frac{2}{3} \Delta\right) \cdot
$$

In addition, one has, for the denominator of the second term of Eq. 4.1.8,

$$
s_{\ell \mathrm{m}} s_{\mathrm{m} \ell}=\mathrm{s}_{11}^{2}+\mathrm{s}_{22}^{2}+\mathrm{s}_{33}^{2}+2 \mathrm{~s}_{12}^{2}+2 \mathrm{~s}_{13}^{2}+2 \mathrm{~s}_{23}^{2}
$$

Equation 4.1.10 gives the components of the force acting on a single sphere (bubble or particle). Let $\mathrm{N}$ be the number of gas bubbles or particles in a cell of volume $\mathrm{V}_{\mathrm{f}}$. The gas volume in the cell is

$$
V_{g}=\alpha_{g} V_{f}=N \frac{4}{3} \pi r_{b}^{3}=N \frac{m_{b}}{\rho_{b}}
$$

where $m_{b}$ and $\rho_{b}$ are the average mass and density of a bubble. The force per unit volume acting on the bubbles is

$$
\begin{aligned}
F_{L i} & =\frac{N L_{i}}{v_{f}}=\frac{N L_{i} \alpha_{g}}{v_{g}}=\frac{N L_{i} \alpha_{g}}{N \frac{4}{3} \pi r_{b}^{3}} \\
& =\frac{6.46 \times 3}{4 \pi} \frac{\alpha_{g} \rho_{\ell} v_{\ell}^{1 / 2}}{r_{b}} v_{S \ell j} \frac{2 S_{i j}}{\left(2 S_{\ell m} S_{m \ell}\right)^{1 / 4}} \quad(i, j=1,2,3=x, y, z) \\
& =6.17 \frac{\alpha_{g} \rho_{\ell} v_{\ell}^{1 / 2}}{2 r_{b}}\left\{\Sigma_{j}\left[\left(u_{g j}-u_{\ell j}\right)\left(\frac{\partial u_{i}}{\partial x_{j}}+\frac{\partial u_{j}}{\partial x_{i}}\right)\right]-\left(u_{g i}-u_{\ell i}\right) \frac{\Delta}{3}\right\}\left(2 S_{\ell m} S_{m \ell}\right)^{-1 / 4} .
\end{aligned}
$$

The lift force acts in opposite directions upon the phases.

For cylindrical $(r, \theta, z)$ geometry, the components of the strain rate tensor $\overline{\bar{S}}$ are

$$
\begin{aligned}
& S_{r r}=\frac{\partial u}{\partial r}-\frac{\Delta}{3} \\
& S_{r \theta}=\frac{1}{2}\left[r \frac{\partial(v / r)}{\partial r}+\frac{1}{r} \frac{\partial u}{\partial \theta}\right] \\
& S_{r z}=\frac{1}{2}\left(\frac{\partial u}{\partial z}+\frac{\partial w}{\partial r}\right) \\
& S_{\theta \theta}=\frac{u}{r}+\frac{1}{r} \frac{\partial v}{\partial \theta}-\frac{\Delta}{3}, \\
& S_{\theta z}=\frac{1}{2}\left(\frac{1}{r} \frac{\partial w}{\partial \theta}+\frac{\partial v}{\partial z}\right),
\end{aligned}
$$


and

$$
\mathrm{S}_{z z}=\frac{\partial \mathrm{w}}{\partial z}-\frac{\Delta}{3}
$$

Hence, the components of the force per unit volume acting on the bubbles are

$$
\begin{aligned}
\mathrm{F}_{\mathrm{Lr}}= & \mathrm{C}\left\{\left(\mathrm{u}_{\mathrm{g}}-\mathrm{u}_{\ell}\right)\left(2 \frac{\partial \mathrm{u}_{\ell}}{\partial \mathrm{r}}-\frac{2 \Delta}{3}\right)+\left(\mathrm{v}_{\mathrm{g}}-\mathrm{v}_{\ell}\right)\left[\mathrm{r} \frac{\partial\left(\mathrm{v}_{\ell} / \mathrm{r}\right)}{\partial \mathrm{r}}+\frac{1}{\mathrm{r}} \frac{\partial \mathrm{u}_{\ell}}{\partial \theta}\right]\right. \\
& \left.+\left(\mathrm{w}_{\mathrm{g}}-\mathrm{w}_{\ell}\right)\left(\frac{\partial \mathrm{u}_{\ell}}{\partial \mathrm{z}}+\frac{\partial \mathrm{w}_{\ell}}{\partial \mathrm{r}}\right)\right\}, \\
\mathrm{F}_{\mathrm{L} \theta}= & \mathrm{C}\left\{\left(\mathrm{u}_{\mathrm{g}}-\mathrm{u}_{\ell}\right)\left[\mathrm{r} \frac{\partial\left(\mathrm{v}_{\ell} / \mathrm{r}\right)}{\partial \mathrm{r}}+\frac{1}{\mathrm{r}} \frac{\partial \mathrm{u}_{\ell}}{\partial \mathrm{r}}\right]+\left(\mathrm{v}_{\mathrm{g}}-\mathrm{v}_{\ell}\right)\left[2\left(\frac{\mathrm{u}_{\ell}}{\mathrm{r}}+\frac{1}{\mathrm{r}} \frac{\partial \mathrm{v}_{\ell}}{\partial \theta}\right)-\frac{2}{3} \Delta\right]\right. \\
& \left.+\left(\mathrm{w}_{\mathrm{g}}-\mathrm{w}_{\ell}\right)\left(\frac{1}{\mathrm{r}} \frac{\partial \mathrm{w}_{\ell}}{\partial \theta}+\frac{\partial \mathrm{v}_{\ell}}{\partial \mathrm{z}}\right)\right\}, \\
\mathrm{F}_{\mathrm{Lz}}= & \mathrm{C}\left\{\left(\mathrm{u}_{\mathrm{g}}-\mathrm{u}_{\ell}\right)\left(\frac{\partial \mathrm{u}_{\ell}}{\partial \mathrm{z}}+\frac{\partial \mathrm{w}_{\ell}}{\partial \mathrm{r}}\right)+\left(\mathrm{v}_{\mathrm{g}}-\mathrm{v}_{\ell}\right)\left(\frac{1}{\mathrm{r}} \frac{\partial \mathrm{w}_{\ell}}{\partial \theta}+\frac{\partial \mathrm{v}_{\ell}}{\partial \mathrm{z}}\right)\right. \\
& \left.+\left(\mathrm{w}_{\mathrm{g}}-\mathrm{w}_{\ell}\right)\left(2 \frac{\partial \mathrm{w}_{\ell}}{\partial \mathrm{z}}-\frac{2}{3} \Delta\right)\right\},
\end{aligned}
$$

with

$$
\mathrm{C}=\frac{6.17 \alpha_{\mathrm{g}} \rho_{\ell} \nu_{\ell}^{1 / 2} /\left(2 \mathrm{r}_{\mathrm{b}}\right)}{\left(2 \mathrm{~S}_{\ell \mathrm{m}} \mathrm{S}_{\mathrm{m} \ell}\right)^{-1 / 4}}
$$

\subsection{Drag Force}

\subsubsection{Bubbly Flow}

The momentum exchange function $\mathrm{K}^{\mathrm{M}}$ appearing on the right-hand side of momentum equation Eq. 3.1.2 is computed for bubbly flow as

$$
K^{M}=\frac{3}{8} C_{D} \alpha_{g} \rho_{\ell} \frac{\left|\vec{V}_{S \ell}\right|}{r_{b}}
$$

with 


$$
C_{D}= \begin{cases}\frac{24}{R e_{b}}, & \text { if } R e_{b}<1 \text { (Stokes regime) } \\ \frac{24}{R e_{b}}\left(1+0.1 \operatorname{Re}_{\mathrm{b}}^{0.75}\right), & \text { if } 1<R e_{b} \leq 5000 \text { (viscous regime). } \\ 8 / 3 . & \text { if } 5000<\operatorname{Re}_{\mathrm{b}} \text { (turbulent regime) }\end{cases}
$$

The bubble Reynolds number $\mathrm{Re}_{\mathrm{b}}$ has been defined by Eq. 3.2.3.1. The average radius of the bubbles is estimated assuming a Weber number

$$
\mathrm{We}=\frac{2 \mathrm{r}_{\mathrm{b} \rho \ell}\left|\overrightarrow{\mathrm{V}}_{\mathrm{S} \ell}\right|^{2}}{\sigma_{\ell \mathrm{g}}}=10
$$

where $\sigma_{\lg }(\mathrm{N} / \mathrm{m})$ is the gas/water surface tension. The interfacial area, important because it can be evaluated experimentally and compared with calculations, is given (in bubbly flow) by

$$
A_{i}=\frac{3 \alpha_{g}}{r_{b}} \cdot\left(m^{2} / m^{3}\right)
$$

\subsubsection{Suspension Flow}

The momentum exchange function is computed by 12

$$
\mathrm{K}= \begin{cases}\frac{150}{\alpha_{\ell}} \frac{\alpha_{\mathrm{g}}^{2}}{4} \frac{\mu_{\ell}}{2}+1.75 \frac{\rho_{\ell} \alpha_{\mathrm{g}}\left|\overrightarrow{\mathrm{V}}_{\mathrm{S} \ell}\right|}{2 \mathrm{r}_{\mathrm{b}}} & \text { if } \alpha_{\ell} \leq 0.8 \\ \frac{3}{4} \mathrm{C}_{\mathrm{D}} \frac{\alpha_{\mathrm{g} \rho_{\ell}\left|\overrightarrow{\mathrm{V}}_{\mathrm{S} \ell}\right|} \mathrm{r}_{\mathrm{b}}}{\alpha_{\ell}-2.7}, & \text { if } \alpha_{\ell}>0.8 .\end{cases}
$$

with

$$
C_{D}= \begin{cases}\frac{24}{\operatorname{Re}_{p}}\left(1+0.15 \operatorname{Re}_{p}^{0.687}\right) & \text { if } \operatorname{Re}_{p} \leq 1,000 \\ 0.44 & \text { if } \operatorname{Re}_{p}>1,000\end{cases}
$$

The particle Reynolds number is defined by

$$
\operatorname{Re}_{\mathrm{p}}=\frac{2 \mathrm{r}_{\mathrm{b} \rho_{\ell} \alpha_{\ell}\left|\overline{\mathrm{V}}_{\mathrm{S} \ell}\right|}}{\mu_{\ell}}
$$

The fluid viscosity $\mu_{\ell}$ is taken to be a constant for isothermal flow. The solids viscosity $\mu_{\mathrm{g}}$ is obtained from Krieger's ${ }^{13}$ empirical expression for reduced viscosity $\eta_{\mathrm{r}}$, given by

$$
\eta_{\mathbf{r}}=\frac{\alpha_{\mathrm{g}} \mu_{\mathrm{g}}+\alpha_{\ell} \mu_{\ell}}{\mu_{\ell}}=\left(1-\frac{\alpha_{\mathrm{g}}}{0.68}\right)^{-1.82} \text {. }
$$




\subsection{Virtual Mass Force}

Let $F_{\mathrm{vm}}\left(\mathrm{N} / \mathrm{m}^{3}\right)$ be the virtual mass force for a unit volume of the carrying fluid, and $\mathrm{f}_{\mathrm{vm}}$ (N) the virtual mass force acting on one particle. One has

$$
\begin{aligned}
\overrightarrow{\mathrm{f}}_{\mathrm{vm}} & =\rho_{\mathrm{f}} \mathrm{V}_{\mathrm{b}} \mathrm{C}_{\mathrm{vm}}\left(\frac{D \overrightarrow{\mathrm{u}}_{\ell}}{\mathrm{Dt}}-\frac{D \overrightarrow{\mathrm{u}}_{\mathrm{g}}}{\mathrm{Dt}}\right)=\rho_{\mathrm{f}} \frac{\mathrm{m}_{\mathrm{b}}}{\rho_{\mathrm{b}}} \mathrm{C}_{\mathrm{vm}}\left(\frac{D \overrightarrow{\mathrm{u}}_{\ell}}{D \mathrm{t}}-\frac{D \overrightarrow{\mathrm{u}}_{\mathrm{g}}}{D \mathrm{t}}\right) \\
& =\frac{\rho_{\mathrm{f}}}{\rho_{\mathrm{b}}} \mathrm{m}_{\mathrm{b}} \mathrm{C}_{\mathrm{vm}}\left[\frac{\partial \overrightarrow{\mathrm{u}}_{\ell}}{\partial \mathrm{t}}+\overrightarrow{\mathrm{u}}_{\ell} \cdot \nabla \overrightarrow{\mathrm{u}}_{\ell}-\left(\frac{\partial \overrightarrow{\mathrm{u}}_{\mathrm{g}}}{\partial \mathrm{t}}+\overrightarrow{\mathrm{u}}_{\mathrm{g}} \cdot \nabla \overrightarrow{\mathrm{u}}_{\mathrm{g}}\right)\right]
\end{aligned}
$$

and

$$
\vec{F}_{v m}=\frac{N \vec{f}_{v m}}{V}=n \vec{f}_{v m}=n m_{b} \frac{\rho_{f}}{\rho_{b}} C_{v m} \vec{a}_{v m}=\alpha_{b} \rho_{f} C_{v m} \vec{a}_{v m},
$$

having used $n m_{b}=\alpha_{b} \rho_{b}$ and the definition of virtual mass acceleration

$$
\overrightarrow{\mathrm{a}}_{\mathrm{vm}}=\frac{\mathrm{D} \overrightarrow{\mathrm{u}}_{\ell}}{\mathrm{Dt}}-\frac{\mathrm{D} \overrightarrow{\mathrm{u}}_{\mathrm{g}}}{\mathrm{Dt}}
$$

Hence, for every coordinate direction $i(=x, y, z)$, the component of the virtual mass force is

$$
F_{v m, i}=\alpha_{b} \rho_{f} C_{v m}\left[\frac{\partial u_{\ell \mathbf{i}}}{\partial t}+u_{\ell j} \frac{\partial u_{\ell i}}{\partial x_{j}}-\left(\frac{\partial u_{g i}}{\partial t}+u_{g j} \frac{\partial u_{g i}}{\partial x_{j}}\right)\right]
$$

For spherical particles or nondeformable bubbles, the theoretically derived value for $\mathrm{C}_{\mathrm{vm}}$ is 0.5 . Experiments performed by Odar ${ }^{14}$ suggest that $\mathrm{C}_{\mathrm{vm}}$ can be a function of the acceleration modulus

$$
C_{\mathrm{vm}}=1.05-\frac{0.66}{\mathrm{~A}_{\mathrm{c}}^{2}+0.012}
$$

with $A_{c}$, the acceleration modulus, given by

$$
A_{c}=\frac{\left|\overrightarrow{\mathrm{u}}_{\ell}-\overrightarrow{\mathrm{u}}_{\mathrm{g}}\right|^{2}}{\left|\overrightarrow{\mathrm{a}}_{\mathrm{vm}}\right| \mathrm{d}_{\mathrm{b}}}
$$

So far, $\mathrm{C}_{\mathrm{Vm}}=0.5$ has been used in the code for liquid-solids flow and bubbly flow. 


\section{First Assessment of Computations for Turbulent Bubbly Flow}

\subsection{Comparison of COMMIX-M-Calculated Results with Experimental Results of Simonin and Viollet}

Results of numerical computations of turbulent bubbly flow in a vertical axisymmetric pipe, reported in Ref. 15, have been chosen for comparison with results obtained with the COMMIX-M code. The simulated test section consists of a pipe of $50 \mathrm{~mm}$ internal diameter and $4 \mathrm{~m}$ length. Two runs of upward flow, with the characteristics given in Table 1, have been computed. The injection of air bubbles, $2 \mathrm{~mm}$ in diameter, is assumed to be uniformly distributed at the inlet. Calculations with COMMIX-M have been made with 20 radial and 25 axial uniform meshes. The results reported in Ref. 15 and those obtained with COMMIX-M are presented in Figs. 3-10. Figures 3-6 refer to Run No. 1, and Figs. 710 to Run No. 2. All figures present distributions at the same axial level.

Figure 3 indicates that the COMMIX-M calculation fails, so far, to reproduce the sink of the air volume fraction at the wall, whereas Figs. 4 and 5 show that COMMLX-M results for radial distributions of water velocity and air velocity agree reasonably well with the results of Simonin and Viollet. 15

Radial distributions of turbulence kinetic energy in the water phase (Fig. 6) underestimate the production of turbulence kinetic energy near the wall. The results obtained from Run No. 2 (Figs. 7-10) are similar to those obtained from Run No. 1. Further comments and conclusions will be drawn when models are improved and more computations are available.

\subsection{Comparison of COMMIX-M-Calculated Results with Experimental Results of NOVA Test Series}

Preliminary results of the computation of the NOVA test series performed at the Kernforschungszentrum Karlsruhe (KfK) ${ }^{16}$ were obtained for the test runs shown in Table 2. The experiments were run in a vertical pipe of $70 \mathrm{~mm}$ inner diameter and $5 \mathrm{~m}$ length. The geometry was simulated with 20 uniform meshes of $1.75 \mathrm{~mm}$ in the radial direction and 25 uniform meshes $0.16 \mathrm{~m}$ in length (for a total length of $4 \mathrm{~m}$ ) in the axial direction.

Experimental data for the two runs are available only for the void fraction. Some preliminary results of the computations are shown in Figs. 11 and 12 for Run No. 1 and in Figs. 13 and 14 for Run No. 3.

Experimental evaluations of water and air velocities are not available at this time. A comparison of experimental and computed results is possible now only for the void distributions shown in Figs. 11 and 13 for Runs 1 and 3, respectively. Both figures show that the maxima of air volume fraction compare well in experiments and calculation, but that the distributions near the wall are very different. The experimental results show a peak close to the wall, whereas the computed results predict a sink of the void profile before the maximum value. This maximum value is also closer to the wall than in the experimental data. The reason for this discrepancy is likely to depend on the computed pressure radial profiles and on the resulting lift forces. The problem is under investigation. 
Table 1. Characteristics at inlet for computed turbulent bubbly flow experiments reported by Simonin and Viollet ${ }^{15}$

\begin{tabular}{|c|c|c|}
\hline Characteristics & Run No. 1 & Run No. 2 \\
\hline $\begin{array}{l}\text { Volumetric flux (m/s): Water } j_{1} \\
\text { Air jg }\end{array}$ & $\begin{array}{l}0.87 \\
0.005\end{array}$ & $\begin{array}{l}0.87 \\
0.10\end{array}$ \\
\hline 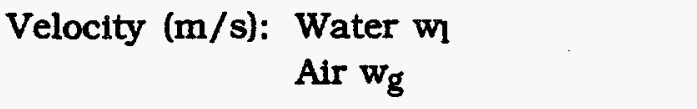 & $\begin{array}{l}0.92 \\
0.92\end{array}$ & $\begin{array}{l}0.97 \\
0.97\end{array}$ \\
\hline $\begin{aligned} \text { Density }\left(\mathrm{kg} / \mathrm{m}^{3}\right): & \text { Water } \rho_{l} \\
& \text { Air } \rho_{\mathrm{g}}\end{aligned}$ & $\begin{array}{r}997 \\
1.18\end{array}$ & $\begin{array}{r}997 \\
1.18\end{array}$ \\
\hline $\begin{array}{ll}\text { Mass flow }(\mathrm{kg} / \mathrm{s}): & \text { Water } \mathrm{G}_{\mathrm{l}} \\
& \text { Air } \mathrm{G}_{\mathrm{g}}\end{array}$ & $\begin{array}{c}1.703 \\
1.158 \times 10^{-4}\end{array}$ & $\begin{array}{c}1.703 \\
2.317 \times 10^{-4}\end{array}$ \\
\hline $\begin{aligned} \text { Volumetric flow rate }\left(\mathrm{m}^{3} / \mathrm{s}\right): \text { Water } \Theta_{1} \\
\text { Air } Q_{g}\end{aligned}$ & $\begin{array}{l}1.708 \times 10^{-3} \\
9.817 \times 10^{-5}\end{array}$ & $\begin{array}{l}1.708 \times 10^{-3} \\
1.963 \times 10^{-4}\end{array}$ \\
\hline $\begin{array}{l}\text { Flowing quality: Water } \mathbf{x}_{\mathbf{l}} \\
\text { Air } x_{\mathbf{g}}\end{array}$ & $\begin{array}{l}0.999932 \\
0.000068\end{array}$ & $\begin{array}{l}0.999864 \\
0.000136\end{array}$ \\
\hline 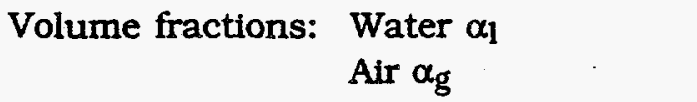 & $\begin{array}{l}0.9456 \\
0.0544\end{array}$ & $\begin{array}{l}0.8969 \\
0.1031\end{array}$ \\
\hline
\end{tabular}

Table 2. Characteristics at inlet of two simulated test runs of NOVA series

\begin{tabular}{ccc}
\hline Characteristics & Run No. $1^{\mathrm{a}}$ & Run No. $3^{\mathrm{a}}$ \\
\hline Velocity (m/s): Water $\mathrm{w}_{1}$ & 1.86 & 2.04 \\
Air $\mathrm{w}_{\mathrm{g}}$ & 2.28 & 2.50 \\
Mass flow (kg/s): Water $\mathrm{G}_{\mathrm{I}}$ & 6.944 & 6.944 \\
$\quad$ Air $\mathrm{G}_{\mathrm{g}}$ & $7.2 \times 10^{-4}$ & $2.41 \times 10^{-3}$ \\
Flow quality: Water $\mathrm{x}_{1}$ & 0.999948 & 0.999827 \\
Air $\mathrm{x}_{\mathrm{g}}$ & 0.000052 & 0.000173 \\
Volume fraction: Water $\alpha_{1}$ & 0.959 & 0.874 \\
$\quad$ Air $\alpha_{\mathrm{g}}$ & 0.041 & 0.126 \\
\hline
\end{tabular}

aVolumetric flow rate $Q_{1}=25 \mathrm{~m}^{3} / \mathrm{h}$. 


\section{First Assessment of Computations of Turbulent Particulate Flow}

\subsection{Numerical Computation of Attenuation of Turbulent Kinetic Energy for Small Particles}

The attenuation of turbulent kinetic energy due to small particles has been investigated numerically using the modeling approach explained in Section 3.2.3. For this purpose, an independent computer program called PARTVI has been used. The list of the program is given for reference in the Appendix. Assuming that particles of density $\rho_{b}=1000 \mathrm{~kg} / \mathrm{m}^{3}$ are transported by air flow $\left(\rho_{\ell}=1.2 \mathrm{~kg} / \mathrm{m}^{3}, v_{\ell}=1.57 \times 10^{-5} \mathrm{~m}^{2} / \mathrm{s}\right)$, we have computed three cases with particle volume fractions $\alpha_{b}=0.01 / 0.005 / 0.001$, respectively. The corresponding mean concentrations of the particles are $W=\alpha_{b} \rho_{b} /\left(\alpha_{b} \rho_{b}+\alpha_{\ell} \rho_{\ell}\right)=$ $0.894 / 0.807 / 0.455$. Particle diameter ranged from 0.1 to $3 \mathrm{~mm}$ in steps of $0.1 \mathrm{~mm}$. The integral attenuations, defined by Eq. 3.2.3.32, are shown versus the particle diameter in Fig. 15. For particles with large diameters, the attenuation factor approaches the limit value of 1. Similarly, for very small particles $\left(\alpha_{b}<10^{-6}\right)$ there is practically no attenuation. Between these limit values, the plots show very strong attenuation in the range between $\alpha_{b}$ $=0.1$ and $\approx 1.5 \mathrm{~mm}$.

A subroutine based on the approach used in the PARTVI program has been linked to the COMMIX-M code and has been used for the case of particle Reynolds number smaller than 110. This is the case for the numerical computation of one of the test cases discussed in the next section.

\subsection{Comparison of COMMIX-M-Calculated Results with Experimental Results of Tsuji, Morikawa, and Shiomi}

Measurements of air and solid particle velocities in a vertical pipe of $30.5 \mathrm{~mm}$ inner diameter have been reported in Ref. 17 for spherical particles with diameters ranging from 0.2 to $3 \mathrm{~mm}$. Particle density ranged from 970 to $1030 \mathrm{~kg} / \mathrm{m}^{3}$. The value $\rho_{b}=1000 \mathrm{~kg} / \mathrm{m}^{3}$ has been used in the calculations. It was confirmed experimentally that the presence of large particles enhances the turbulent kinetic energy of the carrying flow, while small particles damp the turbulence. From the several runs of the experimental series, four test cases have been selected for the numerical calculations. The main characteristics of these test cases are summarized in Table 3, where A denotes the cross-flow area of the pipe. Test case 1 is a reference case without particles and gives information about the intensity of the turbulent kinetic energy of the undisturbed main air flow. In test cases 2 and 3 , with large transported particles of $3 \mathrm{~mm}$ diameter, the intensity of turbulent kinetic energy is expected to increase with respect to the reference case because of the presence of the particles. Conversely, in test case 4 , with small particles of $0.2 \mathrm{~mm}$ diameter, the intensity of turbulent kinetic energy is expected to be damped by the particles.

A comparison between experimental and computed results is shown in the reference test case 1 without particles $(\mathrm{m}=0)$ in Fig. 16. The intensity of turbulence associated with the oscillations of the velocity component in the axial direction $w^{\prime}$ is normalized to the axial air velocity $W_{c}$. The results of two calculations are shown: the first calculation was performed with the COMMIX-1C code by using the $K-\varepsilon$ model. Thus $w^{\prime}$ is replaced by $(2 \mathrm{~K} / 3)^{1 / 2}$, assuming isotropic turbulence. The computed results are in good agreement with the experimental values at the pipe axis, but show a deviation of $\approx 20 \%$ at the wall; the 
Table 3. Characteristics of computed experiments from Tsuji, Morikawa, and Shiomi series

Test Case

\begin{tabular}{|c|c|c|c|c|}
\hline Characteristic & 1 & 2 & 3 & 4 \\
\hline $\begin{array}{l}\text { Particle diameter } \\
d_{b}(\mathrm{~mm})\end{array}$ & - & 3 & 3 & 0.2 \\
\hline $\begin{array}{l}\text { Particle volume } \\
\text { fraction } \alpha_{b}\end{array}$ & 0 & 0.00072 & 0.004 & 0.0016 \\
\hline $\begin{array}{l}\text { Loading ratio } \\
\qquad \mathrm{m}=\alpha_{\mathrm{b}} \rho_{\mathrm{b}} / \alpha_{\ell} \rho_{\ell}\end{array}$ & 0 & 0.6 & 3.4 & 1.3 \\
\hline $\begin{array}{l}\text { Inlet axial mean velocity } \\
\bar{W}(\mathrm{~m} / \mathrm{s})\end{array}$ & 11.1 & 12.1 & 11.8 & 10.7 \\
\hline $\begin{array}{l}\text { Particle volumetric flow } \\
\mathrm{Qb}_{\mathrm{b}}=\overline{\mathrm{W}} \alpha_{\mathrm{b}} \mathrm{A}\left(\mathrm{m}^{3} / \mathrm{s}\right)\end{array}$ & 0 & $5.95 \times 10^{-6}$ & $3.41 \times 10^{-5}$ & $1.20 \times 10^{-5}$ \\
\hline $\begin{array}{l}\text { Air volumetric flow } \\
\mathrm{Q}_{\ell}=\overline{\mathrm{W}} \alpha_{\ell} \mathrm{A}\left(\mathrm{m}^{3} / \mathrm{s}\right)\end{array}$ & $7.84 \times 10^{-3}$ & $8.26 \times 10^{-3}$ & $8.30 \times 10^{-3}$ & $7.49 \times 10^{-3}$ \\
\hline $\begin{array}{l}\text { Particle mass flow } \\
G_{\mathrm{b}}=\rho_{\mathrm{b}} Q_{\mathrm{b}}(\mathrm{kg} / \mathrm{s})\end{array}$ & 0 & $5.95 \times 10^{-3}$ & $3.41 \times 10^{-2}$ & $1.20 \times 10^{-2}$ \\
\hline $\begin{array}{l}\text { Air mass flow } \\
\mathrm{G}_{\ell}=\rho_{\ell} \mathrm{B}_{\ell}(\mathrm{kg} / \mathrm{s})\end{array}$ & $9.41 \times 10^{-3}$ & $9.91 \times 10^{-3}$ & $9.96 \times 10^{-3}$ & $8.99 \times 10^{-3}$ \\
\hline $\begin{array}{l}\text { Particle mass fraction } \\
\mathrm{x}_{\mathrm{b}}=\mathrm{G}_{\mathrm{b}} /\left(\mathrm{G}_{\mathrm{b}}+\mathrm{G}_{\ell}\right)\end{array}$ & 0 & 0.375 & 0.774 & 0.571 \\
\hline $\begin{array}{l}\text { Air mass fraction } \\
\mathrm{x}_{\ell}=\mathrm{G}_{\ell} /\left(\mathrm{G}_{\mathrm{b}}+\mathrm{G}_{\ell}\right)\end{array}$ & 1 & 0.625 & 0.226 & 0.429 \\
\hline $\begin{array}{l}\text { Maximum computed slip } \\
\text { velocity }\left|\mathrm{Vs}_{\ell}\right|(\mathrm{m} / \mathrm{s})\end{array}$ & - & 2.98 & 3.48 & 0.6 \\
\hline $\begin{array}{l}\text { Maximum particle } \\
\text { Reynolds number } \\
\operatorname{Re}_{\mathrm{b}}=\frac{\mathrm{d}_{\mathrm{b}} \rho_{\ell} \mid \mathrm{V}_{\mathrm{s} \ell}}{\mu_{\ell}}\end{array}$ & - & 569 & 665 & 8 \\
\hline
\end{tabular}

second calculation was performed with the COMMIX-M code by using the Reynolds Stress Model (RSM). The RSM shows better agreement close to the wall but a deviation of $\approx 30 \%$ at the pipe center.

A comparison between experimental and computed normalized turbulence intensity of air is shown in Fig. 17 for test case 2 with loading ratio $\mathrm{m}=0.6$. Compared with the case with $\mathrm{m}=0$, we see that the turbulence intensity is increased by almost $50 \%$ at the pipe center and by $\approx 10 \%$ at the wall. In this case, agreement between experimental and 
computed results is very good at the pipe center, while at the wall the computed intensity of the turbulence is underpredicted by $10-15 \%$.

A further increase of turbulence intensity with respect to the reference case is observed in test case 3 , as shown in Fig. 18. The turbulence intensity at the pipe center is more than doubled, while at the wall the increase is smaller $(=15 \%)$. As in the previous case, agreement between experiment and calculation is good at the pipe center while the computed values are underpredicted as we proceed toward the pipe wall.

The normalized axial velocities of air and particles for test case 3 are shown in Fig. 19. While there is no comparison with experimental data, the information is given for future reference. It is also relevant to estimate the particles Reynolds number, which is based on the slip velocity.

Figure 20 shows a comparison of experimental and computed intensity of turbulence for test case 4 with the small particles of $0.2 \mathrm{~mm}$ diameter. The plot labeled $\mathrm{m}=0$ refers to air flow without particles, but with the same mass velocity $\bar{W}=10.7$ (which is less than in the reference test case 1). Presence of the small particles damps the turbulence intensity at the pipe center by $\approx 30 \%$, while at the wall there is no or negligible damping. The computed results agree with the experimental ones at the pipe center and at the wall, but the distribution between shows considerable deviations.

Normalized velocity distributions for the test case 4 are shown in Fig. 21. Computed and experimental values for the air flow compare very well from the pipe axis to $r / R=0.8$, while some discrepancy remains at the wall.

\section{Data Analysis}

A program called PROCESS has been linked to COMMLX-M to compute the energy spectral distribution of the velocity fluctuations in three coordinate directions and to compute the crosscorrelations of any two signals.

In the course of a time-dependent calculation made with COMMLX-M, selected data, e.g., $u_{i}(i=x, y, z), T, K_{1}$, etc., were written into a DATABASE file, which consists typically of values taken at some thousands of time points. PROCESS reads the DATABASE file and processes the information in a sequence of blocks of given length $L$ (i.e., blocks consisting of values referring to $L$ time points). $L$, which must be a power of 2 , is typically 256 .

For every block of data of length $L$, velocity components are first processed to compute their energy spectra. The calculations proceed as described below.

Let $\tilde{\mathrm{u}}(\mathrm{t}), \overline{\mathrm{u}}$, and $\mathrm{u}(\mathrm{t})$ be the instantaneous value, mean value over a block of length $\mathrm{L}$, and fluctuation from the mean value of a velocity component, respectively, therefore

$$
\overline{\mathrm{u}}(\mathrm{t})=\overline{\mathrm{u}}+\mathrm{u}(\mathrm{t}) \text {. }
$$

First, the momenta of $\bar{u}(t)$ are computed, namely,

$$
\overline{\mathrm{u}}=\text { Mean value }
$$




$$
\begin{aligned}
& \sigma^{2}=\overline{u^{2}}=\text { Variance } \\
& \sigma=\frac{\overline{u^{3}}}{S=\frac{u^{3}}{\sigma^{3}}}=\text { Skewness } \\
& \mathrm{Ku}=\frac{\mathrm{u}^{4}}{\sigma^{4}}=\text { Kurtosis. }
\end{aligned}
$$

Hence, the velocity fluctuations $u(t)$ are computed from Eq. 6.1.

Then, the autocorrelation of the signal $u(t)$ is computed as

$$
\rho(\tau)=\frac{1}{\overline{u^{2}}} \overline{u(t) u\left(t^{\prime}\right)}
$$

with $\tau=t^{\prime}-t$. The Fourier transform of the autocorrelation then gives the power spectral density, or energy spectrum

$$
S(\omega)=\frac{1}{2 \pi} \int_{-\infty}^{+\infty} \mathrm{e}^{-\mathrm{i} \tau \omega} \rho(\tau) \mathrm{d} \tau
$$

Its antitransform is

$$
\rho(\tau)=\int_{-\infty}^{+\infty} e^{i \tau \omega} S(\omega) d \omega
$$

PROCESS also computes, if required, the crosscorrelations of different signals at the same location or of the same signal at different locations. The crosscorrelation of two signals $\mathrm{u}_{1}(\mathrm{t}), \mathrm{u}_{2}(\mathrm{t})$ is given by

$$
\rho_{1-2}(\tau)=\frac{1}{\sigma_{1} \sigma_{2}} \overline{u_{1}(t) u_{2}\left(t^{\prime}\right)}
$$

A simplified flow chart of PROCESS is shown in Fig. 22.

\section{Acknowledgments}

This work has been sponsored by the U.S. Department of Energy, Pittsburgh Energy Technology Center. The authors express their gratitude to Ms. S. Moll and Ms. J. Fisher for their accurate work in typing the manuscript. 


\section{References}

1. Y. A. Hassan, Implementation of a Mass-Flow-Weighted Skew-Upwind Differencing Scheme in COMMIX-1A, Electric Power Research Institute Report EPRI NP-3518 (1984).

2. S. C. Eisenstat, M. C. Gursky, M. H. Schultz, and A. H. Sherman, Yale Sparse Matrix Package, II. The Nonsymmetric Codes, Research Report \#114, Dept. of Computer Science, Yale University (1977).

3. H. C. Elman, Iterative Methods for Large, Sparse, Nonsymmetric Systems of Linear Equations, Ph.D. Dissertation, Yale University (May 1982).

4. M. Bottoni et al., COMMLX-M manual, draft of internal report, unpublished (1993).

5. J. Ding et al., Analysis of Liquid-Solids Suspension Velocities and Concentrations Obtained by NMR Imaging. NSF-DOE Workshop on Flow of Particles and Fluids, Gaithersburg, MD (Sept. 17-18, 1992).

6. H. M. Domanus, et al., COMMLX-1C: A Three-Dimensional Transient Single-Phase Computer Program for Thermal Hydraulic Analysis of Single and Multicomponent Systems, Vol. I, Equations and Numerics; Vol. II, User's Manual, NUREG/CR-5649, Argonne National Laboratory Report ANL-90-33 (Nov. 1990).

7. M. Bottoni and F. C. Chang. Implementation of an Anisotropic Turbulence Model in the COMMIX-1C/ATM Computer Code, ASME Pressure Vessel and Piping (PVP) Division Conference, Denver, CO (July 25-29, 1993).

8. A. M. Al Taweel and J. Landau, Turbulence Modulation in Two-Phase Jets, Int. J. Multiphase Flow, Vol. 3, 341-351 (1977).

9. S. L. Lee and M. A. Wiesler, Theory on Transverse Migration of Particles in a Turbulent Two-Phase Suspension Flow Due to Turbulent Diffusion - I, Int. J. Multiphase Flow, Vol. 13. 99-111 (1987).

10. H. Tennekes and J. L. Lumley, A First Course in Turbulence, the MIT Press, Cambridge, MA (1972).

11. P. G. Saffman, The Lift on a Small Sphere in a Slow Shear Flow, J. Fluid Mech., 22, Part 2, 385-400 (1965).

12. R. B. Bird, W. E. Stewart, and E. N. Lightfoot, Transport Phenomena, John Wiley, New York (1960).

13. I. M. Krieger, Adv. Colloid Interface Sci., 3, 111 (1972).

14. F. Odar, Verification of Proposed Equation for Calculation of Forces on a Sphere Accelerating in a Viscous Fluid, J. Fluid Mech. 25, 591-592 (1966). 
15. O. Simonin and P. L. Viollet, Numerical Study on Phase Dispersion Mechanisms in Turbulent Bubbly Flows, Int. Conf. on Mechanics of Two-Phase Flows, National Taiwan University, Taipei (June 12-15, 1989).

16. Private communication of preliminary data by Dr. W. Sengpiel, Kernforschungszentrum, Karlsruhe, Germany (1991).

17. Y. Tsuji, Y. Morikawa, and H. Shiomi, LDV Measurements of an Air-Solid Two-Phase Flow in a Vertical Pipe, J. Fluid Mech., 139, 417-434 (1984). 

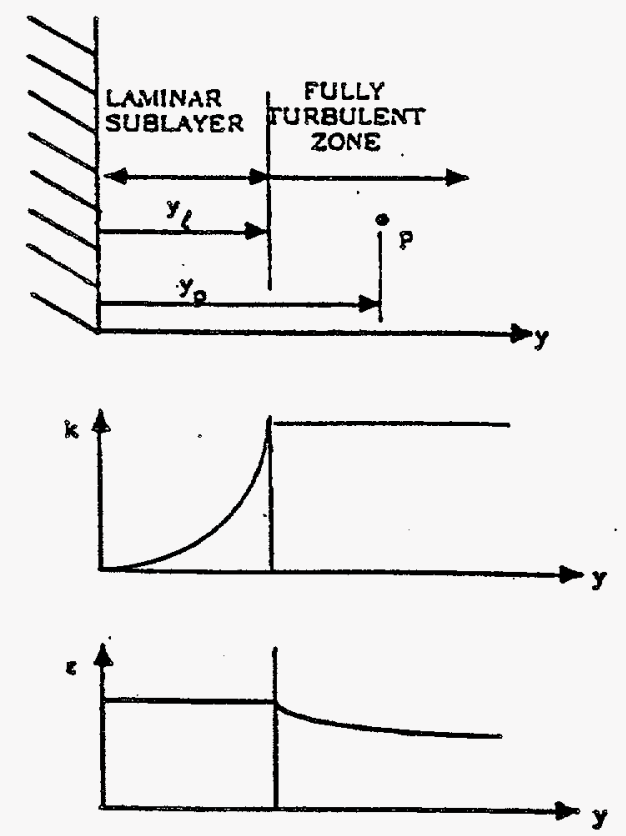

Fig. 1. Two-layer wall function model $\left(y_{p}>y v\right)$

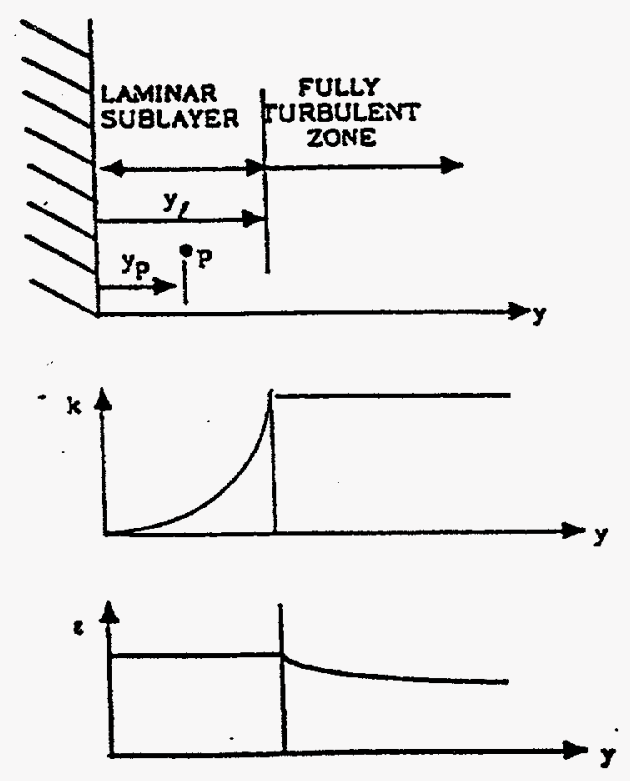

Fig. 2. Two-layer wall function model ( $y_{p} \leq y U$ 


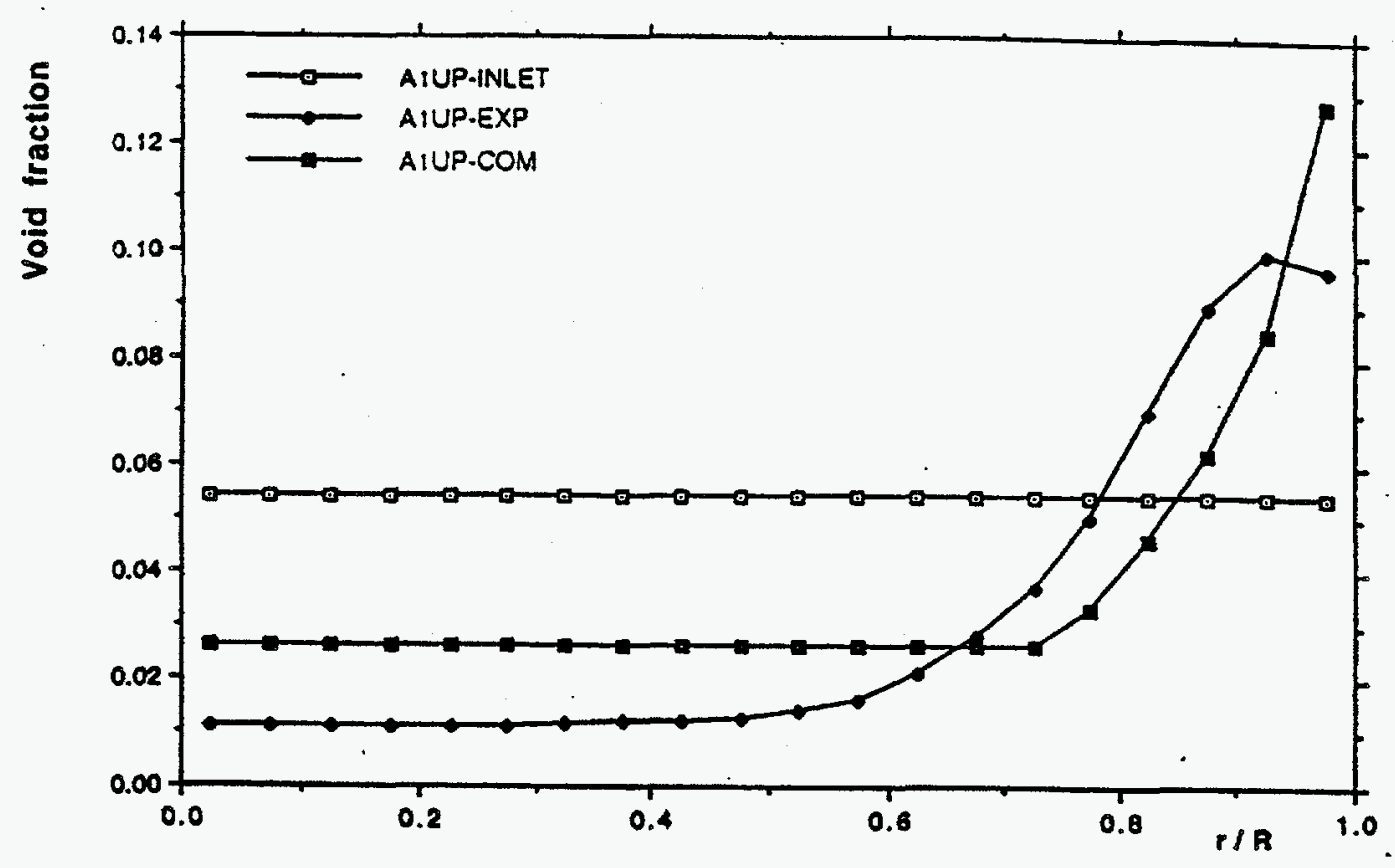

Fig. 3. Run No. 1: radial distribution of air volume fraction at inlet, and comparison of Simonin-Viollet 15 data (EXP) with COMMIX-M computation (COM) at $z=3.12 \mathrm{~m}$.

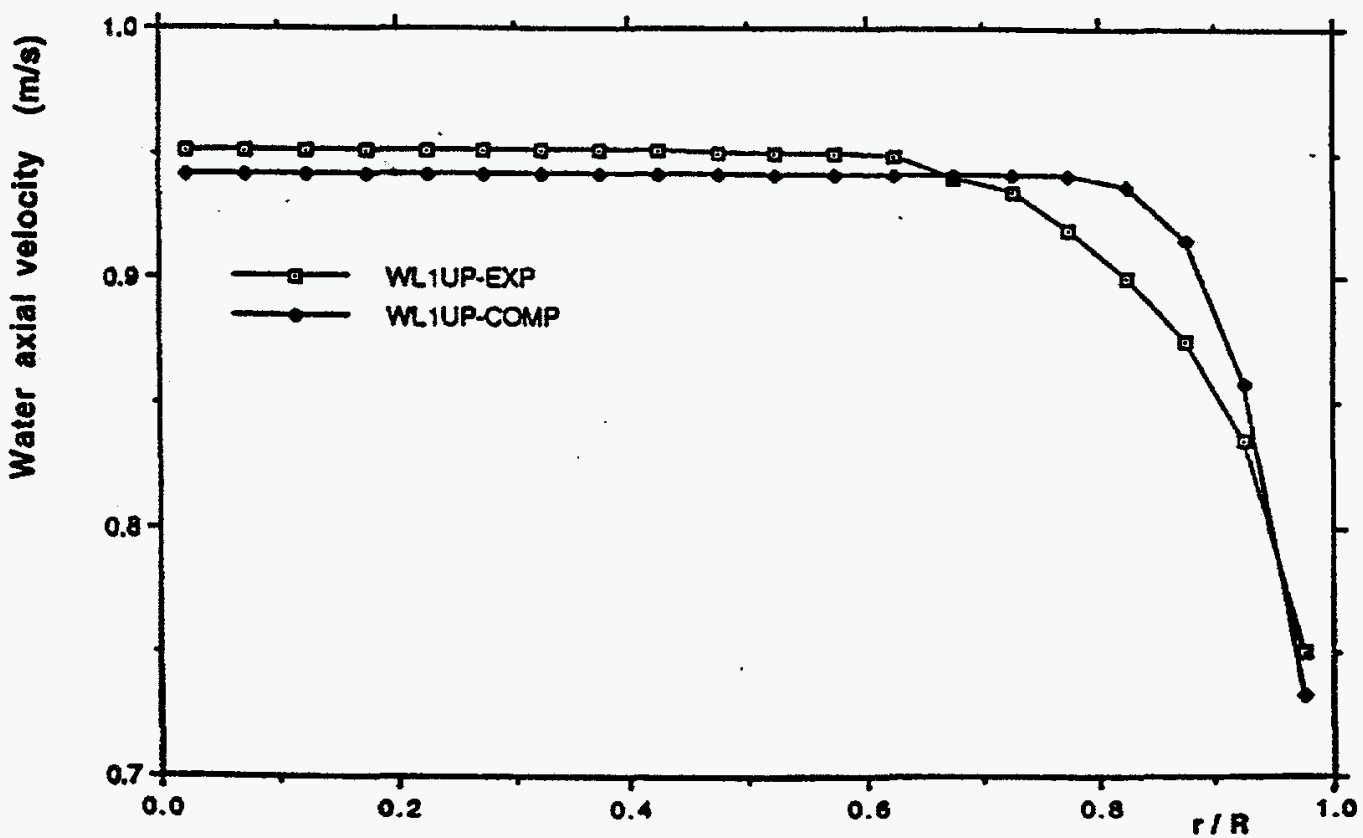

Fig. 4. Run No. 1: radial distribution of water axial velocity at $z=3.12 \mathrm{~m}$. Comparison of Simonin-Viollet ${ }^{15}$ data (EXP) with COMMLX-M computation (COM). 


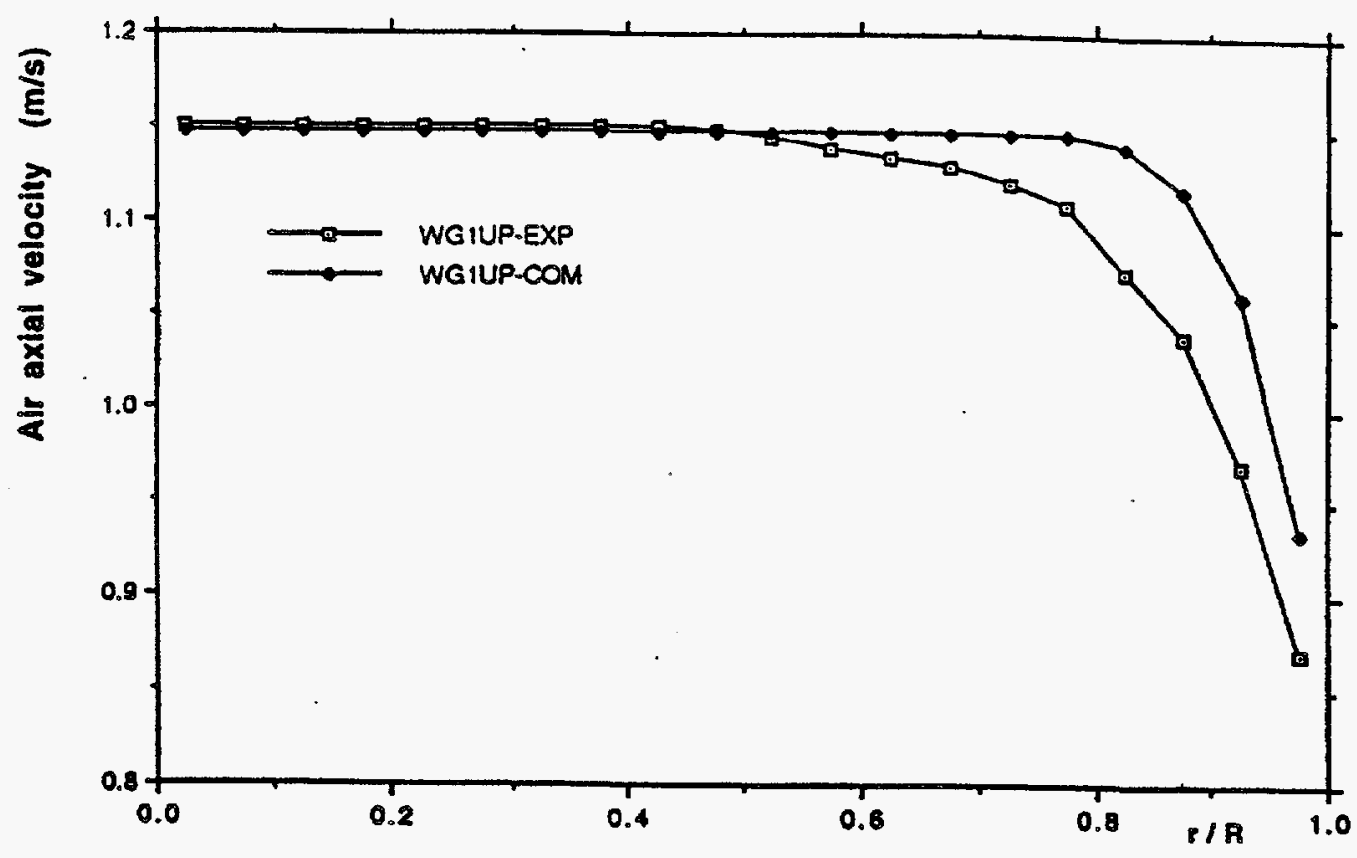

Fig. 5. Run No. 1: radial distribution of air axial velocity at $z=3.12 \mathrm{~m}$. Comparison of Simonin-Viollet 15 data (EXP) with COMMLX-M computation (COM).

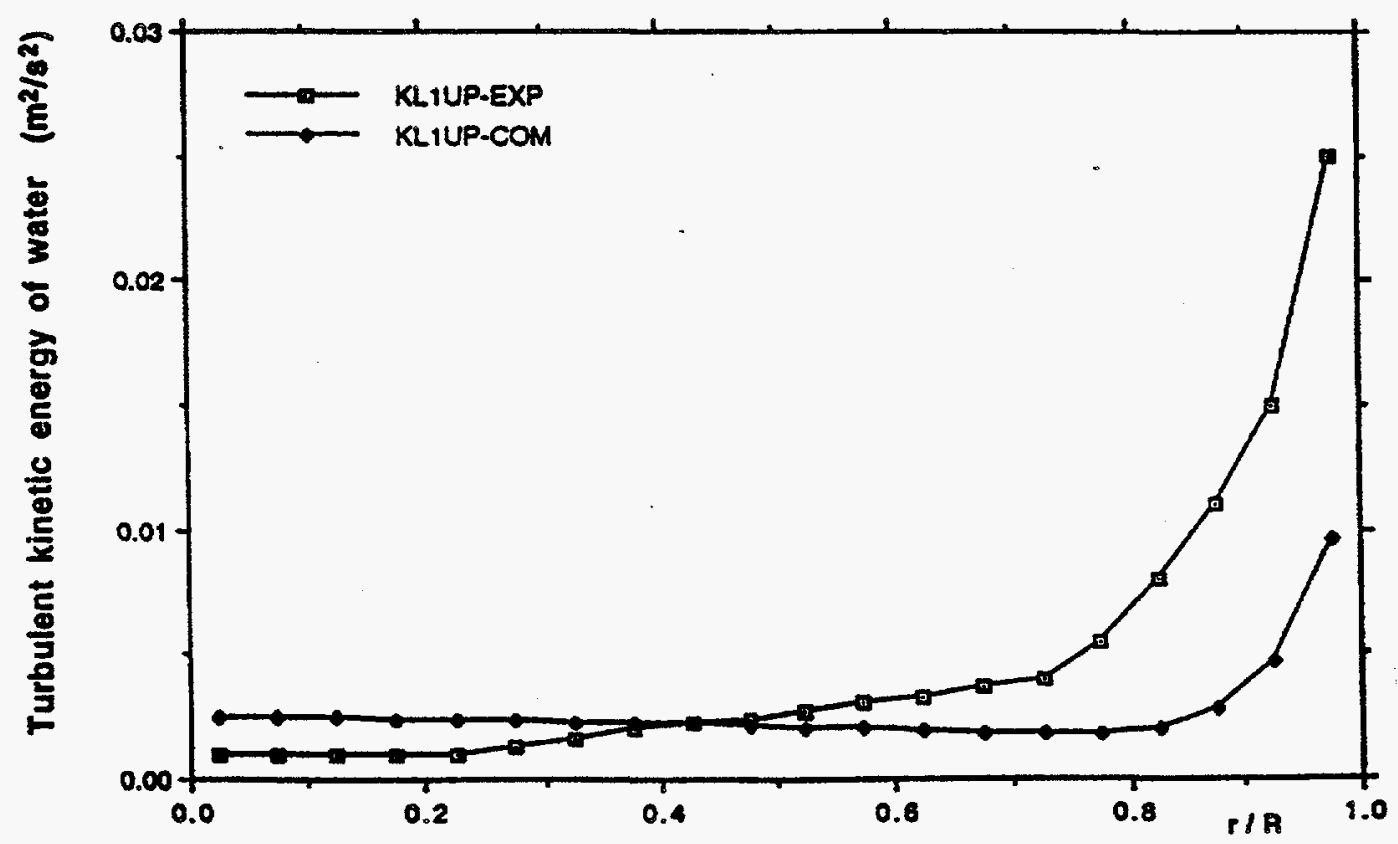

Fig. 6. Run No. 1: radial distribution of turbulence kinetic energy of water phase at $z=3.12 \mathrm{~m}$. Comparison of Simonin-Viollet 15 data (EXP) with COMMIX-M computation (COM). 


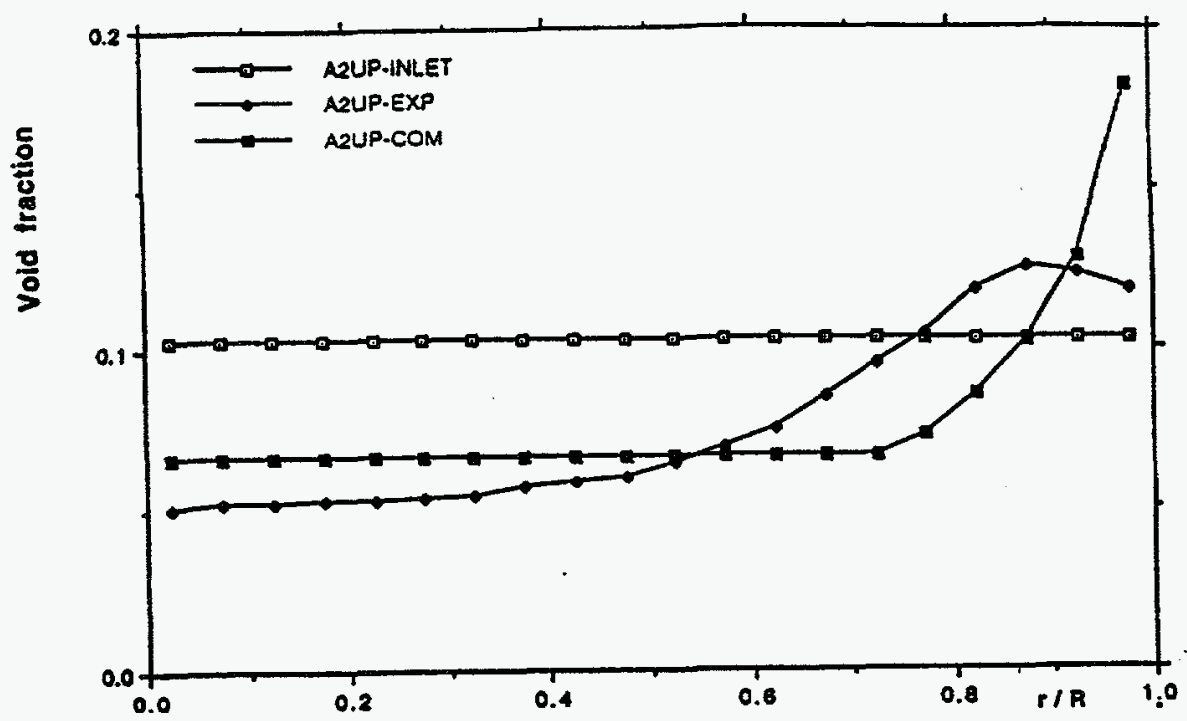

Fig. 7. Run No. 2 : radial distribution of void fraction at inlet, and comparison of Simonin-Viollet ${ }^{15}$ data (EXP) with COMMIX-M computation (COM) at $z=3.12 \mathrm{~m}$.

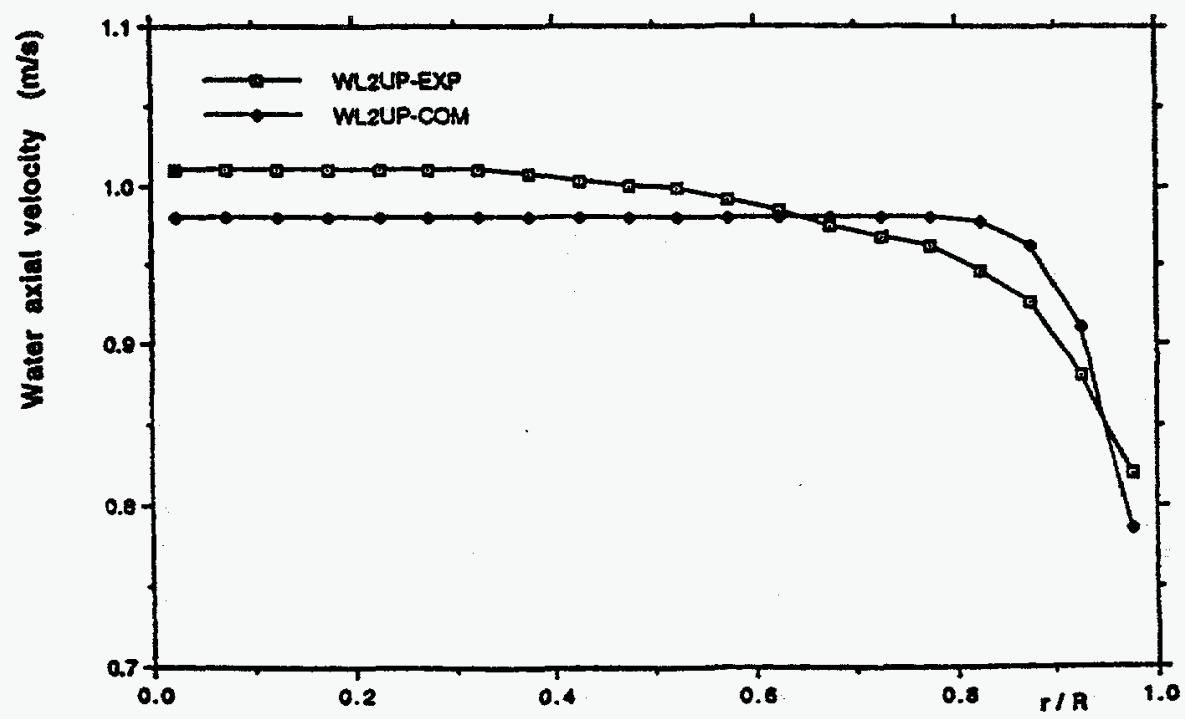

Fig. 8. Run No. 2: radial distribution of water axial velocity at $z=3.12 \mathrm{~m}$. Comparison of Simonin-Viollet ${ }^{15}$ data (EXP) with COMMLX-M computation (COM). 


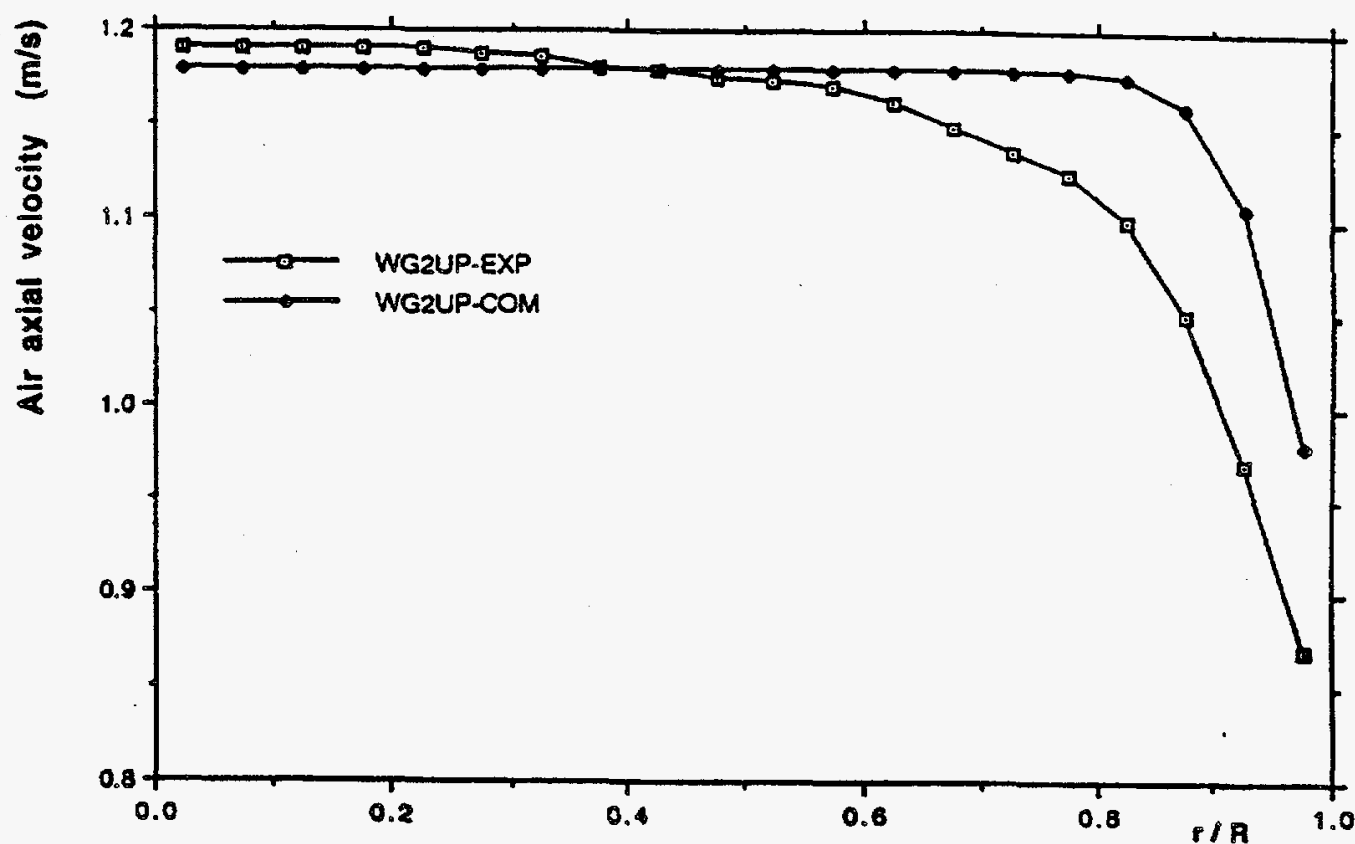

Fig. 9. Run No. 2: radial distribution of air axial velocity at $z=3.12 \mathrm{~m}$. Comparison of Simonin-Viollet 15 data (EXP) with COMMIX-M computation (COM).

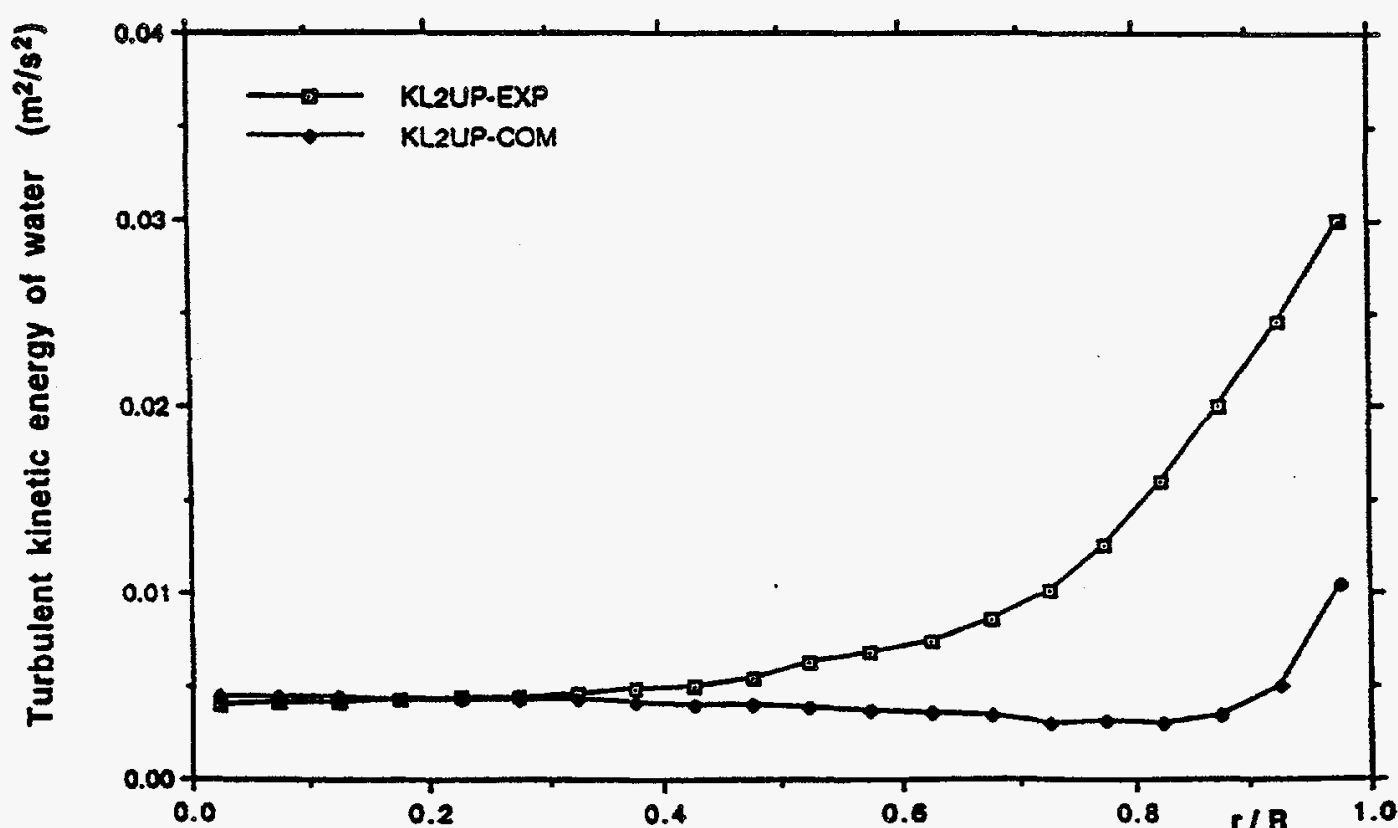

Fig. 10. Run No. 2: radial distribution of turbulence kinetic energy of water phase at $z=3.12 \mathrm{~m}$. Comparison of Simonin-Viollet 15 data (EXP) with COMMLX-M computation (COM). 


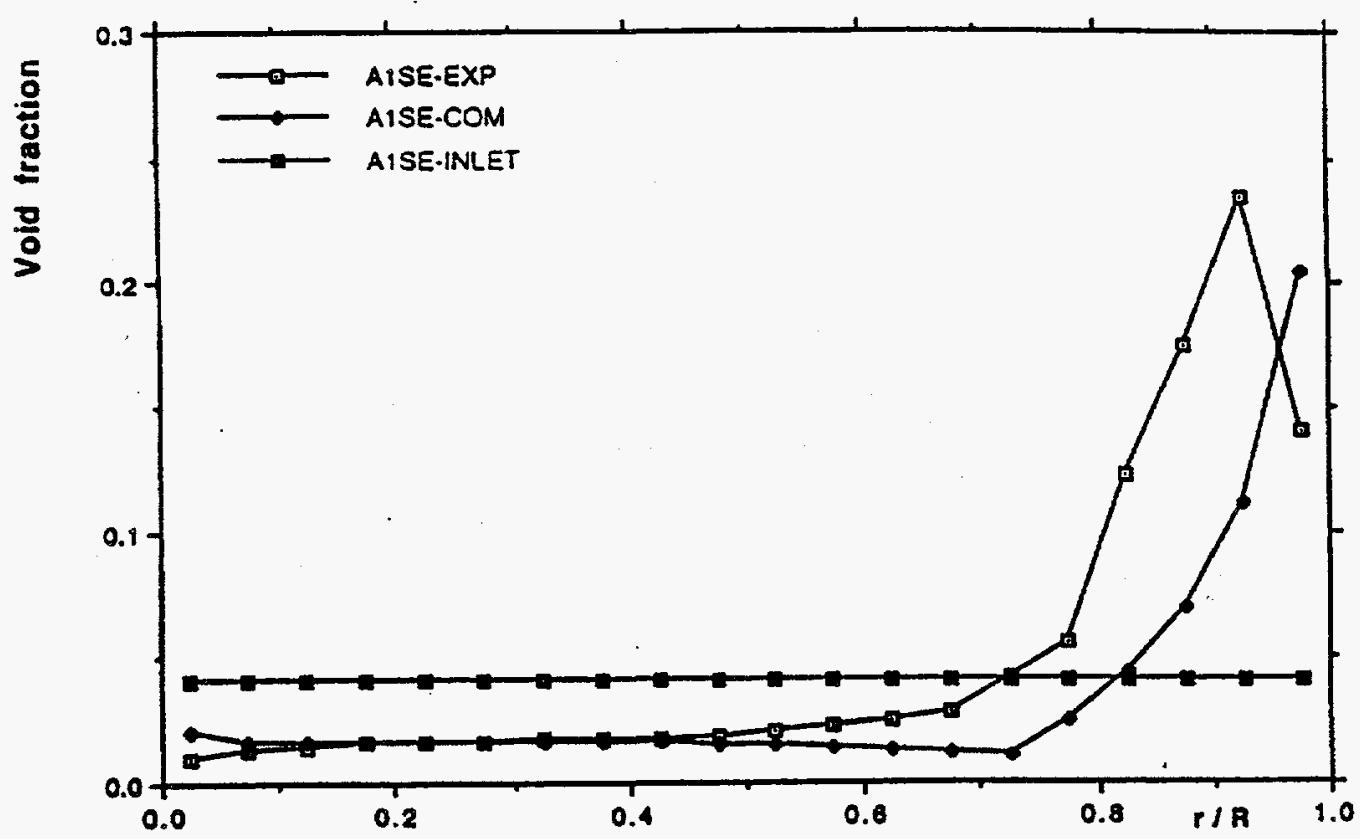

Fig. 11. NOVA test series, Run No. 1: radial distribution of void fraction at inlet, and comparison of experimental data from the NOVA test series $^{16}$ (EXP) with COMMIX-M computation (COM).

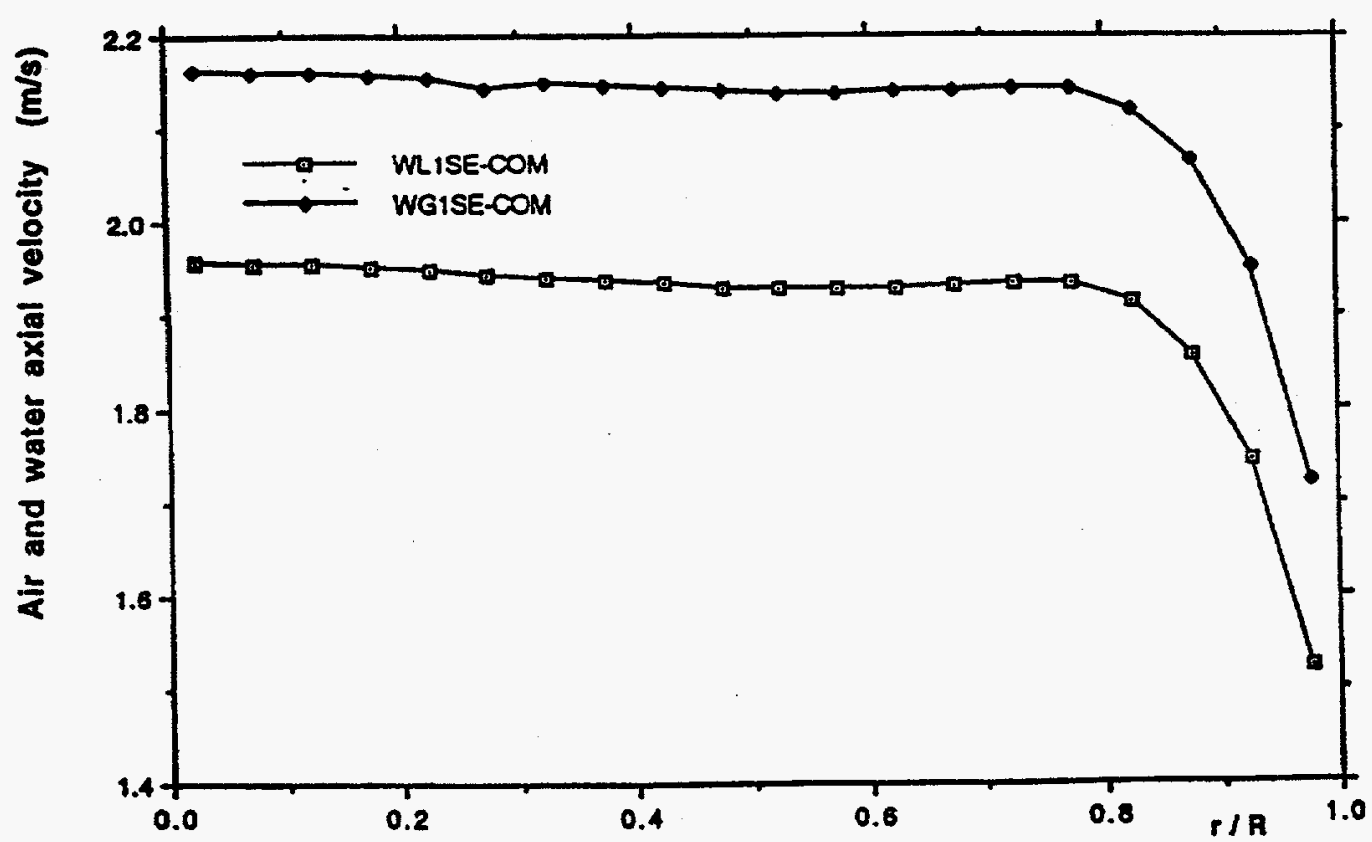

Fig. 12. NOVA test series, Run No. 1: computed radial distributions of air (WG) and water (WL) axial velocities. 


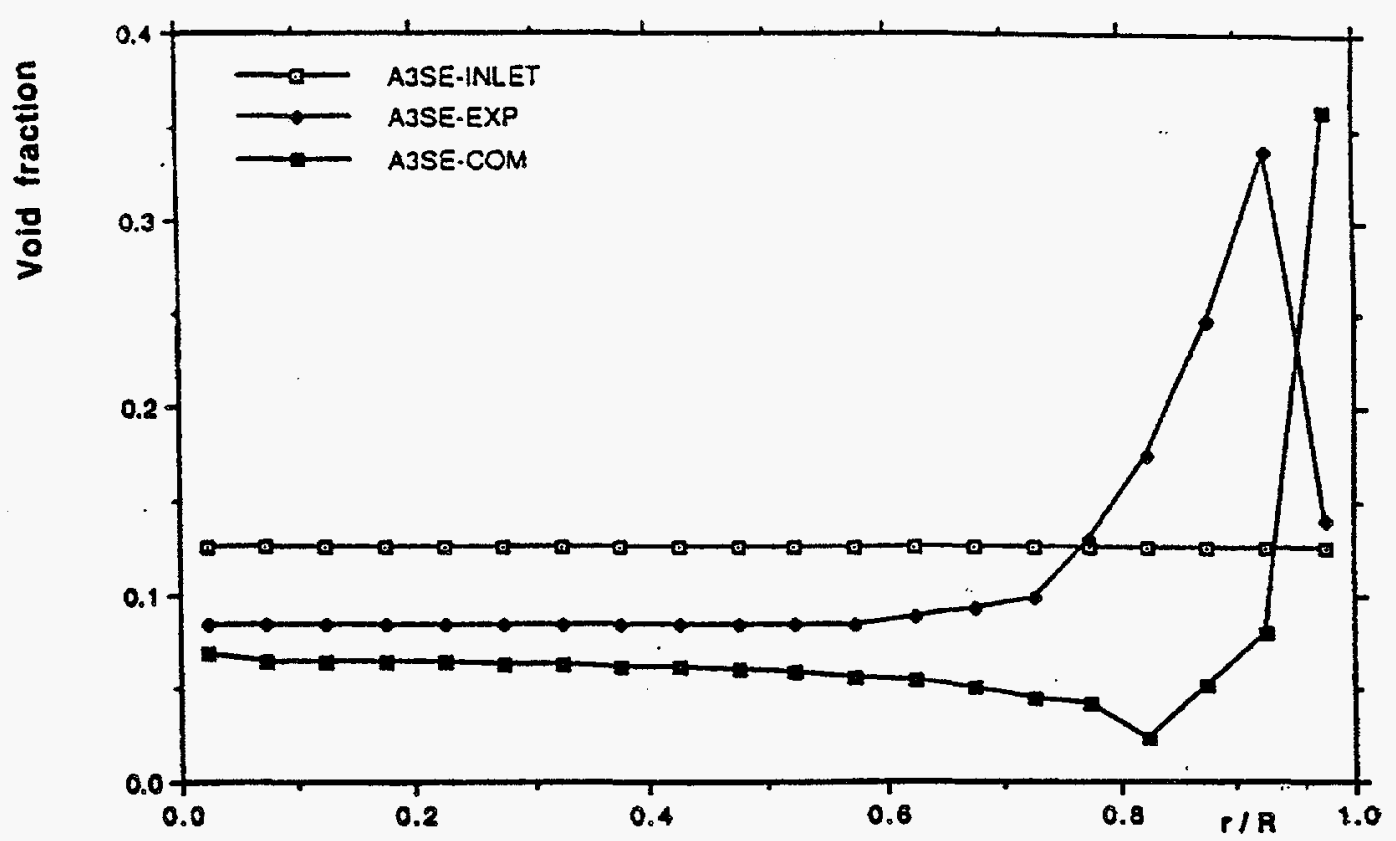

Fig. 13. NOVA test series, Run No. 3: radial distribution of void fraction at outlet, and comparison of experimental data from NOVA test series (EXP) with COMMIX-M computation (COM).

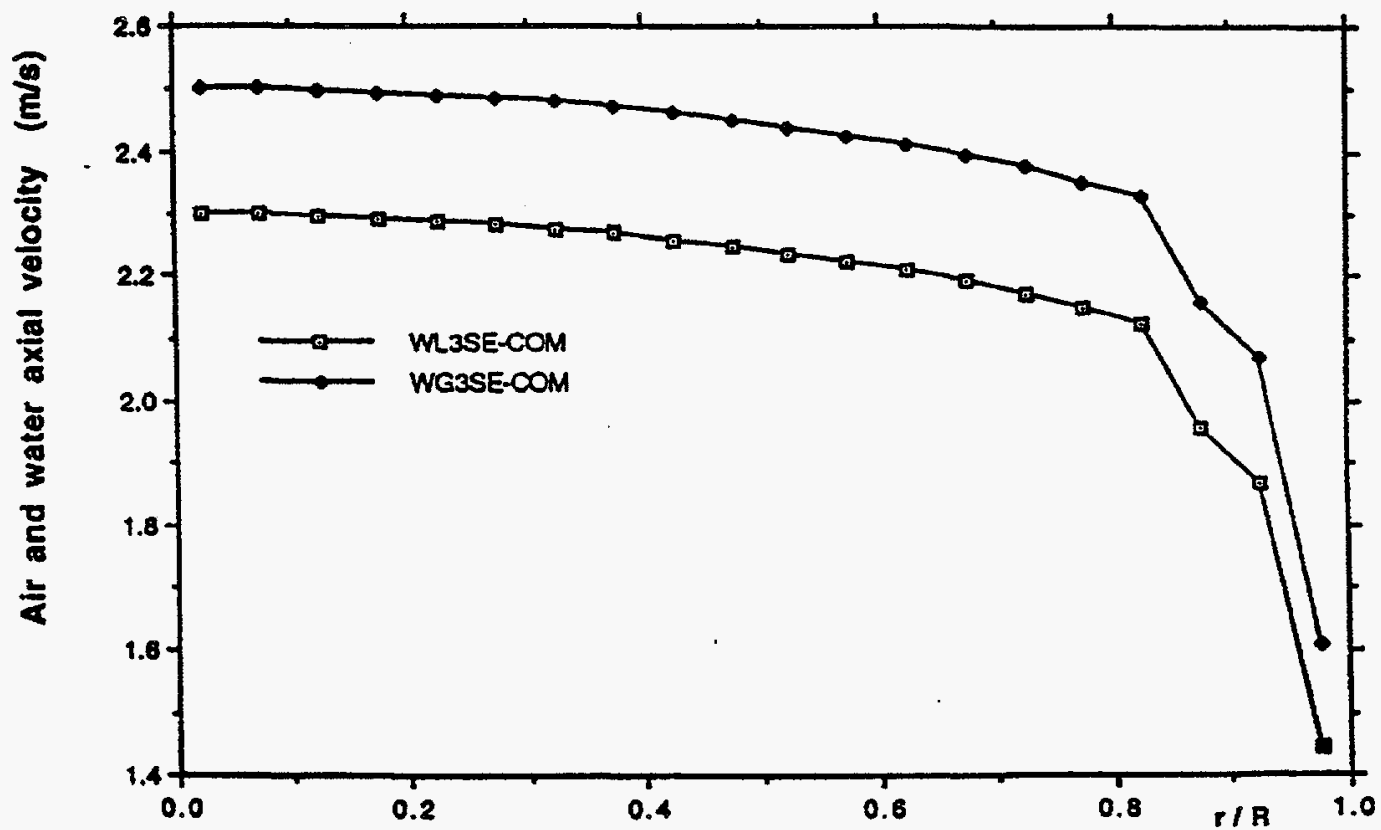

Fig. 14. NOVA test series, Run No. 3: computed radial distributions of air (WG) and water (WL) axial velocities. 


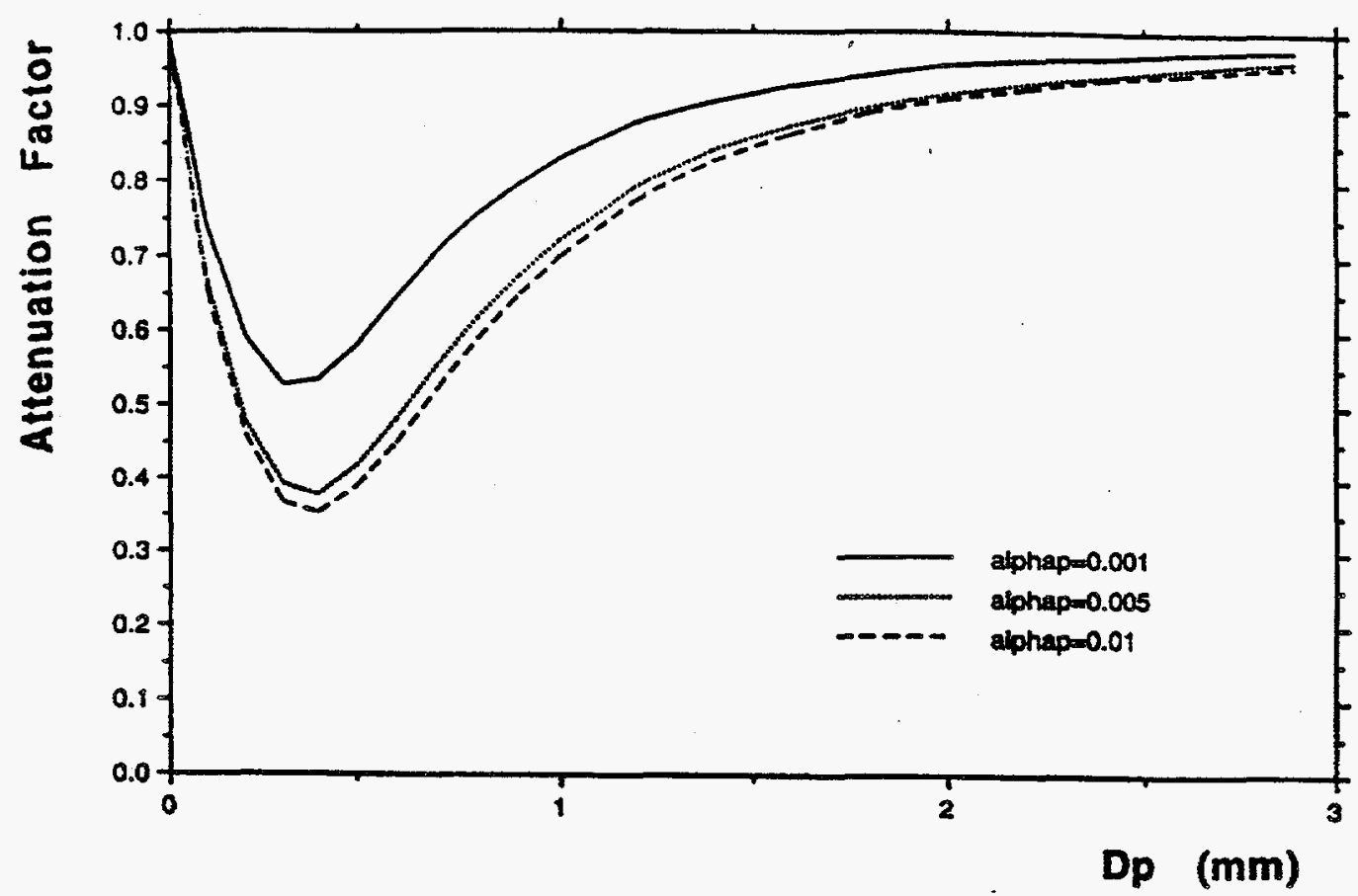

Fig. 15. Attenuation of turbulence intensity due to particles vs. particle diameter.

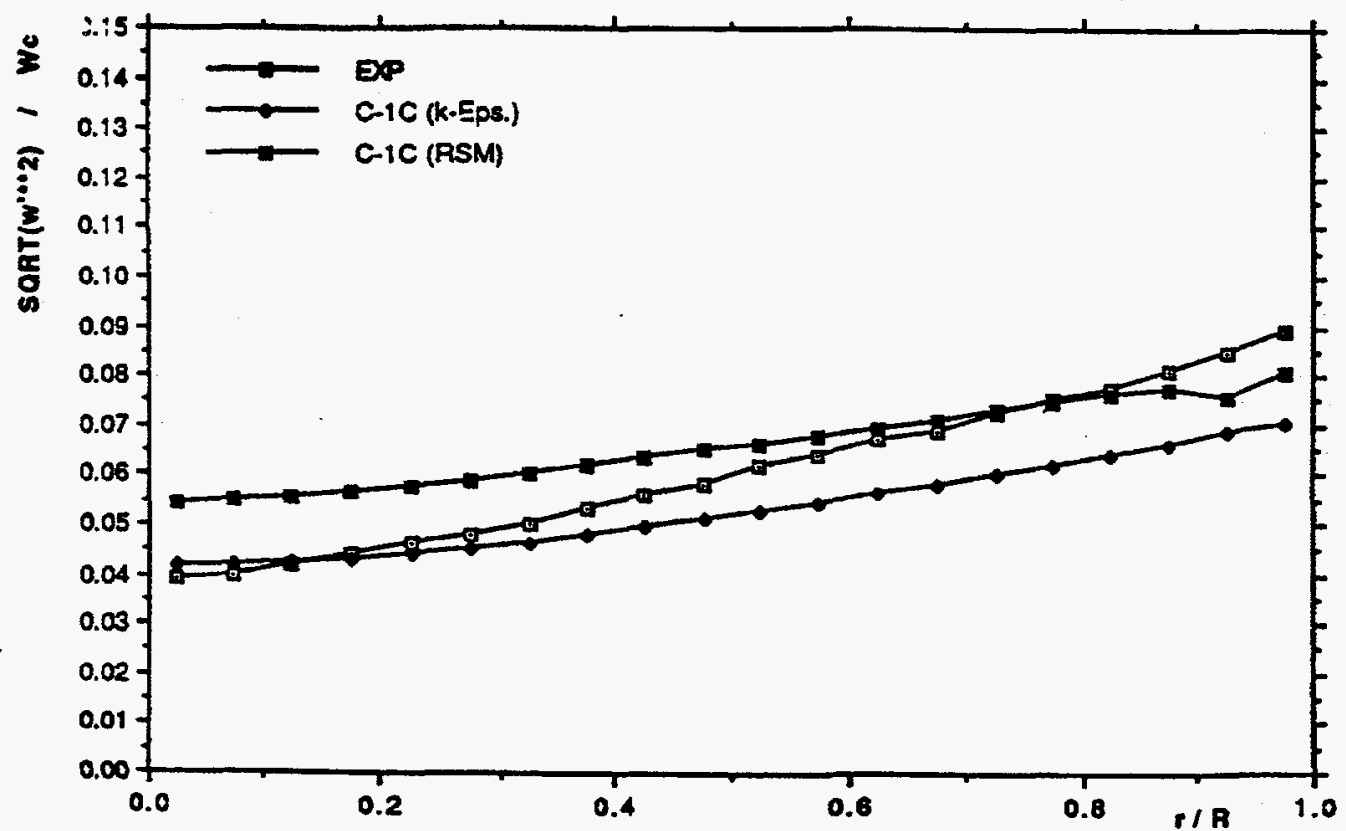

Fig. 16. Radial distribution of turbulence intensity for test case 1 of TsujiMorikawa-Shiomi experiments. 


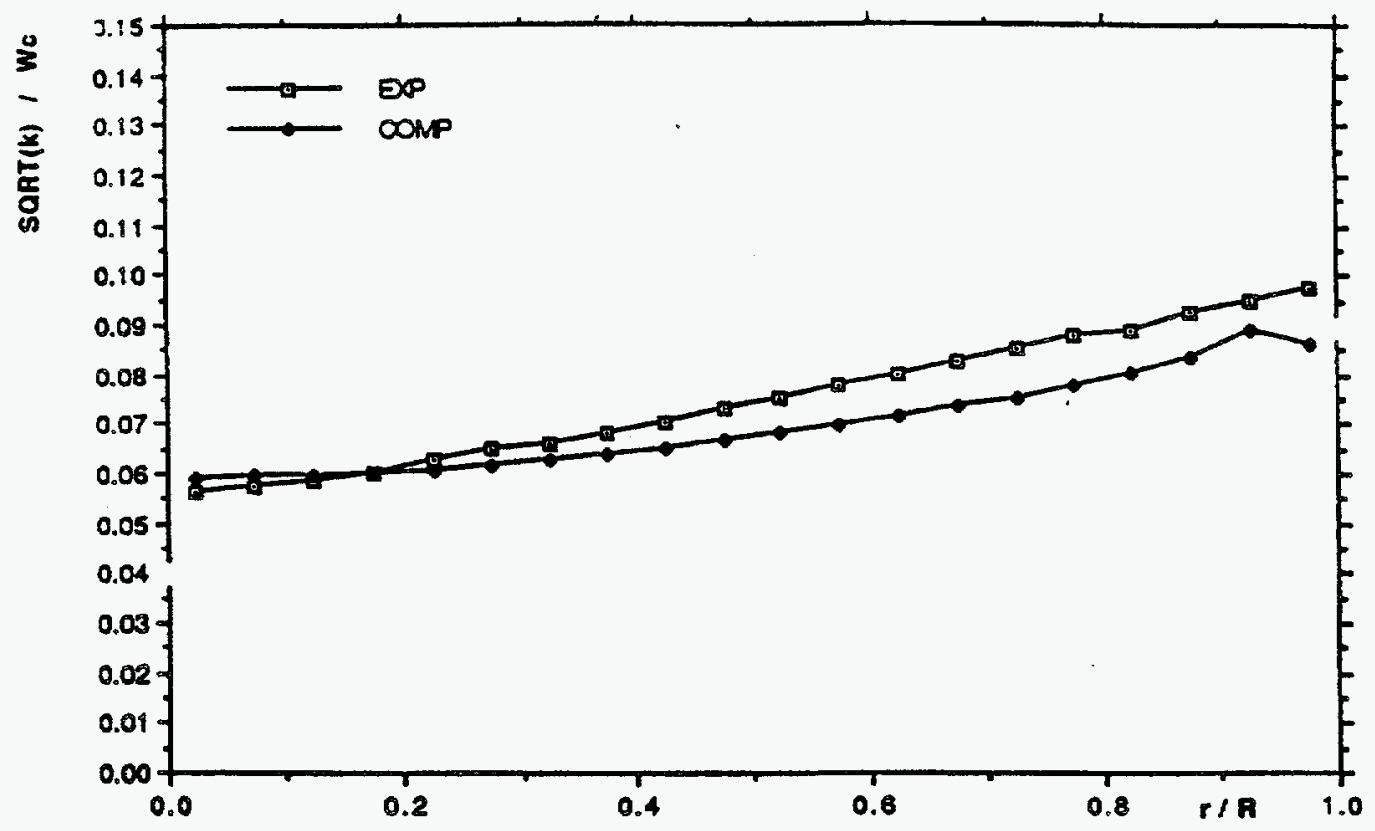

Fig. 17. Radial distribution of turbulence intensity for test case 2 of TsujiMorikawa-Shiomi experiments.

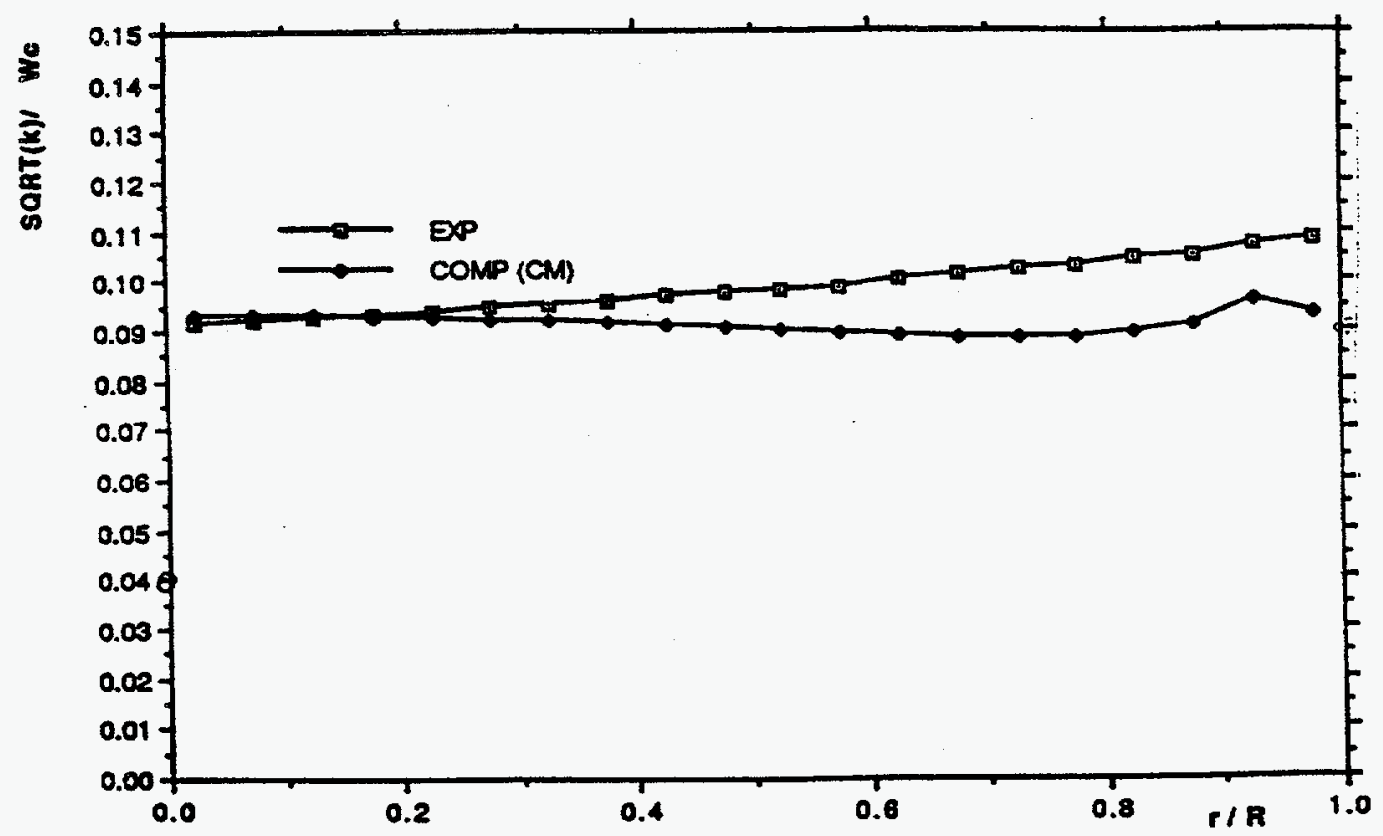

Fig. 18. Radial distribution of turbulence intensity for test case 3 of TsujiMorikawa-Shiomi experiments. 


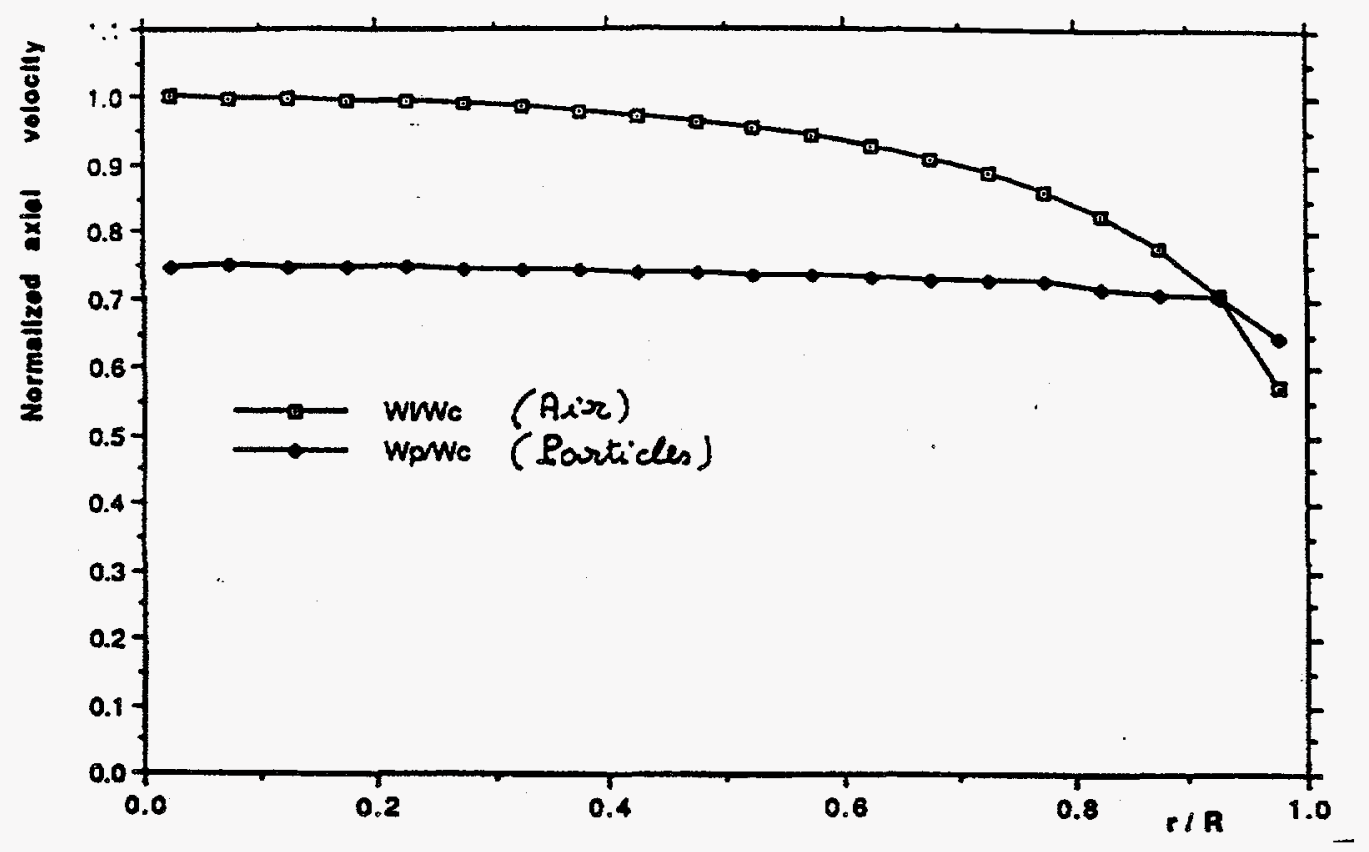

Fig. 19. Radial distribution of normalized axial velocity for test case 3 of Tsuji-Morikawa-Shiomi experiments.

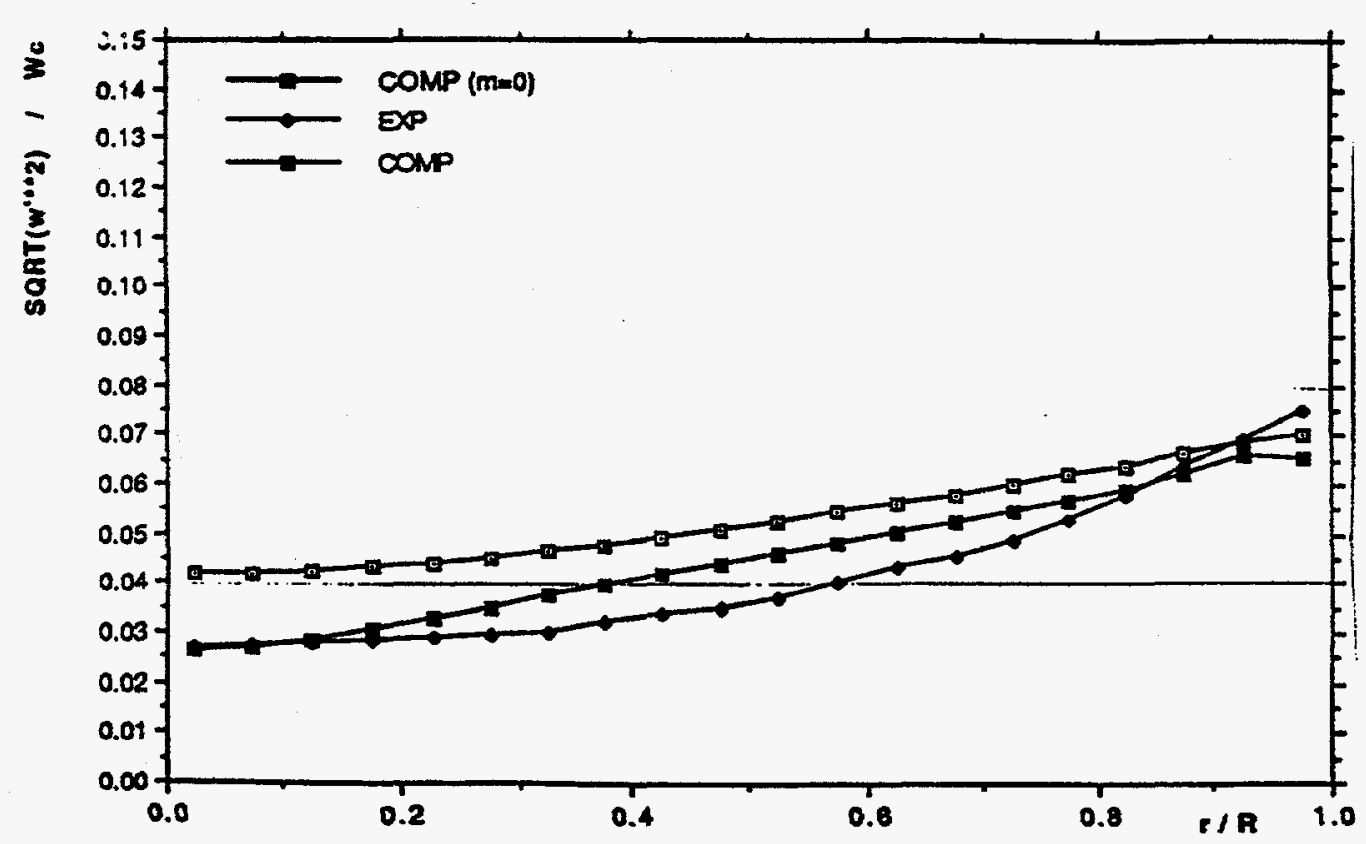

Fig. 20. Radial distribution of turbulence intensity for test case 4 of TsujiMorikawa-Shiomi experiments. 


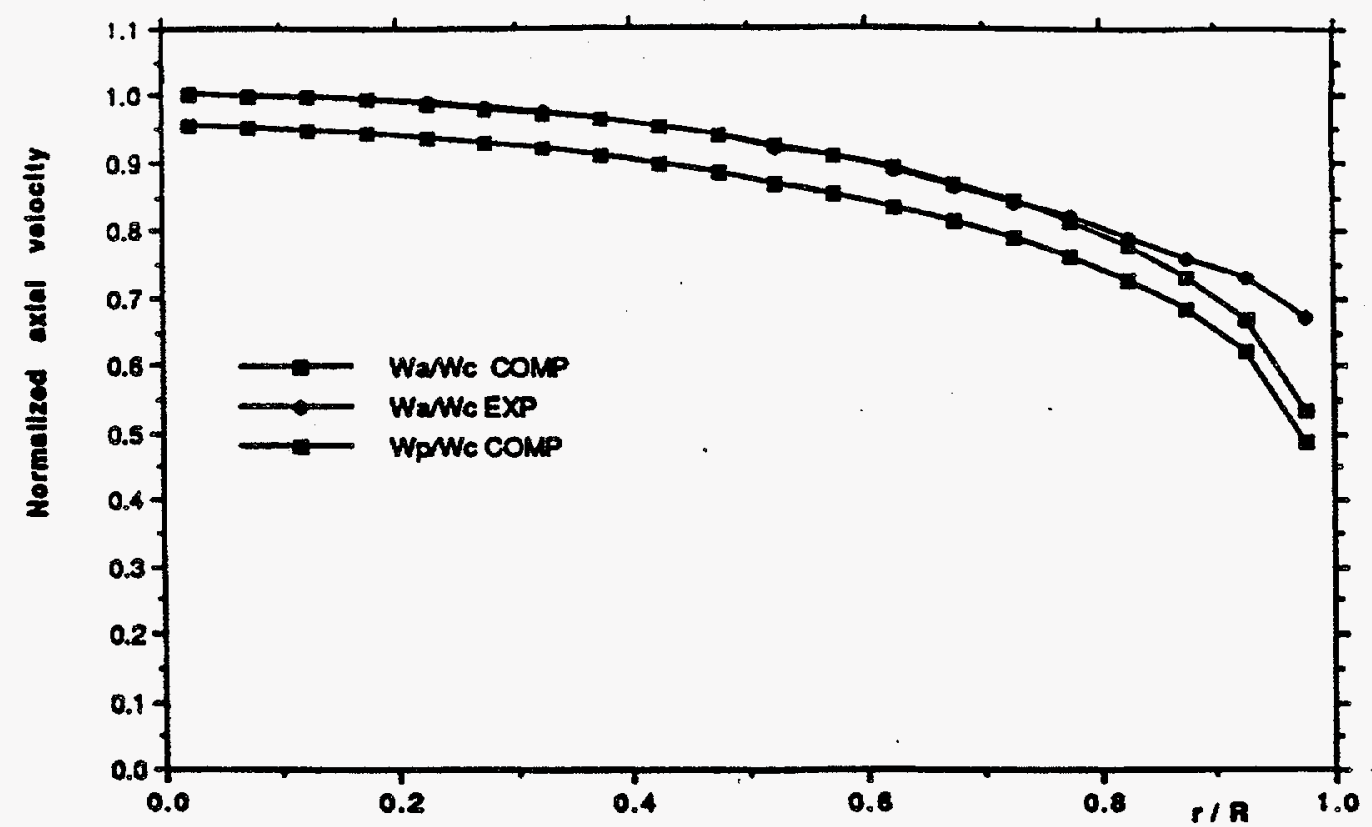

Fig. 21. Radial distribution of normalized axial velocity for test case 4 of Tsuji-Morikawa-Shiomi experiments. 


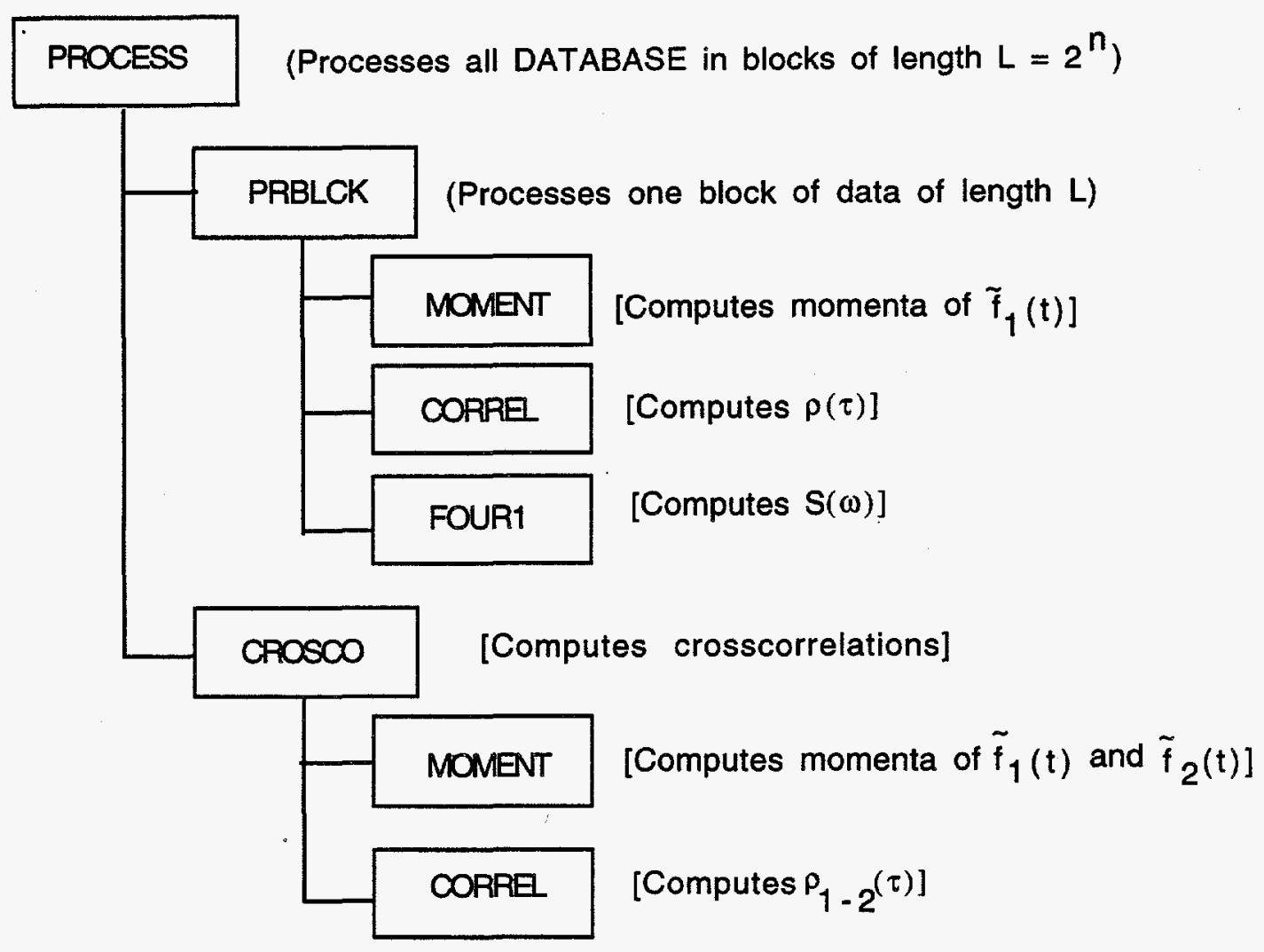

Fig. 22. Simplified flow chart of PROCESS program, used for data analysis 


\section{Appendix l: List of Program PARTVI}

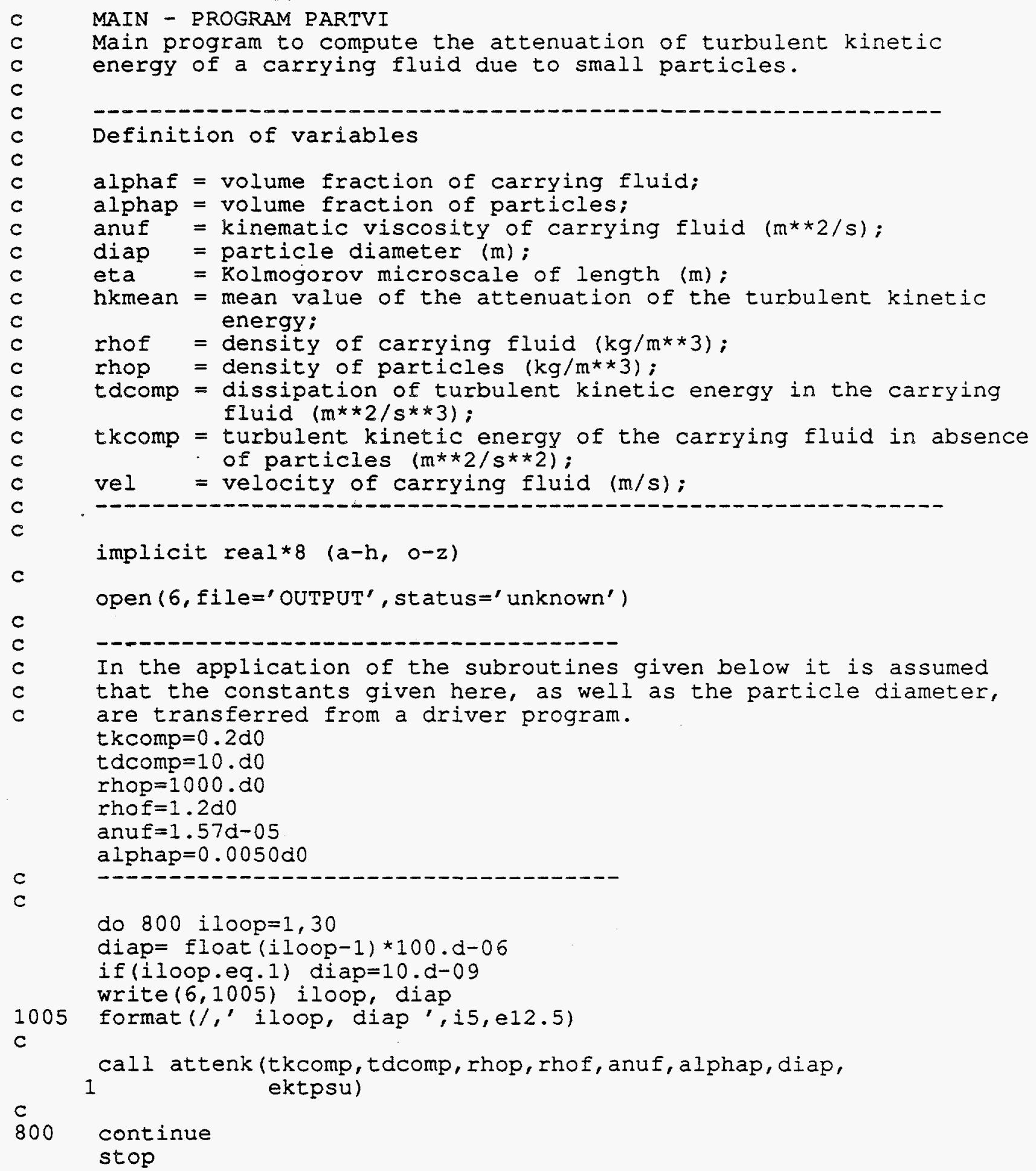


end 1

subroutine attenk (tkcomp, tdcomp, rhop, rhof, anuf, alphap, diap, ektpsu)

C

C

c

C

c

C

C

c

C

c

c

c

C

c

c

c

$c$

C

Computes attenuation of turbulent kinetic energy due to small particles entrained by a fluid. Adapted from: A. M. Al Taweel, $\mathrm{J}$. Landau, Turbulence modulation in two-phase jets. Int. J. Multiphase Flow, 3 (1977), pp. 341-351.

\section{INPUT:}

tdcomp = dissipation of turbulent kinetic energy computed from a driver program;

tkcomp = turbulent kinetic energy computed from a driver proogram without taking into accout attenuation;

alphap, diap, anuf, rhof, rhop;

OUTPUT: ektpsu= attenuated value of turbulent kinetic energy.

implicit real*8 $(a-h, 0-z)$

common/ektp/ adash, vel

data iwrite, imax, il, ngauss $/ 0,300,80,6 /$

vel $=100 . d 0$

vel $=2$. do

alphaf $=1 . d 0$-alphap

et $a=($ anuf $* * 3 /$ tdcomp $) * * 0.25 \mathrm{~d} 0$

al $=e t a * 1 . d 04$

akamin $=1 \cdot d 0 / a 1$

akaint $=30$. do

akamax $=1.204$

$\mathrm{ddk}=\mathrm{akamax}-\mathrm{akamin}$

$g s i=1.5 \mathrm{do}$

ww=alphap*rhop/(alphap*rhop + alphaf*rhof)

phi=rhop/rhof

chi $=0.5 \mathrm{do}$

oned $3=1: \mathrm{do} / 3 \cdot \mathrm{do}$

twod $3=2 \cdot d 0 / 3 \cdot d 0$

fived $3=5 . d 0 / 3 . d 0$

if (iwrite.eq.0) then

write $(6,997)$

write $(6,999)$ imax, il, al, akamin, akaint, akamax

write $(6,998)$ alphap, ww, vel, tdcomp

format (/,' INEORMATION FROM SUBROUTINE ATTENK',/)

format (' alphap, loading=ww, vel, tdcomp', 4e12.5,/)

format (' imax, il, al, akamin/int/max ',2i4, 4el1.5)

iwrite $=1$

endif

delta1=(akaint - akamin)/float(i1)

delta2 = (akamax-akaint $) /$ float $($ imax-i1)

adash $=18 . d 0 *$ anuf $/(\mathrm{diap} * * 2 *(\mathrm{ph} i+\mathrm{ch} i))$

eksu $=0 . d 0$

ektpsu $=0$. do 


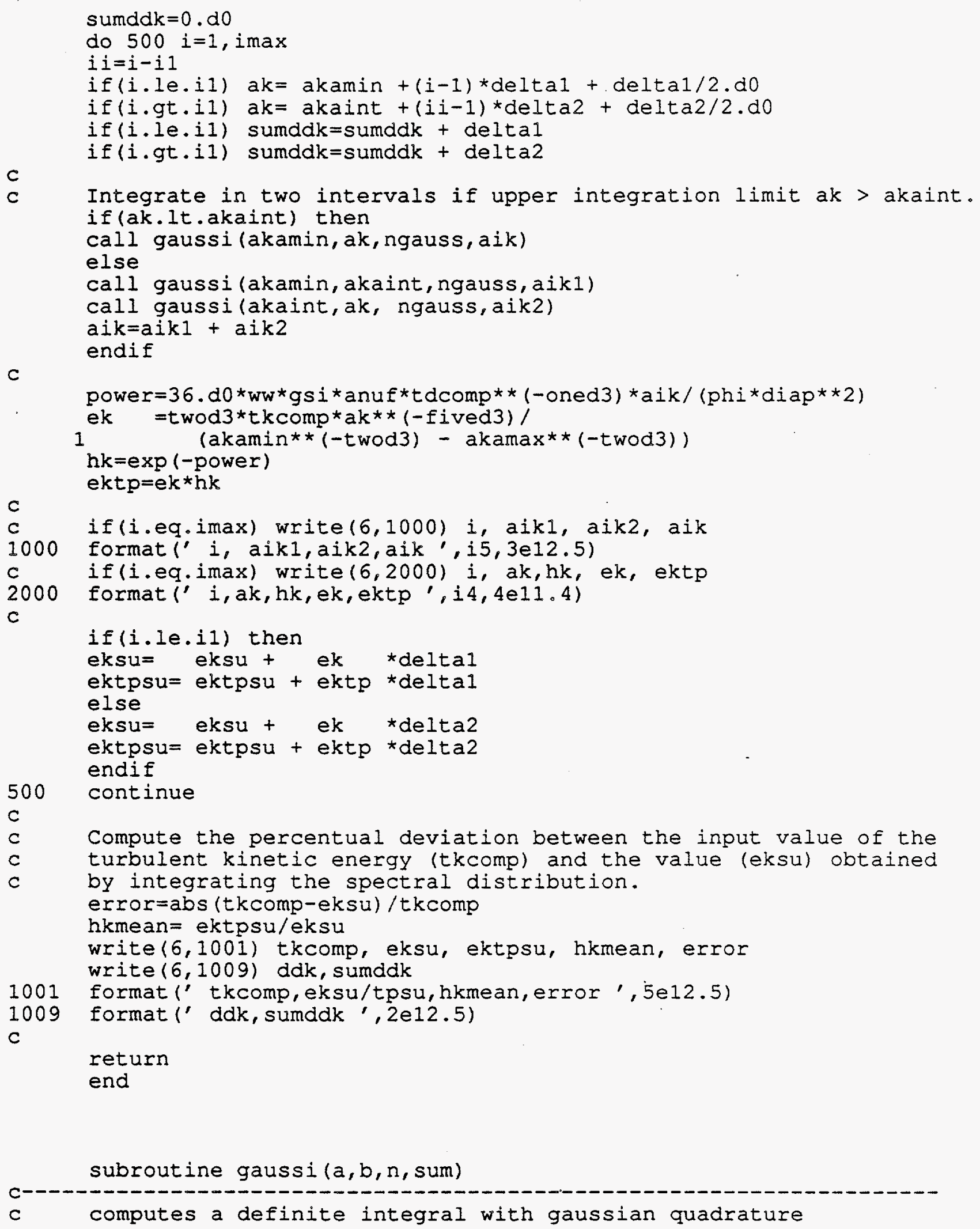




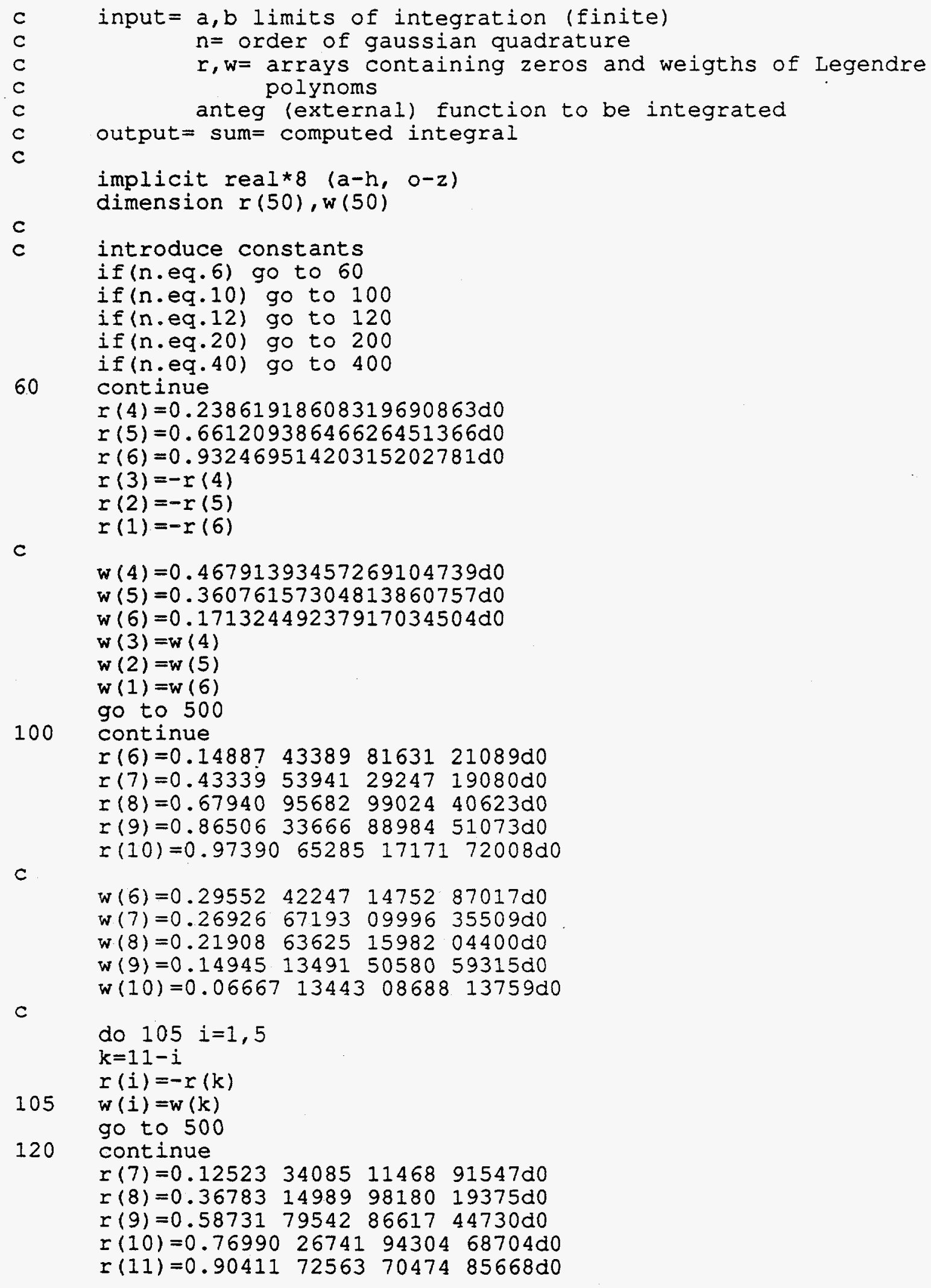


C $r(12)=0.98156 \quad 06342 \quad 46719 \quad 25069 \mathrm{~d} 0$

$w(7)=0.24914 \quad 70458 \quad 13402 \quad 78500 \mathrm{do}$ $w(8)=0.23349 \quad 25365 \quad 38354 \quad 80876 \mathrm{do}$ $w(9)=0.20316 \quad 74267 \quad 23065 \quad 92175 \mathrm{do}$ $w(10)=0.16007 \quad 83285 \quad 43346 \quad 22633 \mathrm{do}$ $w(11)=0.10693 \quad 93259 \quad 95318 \quad 43096 \mathrm{~d} 0$

C $w(12)=0.04717533638651182719 \mathrm{~d} 0$

do $125 i=1,6$

$\mathrm{k}=13-\mathrm{i}$

$r(i)=-r(k)$

$125 \quad w(i)=w(k)$

go to 500

C

200 continue

$I(20)=0.99312859918509492479 \mathrm{do}$

$r(19)=0.96397192727791379127 \mathrm{do}$

$r(18)=0.91223442825132590587 \mathrm{~d} 0$

$r(17)=0.83911697182221882339 \mathrm{~d} 0$

$r(16)=0.74633190646015079261 \mathrm{~d} 0$

$r(15)=0.63605368072651502545 \mathrm{~d} 0$

$r(14)=0.51086700195082709800 \mathrm{do}$

$r(13)=0.37370608871541956067 \mathrm{~d} 0$

$r(12)=0.22778585114164507808 \mathrm{do}$

$r(11)=0.07652652113349733375 \mathrm{do}$

C

$w(20)=0.01761400713915211831 \mathrm{~d} 0$

$w(19)=0.04060142980038694133 \mathrm{do}$

$w(18)=0.06267204833410906357 \mathrm{~d} 0$

$W(17)=0.08327674157670474873 \mathrm{do}$

$w(16)=0.10193011981724043504 \mathrm{do}$

$\mathrm{w} .(15)=0.11819453196151841731 \mathrm{d0}$

$w(14)=0.13168863844917662690 \mathrm{~d} 0$

$w(13)=0.14209610931838205133 d 0$

$w(12)=0.14917298647260374679 d 0$

$w(11)=0.15275338713072585070 \mathrm{do}$

c

do $205 i=1,10$

$k=21-i$

$r(i)=-r(k)$

$205 w(i)=w(k)$

go to 500

$c$

400 continue

c
$r(40)=0.99823770971055920035 \mathrm{do}$
$r(39)=0.99072623869945700645 \mathrm{do}$
$r(38)=0.97725994998377426266 \mathrm{do}$
$r(37)=0.95791681921379165580 \mathrm{do}$
$r(36)=0.93281280827867653336 \mathrm{do}$
$r(35)=0.90209880696887429673 \mathrm{do}$
$r(34)=0.86595950321225950382 \mathrm{~d} 0$
$r(33)=0.82461223083331166320 \mathrm{do}$
$r(32)=0.77830565142651938769 \mathrm{~d} 0$ 
$r(31)=0.72731825518992710328 \mathrm{~d} 0$

$r(30)=0.67195668461417954838 \mathrm{~d} 0$

$r(29)=0.61255388966798023795 \mathrm{~d} 0$

$r(28)=0.54946712509512820208 \mathrm{~d} 0$

$r(27)=0.48307580168617871291 \mathrm{~d} 0$

$r(26)=0.41377920437160500152 \mathrm{~d} 0$

$r(25)=0.34199409082575847301 d 0$

$r(24)=0.26815218500725368114 \mathrm{do}$

$r(23)=0.19269758070137109972 \mathrm{~d} 0$

$r(22)=0.11608407067525520848 \mathrm{~d} 0$

C

$r(21)=0.03877241750605082193 \mathrm{~d} 0$

$w(40)=0.00452127709853319126 \mathrm{~d} 0$

$w(39)=0.01049828453115281362 \mathrm{~d} 0$

$w(38)=0.01642105838190788871 \mathrm{do}$

$w(37)=0.02224584919416695726 \mathrm{do}$

$w(36)=0.02793700698002340110 \mathrm{do}$

$w(35)=0.03346019528254784739 d 0$

$w(34)=0.03878216797447201764 \mathrm{~d} 0$

$w(33)=0.04387090818567327199 \mathrm{~d} 0$

$W(32)=0.04869580763507223206 \mathrm{~d} 0$

$w(31)=0.05322784698393682436 \mathrm{~d} 0$

$w(30)=0.05743976909939155137 \mathrm{~d} 0$

$w(29)=0.06130624249292893917 \mathrm{do}$

$w(28)=0.06480401345660103807 \mathrm{~d} 0$

$w(27)=0.06791204581523390383 \mathrm{do}$

$w(26)=0.07061164739128677970 \mathrm{do}$

$w(25)=0.07288658239580405906 \mathrm{~d} 0$

$w(24)=0.07472316905796826420 \mathrm{do}$

$w(23)=0.07611036190062624237 \mathrm{~d} 0$

$w(22)=0.07703981816424796559 \mathrm{do}$

$\mathrm{w}(21)=0.07750594797842481126 \mathrm{do}$

do $405 i=1,20$

$\mathrm{k}=41-\mathrm{i}$

405

$r(i)=-r(k)$

500

$w(i)=w(k)$

c

c

c

C

510

continue

change the variable so that the integration limits range from $(-1,+1)$. this is equivalent to shift the zeros

do $510 i=1, n$

c

$r(i)=(r(i) *(b-a)+a+b) / 2 . d 0$

c

c

compute the function to be integrated in the shifted zeros and multiply by respective weights

sum $=0 . \mathrm{d} 0$

$c$

do $541 i=1, n$

bet=anteg $(r(i))$

541

sum $=s u m+b e t * w(i)$

c

continue

c

multiply by $(b-a) / 2$. (because of the change of $d x$ ) 
c 900 continue

sum $=s u m *(b-a) / 2 . d 0$

c

return

end

function anteg( $r)$

implicit real*8 $(a-h, 0-z)$

common/ektp/ adash, vel

adash $2=\operatorname{adash} * \star 2$

costh $=1 . d 0 /$ dsqrt $(1 . d 0+($ vel*r/adash $) * \star 2)$

ada $=\operatorname{adash} 2 /((($ vel $* r) * \star 2+\operatorname{adash} 2) \star$ costh $)$

$r k=\operatorname{sqrt}(1 . \mathrm{do}+\mathrm{ada} * \star 2-2 . \mathrm{d} 0 * \mathrm{ada} * \operatorname{costh})$

anteg $=r k * \star 2 / r * \star(5 . d 0 / 3 . d 0)$

return

end 
Sample OUTPUT from Program PARTVI

iloop, diap 1.10000 E-07

INFORMATION FROM SUBROUTINE ATTENK

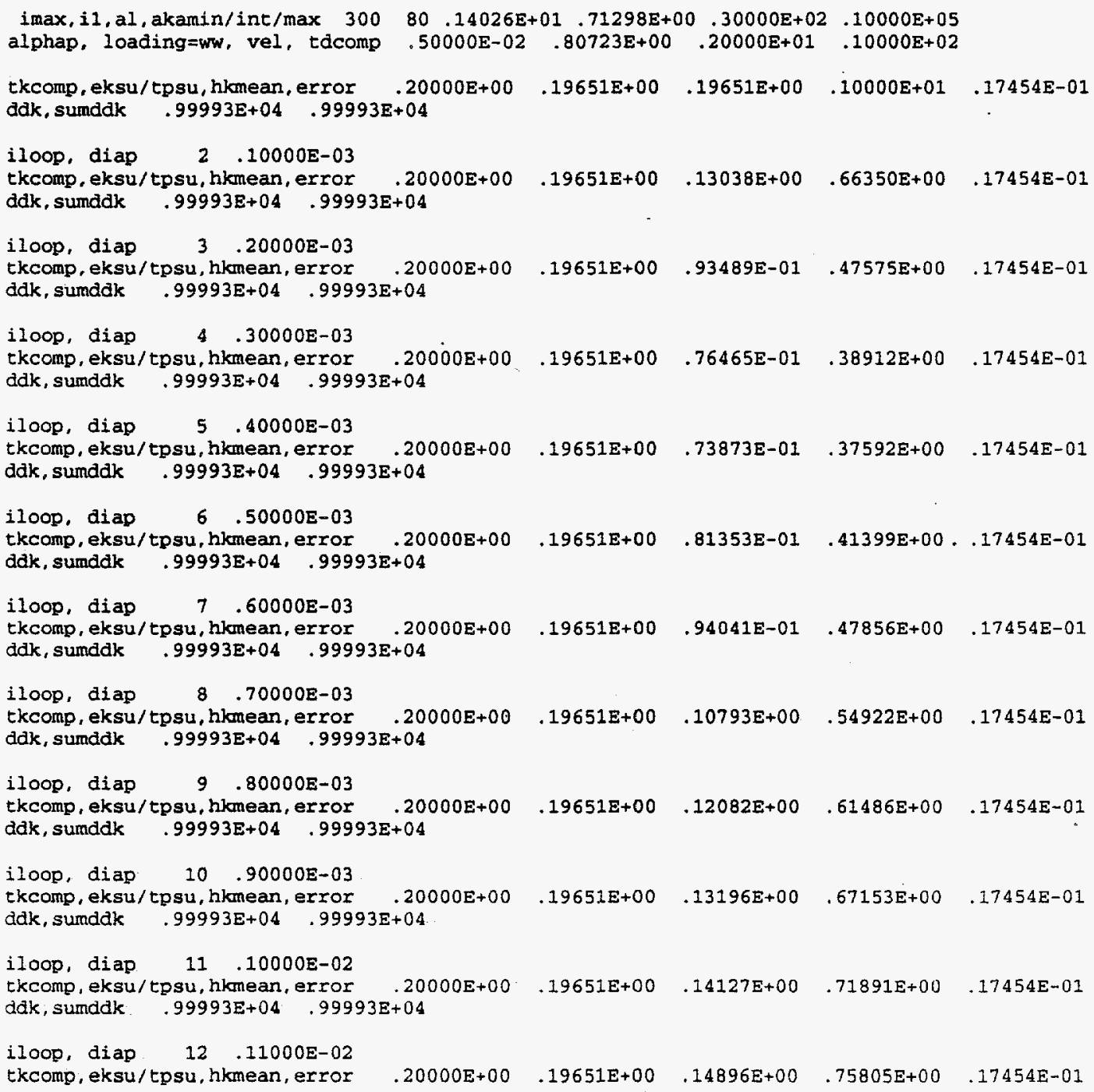


ddk, sunddk $\quad .99993 E+04 \quad .99993 E+04$

iloop, diap $13 \quad .12000 \mathrm{E}-02$

tkcomp, eksu/tpsu, hkmean,

ddk, sumddk .99993E+04 .99993E+04

iloop, diap $14 \quad .13000$ E-02

ddk, sumddk $.99993 \mathrm{E}+04 \quad .99993 \mathrm{E}+04$

iloop, diap 15 .14000E-02

Ckcomp dksu/tpsu, hkmean, error

ddk, sumddk $.99993 \mathrm{E}+04 \quad .99993 \mathrm{E}+04$

iloop, diap $16 \quad .15000 \mathrm{E}-02$

tkcomp, eksu/tpsu, hkmean, error

ddk, sumddk $\quad .99993 \mathrm{E}+04 \quad .99993 \mathrm{E}+04$

$20000 \mathrm{E}+00 \quad .19651 \mathrm{E}+00 \quad .16856 \mathrm{E}+00 \quad .85775 \mathrm{E}+00 \quad .17454 \mathrm{E}-01$

iloop, diap $17 \quad .16000 \mathrm{E}-02$

ckcomp eksu/trsu hkmean error

ddk, sumddk $.99993 \mathrm{E}+04 \quad .99993 \mathrm{E}+04$

iloop, diap $18 \quad .17000 \mathrm{E}-02$

tkcomp, eksu/tpsu, hkmean, error
ddk, sumddk $.99993 \mathrm{E}+04 \quad .99993 \mathrm{E}+04$

iloop, diap $19 \quad .18000 \mathrm{E}-02$

tkcomp, eksu/tpsu, hkmean, error

ddk, sumddk $\quad .99993 \mathrm{E} \ngtr 04 \quad .99993 \mathrm{E} \rightarrow 04$

iloop, diap $20 \quad .19000 \mathrm{E}-02$

tkcomp, eksu/tpsu, hkmean, error

ddk, sumddk $.99993 E+04 \quad .99993 E+04$

$20000 E+00$

iloop, diap 21 .20000E-02

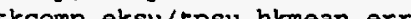

ddk, sumddk .99993E+04 $.99993 \mathrm{E}+04$

iloop, diap 22 .21000E-02

tkcomp, eksu/tpsu, hkmean, exror

ddk, sumddk $\quad .99993 \mathrm{E}+04 \quad .99993 \mathrm{E}+04$

$20000 \mathrm{E}+00 \quad .19651 \mathrm{E}+00 \quad .18151 \mathrm{E}+00 \quad .92369 \mathrm{E}+00 \quad .17454 \mathrm{E}-01$

iloop, diap $23 \quad .22000 \mathrm{E}-02$

tkcomp, eksu/tpsu, hkmean, error $\quad .20000 \mathrm{E}+00 \quad .19651 \mathrm{E}+00 \quad .18278 \mathrm{E}+00 \quad .93014 \mathrm{E}+00 \quad .17454 \mathrm{E}-01$

ddk, sumddk $\quad .99993 E+04 \quad .99993 E+04$

iloop, diap $24 \quad .23000 \mathrm{E}-02$

tkcomp, eksu/tpsu, hkmean, error $\quad .20000 \mathrm{E}+00 \quad .19651 \mathrm{E}+00 \quad .18390 \mathrm{E}+00 \quad .93583 \mathrm{E}+00 \quad .17454 \mathrm{E}-01$

ddk, sumddk $.99993 \mathrm{E}+04 \quad .99993 \mathrm{E}+04$

iloop, diap $25 \quad .24000 \mathrm{E}-02$

tkcomp, eksu/tpsu, hkmean, error $\quad .20000 \mathrm{E}+00 \quad .19651 \mathrm{E}+00 \quad .18489 \mathrm{E}+00 \quad .94086 \mathrm{E}+00 \quad .17454 \mathrm{E}-01$

ddk, sumddk $\quad .99993 \mathrm{E}+04 \quad .99993 \mathrm{E}+04$

iloop, diap $26 \quad .25000 \mathrm{E}-02$

tkcomp, eksu/tpsu, hkmean, error $\quad .20000 \mathrm{E}+00 \quad .19651 \mathrm{E}+00 \quad .18576 \mathrm{E}+00 \quad .94532 \mathrm{E}+0.0 \quad .17454 \mathrm{E}-01$

ddk, sunddk .99993E+04 .99993E+04 
iloop, diap $27 \quad .26000$ E-02

tkcomp, eksu/tpsu, hkmean, error

ddk, sumddk

$.99993 \mathrm{E}+04 \quad .99993 \mathrm{E}+04$

iloop, diap

$28.27000 \mathrm{E}-02$

(t)

ddk, sumddk

$.99993 \mathrm{E}+04 \quad .99993 \mathrm{E}+04$

iloop, diap 29,28000 E-02

su, hkmean, error

$.20000 E+00$

$19651 E+00$

$.18655 \mathrm{E}+00$

$.94931 E+00$

$.17454 E-01$

$.99993 \mathrm{E}+04 \quad .99993 \mathrm{E}+04$

iloop, diap 30.29000 E-02

tkcomp, eksu/tpsu, hkmean, error

ddk, sumddk

$.99993 \mathrm{E}+04 \quad .99993 \mathrm{E}+04$ 


\section{Distribution for ANL-95/6}

Internal:

M. Bottoni (5)

J. X. Bouillard

J. F. C. Chang

T. H. Chien

H. M. Domanus
H. Drucker

R. W. Lyczkowski

C. A. Malefyt

R. B. Poeppel

W. T. Sha (5)
J. G. Sun

R. A. Valentin

R. W. Weeks

TIS Files

\section{External:}

DOE-OSTI for distribution per UC-113 (52)

ANL Libraries

$$
\text { ANL-E (2) }
$$

ANL-W

Manager, Chicago Field Office, DOE

Energy Technology Division Review Committee:

H. K. Birnbaum, University of Illinois, Urbana

R. C. Buchanan, University of Cincinnati, Cincinnati, $\mathrm{OH}$

M. S. Dresselhaus, Massachusetts Institute of Technology, Cambridge, MA

B. G. Jones, University of Illinois, Urbana

C.-Y. Li, Cornell University, Ithaca, NY

S. N. Liu, Fremont, CA

R. E. Smith, SciTech, Inc., Morrisville, NC

W. Sengpiel, KfK, Germany 